\title{
Outcome after laparoscopic antireflux surgery and hiatal hernia repair
}

\author{
Citation for published version (APA):
}

Castelijns, PSS. (2018). Outcome after laparoscopic antireflux surgery and hiatal hernia repair. [Doctoral Thesis, Maastricht University]. Maastricht University. https://doi.org/10.26481/dis.20181219pc

Document status and date:

Published: 01/01/2018

DOI:

10.26481/dis.20181219pc

Document Version:

Publisher's PDF, also known as Version of record

\section{Please check the document version of this publication:}

- A submitted manuscript is the version of the article upon submission and before peer-review. There can be important differences between the submitted version and the official published version of record.

People interested in the research are advised to contact the author for the final version of the publication, or visit the DOI to the publisher's website.

- The final author version and the galley proof are versions of the publication after peer review.

- The final published version features the final layout of the paper including the volume, issue and page numbers.

Link to publication

\footnotetext{
General rights rights.

- You may freely distribute the URL identifying the publication in the public portal. please follow below link for the End User Agreement:

www.umlib.nl/taverne-license

Take down policy

If you believe that this document breaches copyright please contact us at:

repository@maastrichtuniversity.nl

providing details and we will investigate your claim.
}

Copyright and moral rights for the publications made accessible in the public portal are retained by the authors and/or other copyright owners and it is a condition of accessing publications that users recognise and abide by the legal requirements associated with these

- Users may download and print one copy of any publication from the public portal for the purpose of private study or research.

- You may not further distribute the material or use it for any profit-making activity or commercial gain

If the publication is distributed under the terms of Article $25 \mathrm{fa}$ of the Dutch Copyright Act, indicated by the "Taverne" license above, 
Outcome after laparoscopic antireflux

surgery and hiatal hernia repair 
Printing of this thesis was financially supported by:

Rabobank - Chipsoft - Storz - Catharina Ziekenhuis Eindhoven - Maastricht Universitair Medisch Centrum

All rights are reserved. No part of this book may be reproduced or transmitted in any form or by any means, without the written permission from the author or, where appropriate, the publisher of the article.

(C) Bas Castelijns, Maastricht 2018

Layout: Tiny Wouters

Cover design: Christine Muris

Production: Gildeprint, Enschede, The Netherlands

ISBN: 978-94-9301-495-4 


\section{Outcome after laparoscopic antireflux surgery and hiatal hernia repair}

\section{PROEFSCHRIFT}

ter verkrijging van de graad van doctor aan de Universiteit Maastricht, op gezag van de Rector Magnificus, Prof. dr. Rianne M. Letschert, volgens het besluit van het College van Decanen, in het openbaar te verdedigen op woensdag 19 december 2018 om 14.00 uur

door

Petrus Sebastianus Simon Castelijns

Geboren te Geldrop op 4 juni 1991 


\section{Promotor}

Prof. dr. N.D. Bouvy

\section{Co-promotor}

Dr. M.C.G. van de Poll

\section{Beoordelingscommissie}

Prof. dr. L.P.S. Stassen (voorzitter)

Dr. E.J. Hazebroek, Rijnstate Ziekenhuis, Arnhem

Prof. dr. A.A.M. Masclee

Prof. dr. H.J.T. Rutten, Catharina Ziekenhuis, Eindhoven

Dr. J.H.M.B. Stoot, Zuyderland Medisch Centrum, Heerlen-Sittard-Geleen 


\section{Contents}

Chapter 1 General introduction and outline of the thesis 7

Chapter 2 Intrathoracic stomach in hiatal hernia: the role of laparoscopic 21 repair

Chapter 3 A collective review of biological versus synthetic meshreinforced cruroplasty during laparoscopic Nissen fundoplication

Chapter 4 Subjective outcome after laparoscopic hiatal hernia repair for intrathoracic stomach

Chapter 5 Quality of life after Nissen fundoplication in patients with 75 gastroesophageal reflux disease: Comparison between long- and short-term follow-up

Chapter 6 7-year follow up after transoral incisionless fundoplication for treatment of gastroesophageal reflux disease; results of patients who participated in a randomized controlled trial

Chapter 7 A modified technique to create a standardized floppy Nissen fundoplication without a bougie

Chapter 8 Reproducibility and learning curve of a modified technique to create floppy Nissen fundoplication

Chapter 9 General discussion and future perspectives

Summary

Samenvatting

Valorisation addendum

Dankwoord

List of publications

Curriculum vitae 



\section{Chapter 1}

General introduction and outline of the thesis 



\section{History}

The first reports of congenital and posttraumatic diaphragmatic hernias date back as far as the 16th century. The first pioneers on hiatal hernia treatment were Ambrose Pare (1579), Revierius Lazari (1689), Giovanni Batista Morgagni (1761) and Vincent Alexander Bochdalek (1848). ${ }^{1}$ The first surgeon to describe the elective surgical treatment of hiatal hernias was Angelo Soresi in the year of 1919. ${ }^{2}$ Major advancements in the treatment of this condition have been achieved in the second half of the $20^{\text {th }}$ century. In 1950 Richard Sweet published a transthoracic technique to repair the hiatal defect. He even used a piece of fascia lata from the left leg to strengthen the sutures, which may be seen as the predecessor of the later use of pledges or mesh reinforcement. ${ }^{3}$ It was in the same timeframe that Philip Allison and Norman Barrett described the relation between the changed anatomy that comes with a hiatal hernia and functional complaints. They were the first to suggest that this might even lead to oesophagitis in severe cases. ${ }^{4}$ It was this association that triggered Rudolph Nissen to explore the possibility to treat acid reflux surgically, which resulted in the first two successful fundoplications in $1956 .{ }^{5}$ Over time several modifications and other techniques have been proposed by Ronald Belsey $(1961)^{6}$, J. Leigh Collis (1957) ${ }^{7}$, Alan Thal $(1965)^{8}$, Lucius Hill $(1967)^{9}$, and Mario Rosetti (1970). A common side effect of this type of surgery was postoperative dysphagia. In an attempt to reduce the incidence of postoperative dysphagia, partial fundoplications have been described by Dor et al. in $1962^{10}$ and Andre Toupet in $1963 .^{11}$

The development of minimal invasive surgery has led to an increase in anti-reflux procedures. The first laparoscopic fundoplication was performed by Cushieri et al in 1992. ${ }^{12}$ The benefits of laparoscopic surgery compared to the open technique can be found in a reduced complications rate, shorter length of hospital stay, lower morbidity and minimal mortality. ${ }^{13}$ Nowadays laparoscopic treatment is the gold standard for both gastroesophageal reflux disease (GERD) and hiatal hernia repair.

\section{Gastroesophageal reflux disease}

Gastroesophageal reflux disease (GERD) is a condition that develops when the reflux of stomach contents causes troublesome symptoms and/or complications. ${ }^{14}$ Several mechanisms play a role in the development of this condition. Most common cause is disruption of the anti-reflux barrier. Both an intrinsic and an extrinsic sphincter form the anti-reflux barrier. ${ }^{15}$ The intrinsic sphincter consists of a circular muscle, the lower oesophageal sphincter (LES). The extrinsic sphincter is formed by the phrenoesophageal ligaments, which keep the LES in place, and the crural diaphragm. Furthermore, these ligaments create the angle of His, which functions as a flap-valve 
effect to prevent the gastric content to reflux into the oesophagus. ${ }^{16,17}$ Besides failure of the antireflux barrier, an increase of gastric contents and/or increased abdominal pressure plays an important role in the pathogenesis of GERD. Delayed gastric motility and emptying, as well as motility disorders of the oesophagus may predispose patients to develop GERD. Patients with GERD present with typical symptoms of heartburn and regurgitation, which leads to mucosal damage of the oesophagus. In severe cases, this may even result in oesophagitis, Barrett's oesophagus or even oesophageal cancer. ${ }^{18}$ Atypical symptoms that come with GERD are nausea, dysphagia and chronic cough (gastric asthma). ${ }^{14}$

Gastroesophageal reflux disease is the most common benign disorder of the upper gastrointestinal tract, $10-20 \%$ of the Western population reports some degree of heartburn or regurgitation on a weekly basis. ${ }^{19}$ GERD has been proven to reduce quality of life in patients compared with the healthy control population and therefore warrants treatment. $^{20}$ Many studies report on the short term quality of life after anti-reflux surgery, however long-term results are scarce. Besides, it is unknown whether the longterm quality of life is different from the early results. This topic will be addressed in chapter five of this thesis.

\section{Hiatal hernia}

Hiatal hernia is closely related to gastroesophageal reflux disease. This correlation is due to the lack of the extrinsic sphincter. In every human being, there is an opening in the diaphragm, allowing the oesophagus to pass through the thorax into the abdomen. However, in some patients this opening, or hernia, is too large, leading to a shift of the gastroesophageal junction (GEJ) and disruption of the angle of His. This may lead to either GERD, dysphagia, belching or chest pain. This is called a symptomatic hiatal hernia. A hiatal hernia can be either congenital or acquired. There are two types of congenital diaphragmatic defects that have been described by Morgagni and Bochdalek. ${ }^{1}$ However, most patients present with an acquired hiatal hernia, as a result of weakening of the tissue and/or increased abdominal pressure. Hiatal hernia is more frequent among elderly, supporting the hypothesis that weakening of the tissue plays a role in the development of this disease.

In time, four types of hiatal hernia have been described. We will discuss the treatment options for hiatal hernia in detail in chapter two of this thesis. Type I, a sliding hernia, means that the gastroesophageal junction migrates into the thorax. This is the most common type (95\%) and is closely related to gastroesophageal reflux disease. ${ }^{12,21}$ Type II, para-oesophageal hernia, is a defect of the diaphragm with herniation of the gastric fundus through the hiatus into the thorax. Type III is a mixed type of hernia with both aspects of a type I and type II hernia. sometimes more than $50 \%$ of the stomach is 
in the thorax, this is called an intrathorasic stomach. The most severe type of hernia is a type IV, in which not only the stomach, but also other viscera like colon or spleen herniate into the mediastinal sac. In this latter case it is also called an "upside-down stomach". 22

A type 1 hiatal hernia should only be treated when symptoms are bothersome or when severe complications as a result of gastroesophageal reflux disease are present. Type 2, 3 or 4 hiatal hernia's can be, when patients are symptomatic, considered as an indication for surgical repair, due to the risk of an acute volvulus with perforation, gangrene or hemorrhage. ${ }^{23,24}$

\section{Non-surgical treatment}

There are no non-surgical treatment options for the symptomatic hiatal hernia's. The treatment options for GERD however, are more widespread. The first step is to provide general lifestyle advice. No smoking, healthy food, not too many spices, minimal amount of coffee and losing weight if patients are overweight. Second step in the treatment of GERD, is to start with medications such as H2-receptor antagonists, antiacids and proton-pump inhibitors (PPI). ${ }^{25}$ However, this is a symptomatic treatment and besides, a certain amount of the patients become intolerant for medical treatment over time. Furthermore, some patients are not willing to take medication for a lifelong period. ${ }^{26,27}$ This advocates for more long-lasting treatment options.

\section{Surgical treatment}

The surgical treatment of hiatal hernia starts with laparoscopic reduction of the stomach into the abdomen and the diaphragmatic defect is approximated. There is still no consensus regarding many aspects of laparoscopic treatment of large hiatal hernia's. Should we operate the elderly, what to do with a short oesophagus, should a fundoplication routinely be performed? In chapter two of thesis we studied the laparoscopic treatment of these large hiatal hernia's. One of the problems in hiatal hernia surgery is the large recurrence rate of up to $42 \% .{ }^{28}$ Several studies have shown that the use mesh seems to reduce recurrence rate. ${ }^{29}$ Several different meshes are available, broadly categorized into synthetic or biological material, various shapes and fixation methods. ${ }^{30}$ There is still no consensus which mesh type is superior and therefore we have tried to answer this question in chapter 3 of this thesis.

Surgical treatment for GERD is proven to be at least as effective as PPI's in controlling reflux symptoms, some studies even conclude better acid reflux control at the long term. ${ }^{31}$ Early studies have demonstrated superior cost-effectiveness for surgical 
treatment compared to high dose of PPI usage, ${ }^{32}$ although decreased costs of PPI probably reduced this effect. On the other hand, an increasing number of side effects of long term PPI use are becoming apparent such as an increased the risk of dementia, pneumonia, rib fractures, magnesium deficiency, gastrointestinal infections and might even predispose for upper gastrointestinal malignancies. ${ }^{33,34}$ However, when long term PPI use is not desired or not effective, laparoscopic fundoplication is the gold standard in the treatment of GERD. Unfortunately, laparoscopic anti-reflux surgery comes with the risk of complications and recurrences. Several long-term studies report a high degree of dysphagia, gas bloating, inability to belch, vagal nerve injury and even a reoperation rate of up to $15 \%$ is seen. ${ }^{35,36}$ Furthermore, some studies report recurrent acid reflux in $10-20 \%$ of the patients after surgery for a median follow-up of 6.5 years. ${ }^{37-39}$ Due to these side effects that come with anti-reflux surgery, minimal invasive techniques are being developed.

\section{Endoscopic treatment}

One of the less invasive endoscopic treatment options for patients with GERD is the transoral incisionless fundoplication (TIF). There are currently 3 different devices available for this treatment modality. The EsophyX ${ }^{\oplus}$ device (EndoGastric Solutions, Redmond, WA, United States), the Medigus Ultrasonic Surgical Endostapler system (MUSE $^{\mathrm{TM}}$, Medigus Ltd., Omer; Israel) and the GERDX ${ }^{\mathrm{TM}}$ (G-SURG GmbH, SeeonSeebruck, Germany). ${ }^{40,41}$ There are some small differences between the three devices. For the EsophyX, an endoscope is inserted and by means of the application of several polypropylene fastener a 210-270 degrees fundoplication is created. The MUSE device staples the fundus of the stomach tot the oesophagus below the diaphragm using multiple sets of metal stiches placed under an ultrasound-guided technique. The GERDX system also places several sets of stitches to create a full thickness fundoplication. At the short term, TIF seems promising and leads to good symptom control. ${ }^{40,42,43}$ There is one prospective randomized controlled trial that is performed comparing TIF with PPI that shows disappointing results at 1-year of follow-up, with an increasing failure rate over time. ${ }^{44}$ However, even if TIF fails, it is still possible to perform additional anti-reflux surgery in a safe and effective manner. ${ }^{45}$ Due to disappointing results of these endoscopic treatment, the laparoscopic fundoplication is still the golden standard for the treatment of GERD. Long term effects of EsophyX should be evaluated and there might be a group of patients that benefit from this minimal invasive procedure to treat GERD. 


\section{Other surgical techniques}

We have outlined the invasive anti-reflux surgery, the minimal invasive endoscopic techniques and the medical treatment for hiatal hernia and GERD. There are 2 other techniques available for the treatment of GERD, which are the EndoStim LES Stimulation System (Endostim BV, The Hague, the Netherlands) and the the LINX Reflux Management System (Torax Medical, St. Paul, MN, USA). With the EndoStim, two electrodes are laparoscopically placed at the level of the GE-junction and connected to a device that stimulates the LES and therefore enhances the intrinsic anti-reflux barrier. This leads to good anti-reflux control and improved quality of life after 12 months, for a small group of patients. However, the long-term efficacy has yet to be established. ${ }^{46}$ The other technique is the LINX device, which involves the use of magnetic attraction through adjacent magnetic beads, which augments the resistance of the oesophageal sphincter to abnormal opening associated with reflux. ${ }^{47}$ Results regarding reflux control are promising, however a high rate of postoperative dysphagia up to $68 \%$ has been reported and several reports of erosion can be found in the literature. ${ }^{48-50}$ Since the serious complications that come with erosion of devices, the LINX device should be used with care.

\section{Quality of life}

The outcome of surgical treatment can be measured by several methods. In an increasing amount of clinical trials, quality of life has become a third dimension, besides efficacy and safety. Especially for anti-reflux surgery and hiatal hernia repair, since there is very little evidence that this type of surgery prevents cancer or even reduces mortality. The main goal of these treatment modalities is to improve the quality of life in patients with a benign condition of the upper gastrointestinal tract. And as mentioned before, it is proven that GERD and a symptomatic hiatal hernia have a negative impact on the quality of life of patients. ${ }^{20}$ Furthermore, there is very little association between anatomical recurrences and symptoms. ${ }^{51}$ Even the 24-hour PHmetry has a low sensitivity in detecting recurrent GERD. Up to $16 \%$ of patients with a positive 24-h PH monitoring had negative results in the follow-up $\mathrm{PH}$-metry. And even $25 \%$ of the patients with erosive oesophagitis present with a negative $24-\mathrm{h}$ PH metry. ${ }^{52}$ Since the aim of the treatment is to improve quality of life, several questionnaires have been developed over time to assess this outcome measurement. For GERD related complaints, the most commonly used questionnaire is the GERD-HRQL, which is a 16item questionnaire, addressing most bothersome symptoms and its severity. ${ }^{53}$ For patients with the typical symptoms, anti-reflux surgery leads to an improved quality of life in $90 \%$ for the patients. However, when atypical symptoms are present, this is only 
$70 \%{ }^{54,55}$ There are several aspects regarding the treatment of GERD and hiatal hernia, that affect the postoperative quality of life and that are still unknown. We therefore studied the long-term quality of life after both anti-reflux surgery and hiatal hernia repair in this thesis.

\section{Experience of the surgeon}

Anti-reflux surgery and hiatal hernia repair requires advanced laparoscopic skills. Many studies have demonstrated that these operations come with a learning curve of at least 20 procedures. But, even after 100 operations, there is still an improvement in complication rate, recurrence rate, operating time and symptomatic outcome. ${ }^{56}$ When anti-reflux surgery is performed less than 10 times a year in an institution, this is an independent risk factor for a recurrence. ${ }^{57,58}$ Therefore, it is best if anti-reflux surgery is performed in high volume centers with dedicated anti-reflux surgeons. Besides, a proper pre-operative work-up is necessary to avoid complications. All patients should undergo endoscopy combined with $\mathrm{PH}$-metry to retrieve the highest sensitivity for detecting GERD. Furthermore, a manometry should be performed to rule out achalasia and $\mathrm{PH}$-metry should be combined with impedance measurement. Patients with aerophagia should be treated with care, due to the increased risk of postoperative gas bloating. ${ }^{59}$

One of the causes for this learning curve is the creation of a proper fundoplication. When the fundoplication is to narrow, this leads to increased postoperative dysphagia. ${ }^{60}$ Even rotation in the fundoplication seems to increase dysphagia, which emphasizes the importance of a symmetrical fundoplication. ${ }^{61}$ We have therefore developed a modified technique which we describe in this thesis. We further studies whether this technique indeed creates a more reproducible and symmetrical fundoplication. Theoretically modification may reduce the long learning curve. 


\section{Aim of this thesis}

In this thesis, we aimed to study the long-term symptomatic outcome after different treatment options for both hiatal hernia and GERD. We also tried to modify the current technique for Nissen fundoplication with the goal to reduce the learning curve and help beginning surgeons in performing a perfect fundoplication.

Unsolved issues that we have studied in this thesis

- Several technical aspects of the laparoscopic treatment of intrathoracic stomach

- Which type of mesh is superior for the reinforcement of the crural repair

- The long-term quality of life after anti-reflux surgery for GERD

- The long-term quality of life after intrathoracic repair

- Long-term quality of life after transoral incisionless fundoplication (TIF)

- The large learning curve in creating a proper fundoplication

- A method for creating a standardized fundoplication without rotation 


\section{Outline}

Chapter $\mathbf{2}$ is a narrative review that describes the development of laparoscopy in the treatment of large hiatal hernias and intrathoracic stomach. Many aspects of the treatment are evaluated and the most recent literature has been studied and compiled into a review format. Recommendations for the treatment of an intrathoracic stomach are given.

Chapter $\mathbf{3}$ is a collective review that evaluates the results of mesh reinforcement in hiatal hernia repair. All high-quality studies from the past 11 years were studied and data is combined. Recurrence and symptomatic outcome after both biological mesh repair and synthetic mesh repair are compared.

Chapter 4 studies the quality of life after intra-thoracic stomach repair in a large single center cohort, with a follow-up of up to 9.6 years. All patients were sent a standardized questionnaire to evaluate quality of life and re-operation rate. Long-term quality of life, recurrence rate and complication rate are reported.

Chapter 5 analyses the quality of life after Nissen fundoplication for patients with GERD. In this retrospective cohort study, we sent all patients the GERD-HRQL questionnaire and evaluated the results. Outcome for patients with a follow-up longer than 5 years and for patients with a follow-up shorter than 5 years is compared.

Chapter 6 describes the 7-years follow-up after a randomized controlled trial that compared the transoral incisionless fundoplication(TIF) with the treatment of PPI. Quality of life is primary outcome measurement, but also re-operation rate is evaluated. A multi-variate analysis is performed with the goal to find predictors for successful treatment with TIF.

Chapter 7 Describes a modified technique to create a floppy Nissen fundoplication without the use of a bougie. Feasibility and safety in clinical practice are studied. The goal of this technique is to help beginning surgeons to perform a proper fundoplication.

Chapter 8 Studies the actual reproducibility of the modified technique for Nissen fundoplication that has been described in chapter 7. Several fundoplications are created in an ex-vivo experiment by both a resident and an experienced anti-reflux surgeon. Symmetry, size and reproducibility are evaluated.

Chapter 9 provides a general discussion and proposes future perspectives. 


\section{References}

1. Hochberg LA. Thoracic surgery before the 20th century. New York: Vantage Press; 1960.

2. Soresi AL. Diaphragmatic Hernia: Its Unsuspected Frequency: Its Diagnosis: Technic for Radical Cure. Ann Surg. 1919;69(3):254-70.

3. Sweet RH. Esophageal hiatus hernia of the diaphragm; the anatomical characteristics, technic of repair, and results of treatment in 111 consecutive cases. Ann Surg. 1952;135(1):1-13.

4. Allison PR. Reflux esophagitis, sliding hiatal hernia, and the anatomy of repair. Surg Gynecol Obstet. 1951;92(4):419-31.

5. Stylopoulos N, Rattner DW. The history of hiatal hernia surgery: from Bowditch to laparoscopy. Ann Surg. 2005;241(1):185-93.

6. Hiebert CA. Surgical management of esophageal reflux and hiatal hernia. The Ann Thorac Surg. 1961;52(1):159-60.

7. Collis JL. An operation for hiatus hernia with short oesophagus. Thorax. 1957; 12(3):181-8.

8. Thal AP. A unified approach to surgical problems of the esophagogastric junction. Ann Surg. 1968;168(3):542-50.

9. Hill LD. An effective operation for hiatal hernia: an eight year appraisal. Ann Surg. 1967;166(4):681-92.

10. Dor J, Humbert P, Dor V, et al. The role of the modified Nissen procedure in the prevention of reflux following Heller's extramucosal cardiomyotomy. Mem Acad Chir. 1962;88:877-82.

11. Toupet A. Technique d'eosophago-gastroplastie avec phreno-gastropexie dans la cure radicales des hernies hiatales et comme complement de l'operation de Heller dans les cardiospasmes. Mem Acad Chir. 1963;89:394-9.

12. Cuschieri A, Shimi S, Nathanson LK. Laparoscopic reduction, crural repair, and fundoplication of large hiatal hernia. Am J Surg. 1992;163(4):425-30.

13. Peters MJ, Mukhtar A, Yunus RM, Khan S, Pappalardo J, Memon B, et al. Meta-analysis of randomized clinical trials comparing open and laparoscopic anti-reflux surgery. Am J Gastroenterol. 2009;104(6):1548-61; quiz 7, 62.

14. Vakil N, van Zanten SV, Kahrilas P, Dent J, Jones R, Global Consensus G. The Montreal definition and classification of gastroesophageal reflux disease: a global evidence-based consensus. Am J Gastroenterol. 2006;101(8):1900-20; quiz 43.

15. Mittal RK, Balaban DH. The esophagogastric junction. N Engl J Med. 1997; 336(13):924-32.

16. Liebermann-Meffert D, Allgower M, Schmid P, Blum AL. Muscular equivalent of the lower esophageal sphincter. Gastroenterology. 1979;76(1):31-8.

17. Thor KB, Hill LD, Mercer DD, Kozarek RD. Reappraisal of the flap valve mechanism in the gastroesophageal junction. A study of a new valvuloplasty procedure in cadavers. Acta Chir Scand. 1987;153(1):25-8.

18. Dent J, Holloway RH, Toouli J, Dodds WJ. Mechanisms of lower oesophageal sphincter incompetence in patients with symptomatic gastrooesophageal reflux. Gut. 1988;29(8):1020-8.

19. Dent J, El-Serag HB, Wallander MA, Johansson S. Epidemiology of gastro-oesophageal reflux disease: a systematic review. Gut. 2005;54(5):710-7.

20. Revicki DA, Wood M, Maton PN, Sorensen S. The impact of gastroesophageal reflux disease on healthrelated quality of life. Am J Med. 1998;104(3):252-8.

21. Athanasakis H, Tzortzinis A, Tsiaoussis J, Vassilakis JS, Xynos E. Laparoscopic repair of paraesophageal hernia. Endoscopy. 2001;33(7):590-4.

22. Hill LD, Tobias JA. Paraesophageal hernia. Archives of surgery. 1968;96(5):735-44.

23. Leeder PC, Smith G, Dehn TC. Laparoscopic management of large paraesophageal hiatal hernia. Surg Endosc. 2003;17(9):1372-5.

24. Polomsky M, Jones CE, Sepesi B, O'Connor M, Matousek A, Hu R, et al. Should elective repair of intrathoracic stomach be encouraged? J Gastrointest Surg. 2010; 14(2):203-10.

25. Tytgat N, McColl K, Tack J, Holtmann G, Hunt RH, Malfertheiner P, et al. New algorithm for the treatment of gastro-oesophageal reflux disease. Aliment Pharmacol Ther. 2008;27(3):249-56. 
26. El-Serag HB. Time trends of gastroesophageal reflux disease: a systematic review. Clin Gastroenterol Hepatol. 2007;5(1):17-26.

27. Metz DC. Managing gastroesophageal reflux disease for the lifetime of the patient: evaluating the longterm options. Am J Med. 2004;117 Suppl 5A:49S-55S.

28. Draaisma WA, Gooszen HG, Tournoij E, Broeders IA. Controversies in paraesophageal hernia repair: a review of literature. Surg Endosc. 2005;19(10): 1300-8.

29. Furnee $E$, Hazebroek E. Mesh in laparoscopic large hiatal hernia repair: a systematic review of the literature. Surg Endosc. 2013;27(11):3998-4008.

30. Herbella FA, Patti MG, Del Grande JC. Hiatal mesh repair--current status. Surg Laparosc Endosc Percutan Tech. 2011;21(2):61-6.

31. Zhang C, Hu ZW, Yan C, Wu Q, Wu JM, Du X, et al. Nissen fundoplication vs proton pump inhibitors for laryngopharyngeal reflux based on $\mathrm{pH}$-monitoring and symptom-scale. World J Gastroenterol. 2017;23(19):3546-55.

32. Funk LM, Zhang JY, Drosdeck JM, Melvin WS, Walker JP, Perry KA. Long-term cost-effectiveness of medical, endoscopic and surgical management of gastroesophageal reflux disease. Surgery. 2015;157(1):126-36.

33. Corsonello A, Lattanzio F, Bustacchini S, Garasto S, Cozza A, Schepisi R, et al. Adverse events of proton pump inhibitors: potential mechanisms. Curr Drug Metab. 2017.

34. de la Coba Ortiz C, Arguelles Arias F, Martin de Argila de Prados C, Judez Gutierrez J, Linares Rodriguez A, Ortega Alonso A, et al. Proton-pump inhibitors adverse effects: a review of the evidence and position statement by the Sociedad Espanola de Patologia Digestiva. Rev Esp Enferm Dig. 2016;108(4):207-24.

35. Castelijns PSS, Ponten JEH, Vd Poll MCG, Bouvy ND, Smulders JF. Quality of life after nissen fundoplication in patients with gastroesophageal reflux disease: Comparison between long- and shortterm follow-up. J Minim Access Surg. 2017.

36. van Rijn S, Rinsma NF, van Herwaarden-Lindeboom MY, Ringers J, Gooszen HG, van Rijn PJ, et al. Effect of Vagus Nerve Integrity on Short and Long-Term Efficacy of Antireflux Surgery. Am J Gastroenterol. 2016;111(4):508-15.

37. Carlson MA, Frantzides CT. Complications and results of primary minimally invasive antireflux procedures: a review of 10,735 reported cases. J Am Coll Surg. 2001;193(4):428-39.

38. Catarci M, Gentileschi P, Papi C, Carrara A, Marrese R, Gaspari AL, et al. Evidence-based appraisal of antireflux fundoplication. Ann Surg. 2004;239(3):325-37.

39. Maret-Ouda J, Wahlin K, El-Serag HB, Lagergren J. Association Between Laparoscopic Antireflux Surgery and Recurrence of Gastroesophageal Reflux. JAMA. 2017;318(10):939-46.

40. Testoni PA, Mazzoleni G, Testoni SG. Transoral incisionless fundoplication for gastro-esophageal reflux disease: Techniques and outcomes. World J Gastrointest Pharmacol Ther. 2016;7(2):179-89.

41. von Renteln D, Schiefke I, Fuchs KH, Raczynski S, Philipper M, Breithaupt W, et al. Endoscopic fullthickness plication for the treatment of gastroesophageal reflux disease using multiple Plicator implants: 12-month multicenter study results. Surg Endosc. 2009;23(8):1866-75.

42. Witteman BP, Strijkers R, de Vries E, Toemen L, Conchillo JM, Hameeteman W, et al. Transoral incisionless fundoplication for treatment of gastroesophageal reflux disease in clinical practice. Surg Endosc. 2012;26(11):3307-15.

43. Hakansson B, Montgomery M, Cadiere GB, Rajan A, Bruley des Varannes S, Lerhun M, et al. Randomised clinical trial: transoral incisionless fundoplication vs. sham intervention to control chronic GERD. Aliment Pharmacol Ther. 2015;42(11-12):1261-70.

44. Witteman BP, Conchillo JM, Rinsma NF, Betzel B, Peeters A, Koek GH, et al. Randomized controlled trial of transoral incisionless fundoplication vs. proton pump inhibitors for treatment of gastroesophageal reflux disease. Am J Gastroenterol. 2015;110(4):531-42.

45. Witteman BP, Kessing BF, Snijders G, Koek GH, Conchillo JM, Bouvy ND. Revisional laparoscopic antireflux surgery after unsuccessful endoscopic fundoplication. Surg Endosc. 2013;27(6):2231-6.

46. Rodriguez L, Rodriguez P, Gomez B, Ayala JC, Oksenberg D, Perez-Castilla A, et al. Long-term results of electrical stimulation of the lower esophageal sphincter for the treatment of gastroesophageal reflux disease. Endoscopy. 2013;45(8):595-604. 
47. Ganz RA, Gostout CJ, Grudem J, Swanson W, Berg T, DeMeester TR. Use of a magnetic sphincter for the treatment of GERD: a feasibility study. Gastrointest Endosc. 2008;67(2):287-94.

48. Ganz RA, Peters JH, Horgan S, Bemelman WA, Dunst CM, Edmundowicz SA, et al. Esophageal sphincter device for gastroesophageal reflux disease. N Engl J Med. 2013;368(8):719-27.

49. Salvador R, Costantini M, Capovilla G, Polese L, Merigliano S. Esophageal Penetration of the Magnetic Sphincter Augmentation Device: History Repeats Itself. J Laparoendosc Adv Surg Tech A. 2017;27(8):834-8.

50. Bauer M, Meining A, Kranzfelder $M$, Jell A, Schirren R, Wilhelm D, et al. Endoluminal perforation of a magnetic antireflux device. Surg Endosc. 2015;29(12):3806-10.

51. Mittal SK, Bikhchandani J, Gurney O, Yano F, Lee T. Outcomes after repair of the intrathoracic stomach: objective follow-up of up to 5 years. Surg endosc. 2011;25(2):556-66.

52. Swidnicka-Siergiejko A, Dabrowski A. Prolonged 2-day esophageal pH-metry with impedance monitoring improves symptom-reflux association analysis. Dig Dis Sci. 2013;58(9):2556-63.

53. Velanovich V, Vallance SR, Gusz JR, Tapia FV, Harkabus MA. Quality of life scale for gastroesophageal reflux disease. J Am Coll Surg. 1996;183(3):217-24.

54. Kaufman JA, Houghland JE, Quiroga E, Cahill M, Pellegrini CA, Oelschlager BK. Long-term outcomes of laparoscopic antireflux surgery for gastroesophageal reflux disease (GERD)-related airway disorder. Surg Endosc. 2006;20(12):1824-30.

55. Pessaux P, Arnaud JP, Delattre JF, Meyer C, Baulieux J, Mosnier H. Laparoscopic antireflux surgery: fiveyear results and beyond in 1340 patients. Arch Surg. 2005;140(10):946-51.

56. Soot SJ, Eshraghi N, Farahmand M, Sheppard BC, Deveney CW. Transition from open to laparoscopic fundoplication: the learning curve. Arch Surg. 1999;134(3):278-81; discussion 82.

57. Antiporda M, Veenstra B, Jackson C, Kandel P, Daniel Smith C, Bowers SP. Laparoscopic repair of giant paraesophageal hernia: are there factors associated with anatomic recurrence? Surg Endosc. 2018;32(2):945-54.

58. Whealon MD, Blondet JJ, Gahagan JV, Phelan MJ, Nguyen NT. Volume and outcomes relationship in laparoscopic diaphragmatic hernia repair. Surg Endosc. 2017.

59. Bello B, Zoccali M, Gullo R, Allaix ME, Herbella FA, Gasparaitis A, et al. Gastroesophageal reflux disease and antireflux surgery-what is the proper preoperative work-up? J Gastrointest Surg. 2013;17(1):14-20; discussion $\mathrm{p}$

60. Patterson EJ, Herron DM, Hansen PD, Ramzi N, Standage BA, Swanstrom LL. Effect of an esophageal bougie on the incidence of dysphagia following nissen fundoplication: a prospective, blinded, randomized clinical trial. Arch Surg. 2000;135(9):1055-61; discussion 61-2.

61. Leggett PL, Bissell CD, Churchman-Winn R, Ahn C. A comparison of laparoscopic Nissen fundoplication and Rossetti's modification in 239 patients. Surg Endosc. 2000;14(5):473-7. 

Chapter 2 


\section{Abstract}

\section{Introduction}

For decades, intrathoracic stomach has been an indication for surgical repair and over time laparoscopy has become standard treatment. However, there are still many aspects in the treatment of intrathoracic stomach that subject of debate. We performed a literature review to discuss the role of laparoscopy in intrathoracic stomach repair.

\section{Evidence acquisition}

We performed an extensive literature search in PubMed, Embase and Cochrane and reviewed studies from the last 5 years. To provide a complete overview, references from the found studies are also used. All data was compiled into a review format.

\section{Evidence synthesis}

Laparoscopic surgery is proven superior to open hiatal hernia repair in the treatment of intrathoracic stomach. The role of hernia sac excision, short oesophagus, mesh reinforcement, fundoplication, complications and future perspectives are discussed in this review.

\section{Conclusions}

Laparoscopy plays a major role in the treatment of intrathoracic stomach and regarding most aspects of the treatment. All available techniques have their advantages and disadvantages, and the decision on how to repair the intrathoracic stomach, remains a tailored based decision. 


\section{Introduction}

The first reports on congenital and posttraumatic diaphragmatic hernias date back as far as the 16th century. Amongst the first pioneers on hiatal hernia are Ambrose Pare (1579), Revierius Lazari (1689), Giovanni Batista Morgagni (1761) and Vincent Alexander Bochdalek (1848). ${ }^{1}$ Both Morgagni and Bochdalek are known from the most common types of congenital hiatal hernias. In time, there have been four types hiatal hernia described. Type I, a sliding hernia, means that the gastroesophageal junction migrates into the thorax. This is the most common type $(95 \%)$ and it may predispose to gastroesophageal reflux. ${ }^{2,3}$ Type II, para-oesophageal hernia, is a defect of the diaphragm with herniation of the gastric fundus through the hiatus into the thorax. Type III is a mixed type of hernia with both aspects of a type I and type II hernia. Often more than $50 \%$ of the stomach is in the thorax. The most extensive type of hernia is a type IV, in which not only the stomach, but also other viscera like colon or spleen herniate into the mediastinal sac. In this latter case it is also called an "upside-down stomach". An overview of the different types of hernia is depicted in Figure 2.1. ${ }^{5}$ For this review we define an intra-thoracic stomach as a type 3 or type 4 hiatal hernia with at least $50 \%$ of the stomach in the thorax.
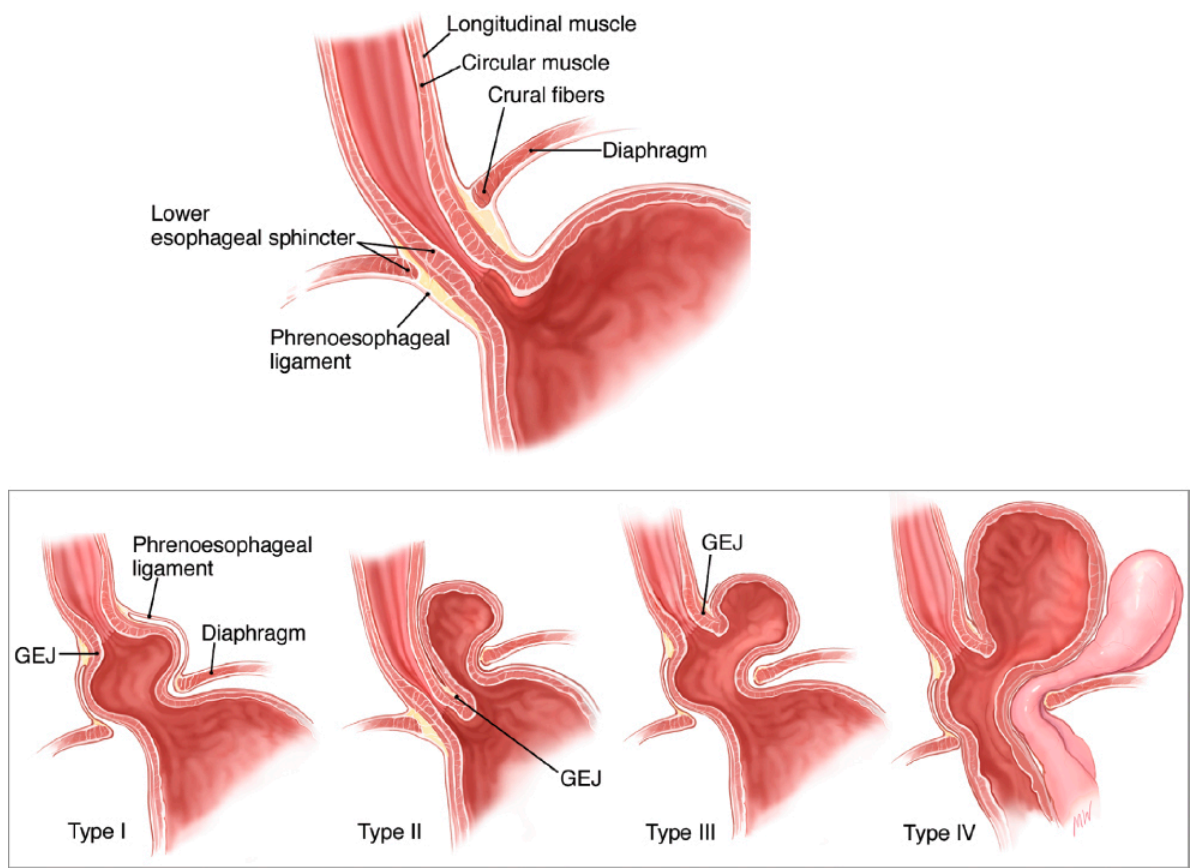

Figure 2.1 Overview of the different types of hiatal hernia 


\section{Surgical treatment}

The first surgeon to describe the elective surgical treatment of hiatal hernias was Angelo Soresi in the year of 1919. ${ }^{6}$ It was 10 years later when Stuart Harrington and his colleagues performed a trial in The Mayo Clinic where they observed asymptomatic patients and performed transabdominal surgery on patients who had a symptomatic diaphragmatic hernia. ${ }^{7}$ If they were unable to close the diaphragmatic defect, they stitched the organs to the abdominal wall to keep them in place; this was called a palliative treatment.

Major advancements in the treatment of this condition have been developed in the second half of the 20th century. In the year of 1950 Richard Sweet published a transthoracic method to repair a hiatal hernia. ${ }^{8}$ He even described the use of a piece of the fascia lata from the left leg to strengthen the sutures, this may be seen as the predecessor for the later use of pledges in hiatal hernia surgery.

Although the relation between a sliding hiatal hernia and acid reflux nowadays is very obvious, this pathophysiological mechanism was only discovered for the first time in the second half of the $20^{\text {th }}$ century. ${ }^{9}$ Philip Allison and Norman Barrett played a major role in the changing perception that an anatomic mechanical condition leads to functional complaints and to oesophagitis in severe cases. They may therefore be credited for the current era of the antireflux surgery. The notion that a hiatal hernia was associated with symptomatic acid reflux was the basis for Rudolph Nissen to explore the possibility to treat acid reflux surgically, leading to his report on the two first successful fundoplications in $1956 .{ }^{10}$ Another pioneer of anti-reflux surgery was Ronald Belsey who started to develop a fundoplication technique in 1949. It was only after three failed trials that he eventually published the Belsey Mark IV procedure in 1961. ${ }^{11}$

Several modifications to these techniques have been developed over time by J. Leigh Collis $(1957)^{12}$, Alan Thal $(1965)^{13}$, Lucius Hill (1967) ${ }^{14}$ and Mario Rosetti (1970). A common and unwanted side effect of this type of surgery was postoperative dysphagia. Partial fundoplications were therefore described by Dor et al. in $1962^{15}$ and Andre Toupet in $1963 .{ }^{16}$ The development of minimal invasive techniques has led to an increase in anti-reflux procedures. The first laparoscopic Nissen fundoplication is performed by Cuschieri et al. in $1992 .^{2}$ In the beginning, $40-50 \%$ of the procedures was converted to an open repair, however over time this is reduced to a very minimum with not even $0.5 \%$ conversion rate. ${ }^{17-19}$ Several types of fundoplication and techniques for hiatal hernia surgery are summarized in Table 2.1.

Several studies have shown better outcome after laparoscopic repair compared with open repair. The mean length of postoperative hospital stay is reduced significantly by one third after laparoscopic repair. ${ }^{20}$ Complication rate is reduced as well by a half for the laparoscopic repair group compared with the open technique. The recurrence rate seems similar around $10 \%$ for both techniques. ${ }^{21}$ Also, the number of patients 
experiencing complications during the initial hospital admission, was reduced from $20.6 \%$ to $8.5 \%$ in the patients that were treated by laparoscopic hiatal hernia repair. ${ }^{22}$ Therefore, laparoscopy has led to a significant shorter postoperative length of stay, lower complication rate, recurrence rate, mortality and even a lower morbidity compared with the open technique. ${ }^{23}$ Nowadays laparoscopy is considered to be the gold standard for the surgical treatment of the intrathoracic stomach. However, several questions remain subject of debate, including the role and timing of laparoscopy in the emergency setting, the use of mesh reinforcement of the cruroplasty, the application of an additional fundoplication to the crural approximation, the hernia sac excision and as well the indication for elective repair in elderly patients with minimal complaints may be questioned.

Table 2.1 Overview of techniques used in hiatal hernia surgery

\begin{tabular}{|c|c|c|}
\hline Name & $\begin{array}{l}\text { Wrap } \\
\text { circumference }\end{array}$ & Description \\
\hline Nissen & 360 & $\begin{array}{l}\text { Total fundoplication, posterior, with complete dissection of the } \\
\text { vasa brevia }\end{array}$ \\
\hline Toupet & 270 & Partial fundoplication, posterior, fixation to the oesophagus \\
\hline Nissen-Rosetti & 360 & $\begin{array}{l}\text { Total fundoplication, posterior, without dissection of the vasa } \\
\text { brevia }\end{array}$ \\
\hline Dor & 90 & Partial fundoplication, anterior, fixation to oesophagus \\
\hline Watson & 180 & Partial fundoplication, anterior, fixation to right crus \\
\hline Collis procedure & - & Oesophageal lengthening procedure \\
\hline Hill & 360 & $\begin{array}{l}\text { Suturing the anterior and posterior phrenoesophageal bundle to } \\
\text { the preaortic fascia }\end{array}$ \\
\hline Belsey-mark IV & 270 & Partial fundoplication, posterior, thoracic approach \\
\hline Anterior gastropexy & - & Suturing the stomach to the ventral abdominal wall \\
\hline Thal & 180 & Partial fundoplication, anterior, fixation to oesophagus \\
\hline
\end{tabular}

\section{Special considerations}

As mentioned above, laparoscopic repair of a para-oesophageal hernia (PEH) or intrathoracic stomach (ITS) seems to be safe and is proven effective. However, there are some aspects that have to be kept in mind. This type of surgery requires advanced laparoscopic skills and therefore comes with a learning curve. It is known for antireflux surgery, which has a close relation with hiatal hernia repair, since these types of surgery are often combined, that the learning curve is at least 20 procedures. However, after 100 procedures there is still an improvement in operation time, conversion rate and a reduction of intra-operative complications. ${ }^{24}$ We also know that reoperation for dysphagia can be reduced from $22 \%$ to as low as $4 \%$ if the initial procedure is performed by an experienced antireflux surgeon. ${ }^{25}$ If this procedure is performed less than 10 times a year in an institution, this is an independent risk factor for recurrence 
and even mortality rate is doubled in low volume centers. ${ }^{26,27}$ The recommendation is therefore, to operate PEH and ITS in a high-volume centre with dedicated and experienced fore-gut surgeons to minimize complications, mortality and recurrence rate.

\section{Evidence acquisition}

For this study, we performed a literature search in PubMed, Embase and Cochrane with the following terms: (((intrathoracic stomach) OR hiatal hernia)) AND (((laparoscopic) OR laparoscopy) OR laparoscopic surgery) We only searched for high quality studies defined as reviews, meta-analysis, randomized controlled trials and retrospective cohort studies with at least 100 patients. Minimum follow-up should be 5 years and only studies published in the last 5 years were seen as recent literature. For this study, we describe the role of laparoscopy in intrathoracic stomach repair in adults, therefore studies that describe patients younger than the age of 18 were excluded. To provide a complete overview of the current literature regarding this subject, we also searched in the references of the included studies for additional valuable studies. All gathered information was examined and compiled into a review format. Since this a narrative review without a specific research question, there is no meta-analysis or statistical analysis performed.

\section{Elective vs. emergent repair}

Most patients with a para-oesophageal hernia or an intrathoracic stomach present with complaints of dysphagia, however also anaemia, chronic cough or acid reflux is reported. These symptoms warrant a concise diagnostic process including oesophageal manometry and 24-hours impedance measurements followed by elective repair if the hernia is indeed considered to be symptomatic. We know from literature that good symptomatic outcome is reported and patients experience little complications after elective repair. ${ }^{28,29}$

Both PEH and ITS may become incarcerated which is a reason for emergent decompression by nasogastric tube followed by surgery in the next few days. Typical complaints for incarceration are pain, hematemesis and profound vomiting. If complaints do not decrease with gastric decompression, surgery should be performed the same day. ${ }^{30}$ Emergency surgery for acute incarceration is related with a higher morbidity and mortality rates up to $3.7 \%$ have been reported, compared with $0.37 \%$ for elective repair. ${ }^{31}$ This might be due to the population of particularly elderly patients with more comorbidities that experience an acute incarcerated stomach. When correction for age and other risk factors is performed in a multivariate analysis, the higher mortality rate after emergency ITS repair diminishes; the risk of complications 
however remains increased after emergency ITS repair. ${ }^{32}$ Therefore elective repair comes with less morbidity and should be performed if patients are symptomatic. However, if emergency surgery is needed, laparoscopy has been proven superior to open surgery for hiatal hernia repair. Mortality rate after emergency repair of an incarcerated intrathoracic stomach is significantly reduced from $5.0 \%$ in the open repair to $1.5 \%$ for the laparoscopic repair. However, what should be done when patients are of an older age and present with minimal symptoms, should elective surgery be performed or should we choose for watchful waiting.

\section{The elderly patient}

If a patient presents with minimal complaints, the questions is raised whether surgery is actually indicated. To this end the complication risk of elective repair should be outweighed to the chance of undergoing emergency surgery and the increased complication risk associated with emergency surgery. Based on a Monte Carlo probabilistic model, the annual risk to undergo emergency surgery is estimated to be $1.1 \%$ with a mortality rate of approximately $3.7-5.5 \%$ compared with a mortality rate of $0.37-1.4 \%$ for the elective repair. ${ }^{32,33}$ Thus, for a patient that is older than 65 , the risks should not outweigh the benefits of an elective repair and watchful waiting is advised. This is supported by a nationwide registry study in the USA performed in 2008 that found a six-fold increased mortality rate of $15.6 \%$ in patients over the age of $80 .^{34}$

However, it should be realized that most data from previous studies were gathered in the pioneering period of laparoscopic repair and since surgeons have become more experienced with minimal invasive surgery over the subsequent years, morbidity and mortality after elective repair has diminished. ${ }^{28}$ Furthermore, the general population gets older and are more vital at an older age. ${ }^{35}$ Even for patients aged over 70, good results have been reported and they should therefore not be withdrawn from elective hiatal hernia repair solitarily based on their age. ${ }^{36-38}$ Elective repair of PEH or ITS remains a tailored made decision and even if symptoms are mild or patients are of an older age, elective surgery should be considered. If the decision is made to perform an operative repair of the hiatal hernia, the operative approach should be chosen. It is possible to approach the hiatal hernia from both the thorax as well as from the abdomen. Is there any evidence proving the superiority of either one of these techniques? 


\section{Transabdominal vs. Transthoracic}

Since a hiatal hernia originates from the diaphragm between the thorax and the abdomen, approach can be from either side, i.e. transabdominal as well as transthoracic. There are no randomized controlled trials published so far, that compare transthoracic hiatal hernia repair with the transabdominal technique. In the early years, $74 \%$ of the procedures was performed transabdominal with open surgery, $17 \%$ transthoracic and only $9 \%$ was performed via transabdominal laparoscopy. ${ }^{39}$ Over time laparoscopy surpassed the open abdominal repair and has become gold standard for hiatal hernia repair. From earlier data, we know that postoperative hospital stay is longer for transthoracic surgery, patients require more often mechanical ventilation (5.6\% of the patients after transthoracic hernia repair) and have a higher risk of a pulmonary embolism. ${ }^{39,40}$ However, these negative effects are seen in the open thoracic approach. Nowadays, thoracoscopic surgery is more often performed and this minimal invasive technique provides a great overview of the oesophagus and the diaphragm. Complication rate is far lower after thoracoscopic techniques, when compared with open thoracic approach. Therefore, when previous abdominal laparoscopic surgery has failed or when the hiatal hernia is fixed in the chest, videoassisted thoracoscopic surgical(VATS) repair may play a promising role for these select group of patients where recurrent abdominal approach seems impossible. ${ }^{41} \mathrm{~A}$ recent study shows promising results for a combined procedure, where abdominal laparoscopy is assisted by VATS in complicated patients with giant hiatal hernias. ${ }^{42}$ In conclusion, the laparoscopic abdominal approach is golden standard, but in select patients the thoracic approach should definitely be considered.

\section{Technical issues}

As mentioned above, the transabdominal laparoscopic technique is the preferred method to repair a hiatal hernia. The instrumentation for this technique is relatively simple and is available in most hospitals that perform laparoscopic surgery. First consideration is the placement of the trocars. The procedure starts with placing the patient in supine position, with the surgeon between the legs. (French position) Then a pneumoperitoneum is created, which can be achieved by open or closed introduction according the preference of the operating surgeon. The trocar that is used for the camera, should be at a ratio of $1 / 3$ to $2 / 3$ between the umbilicus and the xyphoid notch to obtain the best overview during the procedure. For this type of surgery, a 30-degree scope is recommended. Under direct vision the other trocars a placed, to minimize damage to the internal organs. The two trocars that are used to perform the surgery are placed approximately $6 \mathrm{~cm}$ lateral on each side of the first trocar. The liver retractor to facilitate a clear view during the procedure is placed just underneath the Xyphoid notch, or in the right upper quadrant. Finally, one additional trocar should be placed a 
few centimetres lateral of the most left trocar, this can be used by the assistant to aid the surgeon during the procedure. An overview of the position of the trocars is depicted in Figure 2.2. For dissection of the crus several instruments can be used, varying from a diathermy hook to ultrasonic scissors. Some authors advocate that even blunt dissection is possible and recommended to minimize damage to other organs.

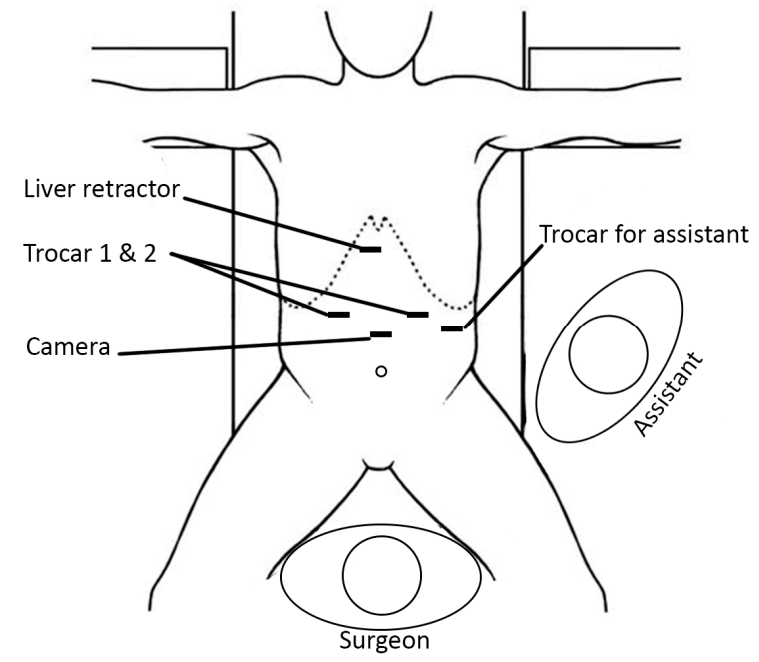

Figure 2.2 Placement of the trocars

For reducing the hernia content and for mobilization of the stomach and other intraabdominal structures, standard laparoscopic equipment can be used, according to the preference of the operating surgeon. The suture repair of the crus should be performed with non-absorbable sutures. The application of a mesh is subject of debate and will be discussed later in this review. There are several other technical aspects in the laparoscopic repair of PEH and ITS requiring further attention and they will be discussed hereafter. in Figure 2.3 the most common used techniques in hiatal hernia surgery are shown.

\section{Hernia sac excision}

A key step during laparoscopic hiatal hernia surgery is to reduce the contents of the hernia back into the abdomen. Especially when the herniation was present for a long time, this can be a challenging part of the procedure, due to the adhesions that have developed over time. Several studies have proven that excision of the hernia sac leads to a lower recurrence rate, especially in the early postoperative period. ${ }^{17,18}$ One 
possible explanation is that due to excision of the hernia sac, the oesophagus will be mobilized further and the tension on the stomach will be reduced. However, the excision of the hernia sac can be very difficult and may result in severe complications such as bleeding or perforation of the stomach or the oesophagus which may even lead to death. ${ }^{43,44}$ To minimize the risk of too much traction on the oesophagus it is best to use a Penrose drain, which can be used to retract the oesophagus and to create a constant tension on the hernia sac. By this method the risk of injury to the oesophagus and the vagal nerve can be minimized. Complete hernia sac resection is recommended due to the lower risk of recurrence, however if this is not possible or if it will be likely that this will result in severe complications, partial excision will suffice.
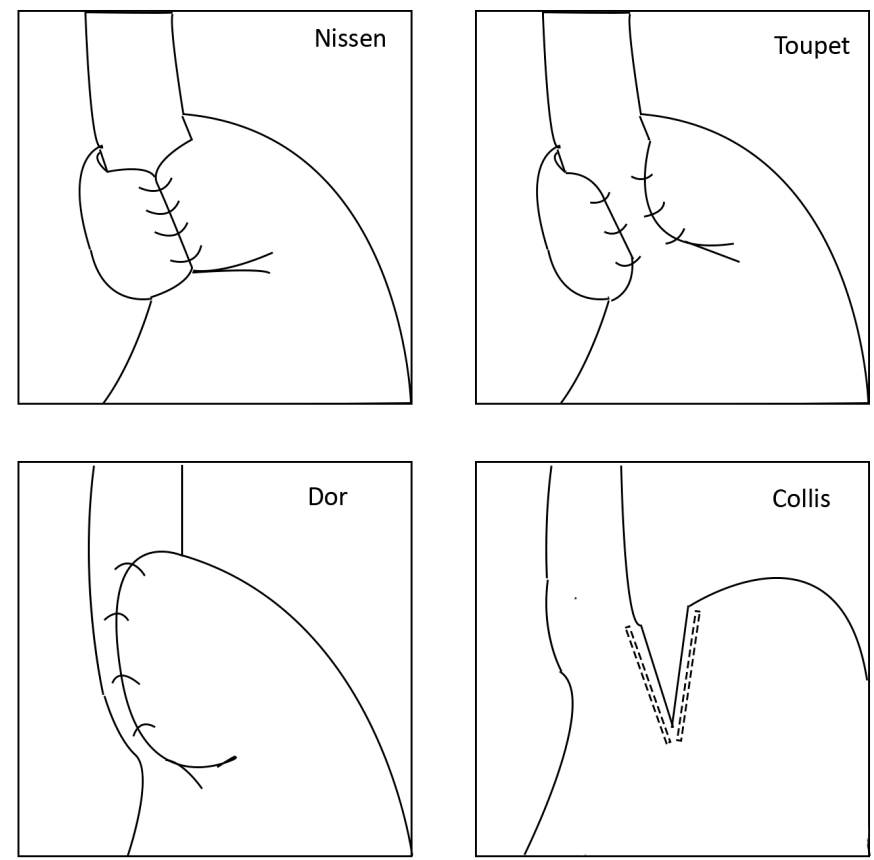

Figure 2.3 Most commonly used techniques in hiatal hernia surgery

\section{The short oesophagus}

A well-known anatomical variation that may predispose patients to develop a recurrent hiatal hernia after laparoscopic ITS or PEH repair is a short oesophagus. The incidence of a short oesophagus depends on the patients that are sampled and varies in the literature between $0-80 \%{ }^{45}$ However, when adequate measurement of the 
oesophagus, after mobilization, is performed, it seems that a true short oesophagus is very rare. ${ }^{46} \mathrm{~A}$ short oesophagus is defined as a GE junction that is $<2-3 \mathrm{~cm}$ intraabdominal and is associated with a recurrent hiatal hernia in $15-25 \%$ of all recurrences. ${ }^{45,47}$ The treatment for short oesophagus is still subject of debate. Some advocate to accept the short oesophagus, where others advocate the need for intervention. Methods to treat the short oesophagus vary from extensive intra-thoracic mobilization of the oesophagus to performing an oesophageal lengthening procedure, from which the Collis gastroplasty is most commonly performed. ${ }^{48}$ Besides the increased risk of perioperative complications due to the oesophageal lengthening procedure, including vagal nerve injury, there are also long-term complications. These include oesophageal aperistalsis and acid producing mucosa above the fundoplication leading to increased postoperative acid reflux. ${ }^{49}$ Despite the possible complications, functional outcome between hiatal hernia repair with EL or without EL seems similar. ${ }^{48}$ Extensive mobilization of the oesophagus comes with perioperative complications as well from which opening the pleura is most commonly seen. When routine mobilization of the oesophagus is performed, complications rarely occur and when measured adequately, a true short oesophagus is rare. Surgeons should therefore not routinely perform a Collis gastroplasty, due to the possible increased risk of complications. When a true short oesophagus is present, the Collis gastroplasty seems to be a safe and effective surgical treatment for this entity and is recommended above extensive oesophageal mobilization.

\section{Mesh reinforcement}

Once the hernia content is reduced, the question is raised on how to close the crural defect. Different techniques are available, almost all starting with suture repair of the crus. There is very little evidence regarding this aspect of the procedure. Most obvious, non-absorbable sutures should be used and if we compare the difference between anterior or posterior suture repair, no significant results regarding symptom control or recurrence rate are found. ${ }^{26}$

Another very large topic of debate is the use of prosthetic or biological material to support the crural repair. Due to the rare but potential life-threatening complications such as oesophageal or aortic erosion that can come with mesh repair, surgeons are conservative in using prosthetic material. However, several reviews have shown the advantage of the reduced recurrence rate due to mesh reinforcement. ${ }^{50-53}$ A significant reduction in recurrence rate is seen from $22.5 \%$ to $12.1 \%$ when mesh is used. Even after sub-analysis for mesh type or for follow-up longer than 2 years, this reduced recurrence rate is still valid. Complication rate for both groups is approximately $15 \% .{ }^{54}$ 
Besides the general complications related to the procedure, the use of a mesh also comes with specific mesh related complications. In general, these are very poorly described in the literature. There are 124 studies, with a total of 5499 patients, that describe mesh related complications. 50 complications are described by case reports where 41 mesh related complications are mentioned in RCT's and observational cohort studies (OCS). This results in a mesh related complication rate of $1.9 \%$. Most reported complications include mesh erosion into either oesophagus, aorta or stomach (53.8\%), stenosis (29.7\%), cardiac tamponade (8.8\%), fibrosis (5.5\%), aortic lesion (2.2\%) and a fistula (1.1\%). ${ }^{54,55}$ Mesh related complications are most probably underreported, but the total amount of implanted meshes is not mentioned in most studies. It is therefore difficult to estimate the actual mesh related complication rate.

The most severe complications that come with mesh placement are related to the fixation of the mesh. In the literature, there are four cases described of cardiac tamponade that was caused by staplers that perforated the pericardium. All patients died due to this complication. ${ }^{56-58}$ Another explanation for mesh related complications is the prosthetic material that is placed either around the oesophagus or in close proximity to the oesophagus with the 'sharp' edges of the mesh against it. Since meshes shrink after placement, even up to $70 \%$, it is expected that when a mesh is placed circumferential around the oesophagus, that this may lead to stenosis. ${ }^{59}$

In order to minimize complications related to the material and to still minimize the risk of recurrence, several mesh types have been developed over time. Biological meshes should result in less material related complications, however they seem to come with a higher recurrence rate. ${ }^{60}$ A review published by the authors of this article, describes the different types of mesh and their results. ${ }^{61}$ From this analysis it seems that synthetic mesh is superior to biological mesh regarding recurrence rate. Synthetic meshes are also less expensive which may be another argument to prefer synthetic over biological meshes. But a very large limitation of this study is the large heterogeneity of the different studies, which makes it impossible to perform a meta-analysis and to draw any strong conclusions.

\section{Fundoplication}

Most patients present with predominantly obstructive symptoms and complaints of dysphagia, between $13 \%$ and $60 \%$ of the patients however also experience some degree of reflux. ${ }^{62-64}$ The rationale for acid reflux that comes with large hiatal hernia is the disruption of the anatomy. The herniation of stomach into the thorax flattens the angle of His and therefore leads to dysfunction of the lower oesophageal sphincter (LES). Even when the stomach is reduced back into the abdomen, often the function of the LES remains disrupted and results in acid reflux. For this reason, most surgeons 
perform an additional fundoplication following the hiatal hernia repair. The addition of a fundoplication does not decrease the incidence of a recurrent hiatal hernia. ${ }^{65}$ Therefore the main reason to perform a fundoplication should be the prevention of acid reflux or the treatment of pre-existent reflux. It has been a large subject of debate which type of fundoplication is superior and many meta-analysis and systematic reviews have been published regarding this subject. Most studies describe patient with mainly gastroesophageal reflux disease (GERD) and not patients with large hiatal hernia. Besides, it is not in the scope of this review to address this discussion in detail. The overall conclusion of the literature is that the higher the degree of fundoplication, the better the reflux control. However, this also comes with an increased risk of postoperative dysphagia. ${ }^{66}$ Dysphagia after hiatal hernia repair with Nissen fundoplication is approximately between $3 \%$ and $24 \% .{ }^{67,68}$ it should kept in mind, that in only $13-47 \%$ of the patients with a type III or type IV hernia, the preoperative endoscopy showed signs of oesophagitis. Severe oesophagitis as a result of long time acid reflux is even more rare. ${ }^{64}$ Postoperative reflux is significantly more prominent in patients that did not receive a fundoplication after ITS repair, however, this did not influence quality of life. ${ }^{69}$ In the contrary, the possible negative side effects of a fundoplication, in particular dysphagia, were not found to be significantly more present. ${ }^{70}$ The routine use of a fundoplication after hiatal hernia repair for intrathoracic stomach should be performed with care, since the clinical benefit seems to be limited.

The application of an anterior gastropexy is less invasive compared to a complete or partial fundoplication and should as well restore the angle of His. This technique is a safe alternative for a fundoplication and should be considered in the elderly patients or in other patients where the surgical risks should be minimized. ${ }^{71}$ The routine application of a gastropexy after cruroplasty in patients with a hiatal hernia shows good control of reflux symptoms. A total of $70.3 \%$ of the patients were asymptomatic after 2 years of follow-up and only $9.9 \%$ of the patients required antireflux medication on daily basis. $^{72}$

To conclude, it is justified to individualize the decision whether to perform a fundoplication in the laparoscopic treatment of an intrathoracic stomach or large paraoesophageal hernia repair. If there is preoperative evidence of severe oesophagitis or severe complaints of reflux, a fundoplication should be considered. In all other cases, a partial fundoplication or gastropexy should be performed to minimize the risk of postoperative dysphagia and to minimize operative time. Even more, since most postoperative acid reflux symptoms are mild and can be controlled with medication. 


\section{Complications after laparoscopic hiatal hernia repair}

There are several complications that are likely to occur in ITS and PEH repair, as a result of the vital structures that may be involved with the herniation and are in close proximity to the area where the surgeon has to perform. Large bleedings from either the aorta, spleen, liver or short-gastric vessels have been reported. ${ }^{73}$ However most bleedings are arterial, also bleedings from large veins such as the vena cave can occur. ${ }^{74}$ These are more feared, since the thin wall of the veins makes it harder to control the bleeding. Most injuries are caused by coagulation devices, electrocautery or ultrasonic devices. $^{75}$

Furthermore, the thoracic organs can be damaged, in particular when a mesh is fixated with tackers, this may cause severe cardiac complications with a high mortality rate. ${ }^{76}$ Damage of other abdominal organs is possible as well, where most injuries occur during the reduction of the content of the hernia sac. Pleural rupture is very often seen in hiatal hernia surgery. Usually, thoracic drainage is not necessary, when positive end expiratory pressure at the end of surgery is kept high $\left(>10 \mathrm{cmh}_{2} \mathrm{O}\right)$, a pneumothorax will rarely occur. If a larger pleural defect is present, a chest tube may be inevitable. ${ }^{77}$

Delayed gastric emptying (DGE) is a complication that is seen after both ITS and PEH repair. This may be the result of organic causes (Diabetes, ulcers, auto-immune disease, neuromotor dysfunction) as well technical causes (Vagal nerve injury or obstruction). The presence of DGE preoperatively is very hard to determine, since gastric emptying studies are not reliable due to the intrathoracic stomach. The rate of DGE in the literature is less than $3 \%$, however with more re-operations the risk of delayed gastric emptying increases. The rationale for this effect may be the increasing risk of vagal nerve damage. ${ }^{78}$ Symptoms that can come with vagal nerve injury are nausea (15\%), vomiting (4\%), diarrhoea (20-30\%) and dumping syndrome (10\%). In contrast with the low incidence of DGE mentioned above, the rate of vagal nerve injury is supposed to be as high as $10-42 \% .{ }^{79}$ The result of vagal nerve injury is increased presence of acid reflux and a higher reoperation rate for severe acid reflux. Also, the quality of life and the postoperative satisfaction is significantly lower when the vagal nerve is damaged. ${ }^{80}$ For some reason, vagal nerve injury is often neglected by the surgeon and symptoms related to unintentional vagal nerve injury are often not recognized. Vagal nerve injury may lead to severe symptoms and a reduced quality of life, therefore, great caution is needed when mobilizing the oesophagus and direct traction to the oesophagus should be minimized. 


\section{Predictors for outcome}

A very important question is, whether there are patient related factors or technical aspects that may predict outcome after ITS or PEH repair. There is still no consistent standard definition for recurrence. The most objective method might be a radiological finding where at least $2 \mathrm{~cm}$ of migration on the barium swallow examination is seen. ${ }^{81}$ This results in a recurrence rate up to 57\%. However most patients remain asymptomatic, thus the relevance of this method may be questioned. ${ }^{82,83}$ Median time for radiologic recurrence is 40 months. $^{84}$ It might be beneficial to only report symptomatic recurrence, which is more relevant in the treatment of patients. Most technical aspects that might influence postoperative outcome such as resection of the hernia sac, mobilization of the oesophagus, mesh reinforcement and performing a fundoplication are mentioned above.

Additional patient related factors such as size of the hernia, age, elevated body mass index (BMI), pulmonary disease have been mentioned as a possible risk factor for recurrence. $^{85}$

A larger size of the hiatal hernia is associated with an increased risk of re-herniation after primary repair. However, for recurrent hiatal hernia repair, this association disappears. This may be due to other, not yet discovered, patient related factors that play an important role in hernia recurrence. ${ }^{86}$

An elevated BMI results in an increased intra-abdominal pressure and might therefore predispose for failure of the cruroplasty and result into an elevated recurrence rate. For antireflux surgery, it has been proven that an increased BMI leads to a high failure rate of the surgical treatment. ${ }^{87}$ For PEH and ITS repair however, this difference in clinical outcome for patients with an increased BMI compared with patients with a normal BMI cannot be confirmed. ${ }^{29,88}$ Nonetheless, surgeons should recommend patient to lose weight, since an increased BMI leads to technical difficulties and overall health is affected by the extra weight.

There are some patient related factors that do influence the postoperative outcome. Both a higher American Society of Anaesthesiologists (ASA) score and an age $>70$ is associated with a longer postoperative hospital stay and a higher complication rate. ${ }^{29,38}$ Age, gender, smoking status, diabetes or pulmonary disease have not been associated with a difference in radiologic recurrence. ${ }^{37,83}$

\section{Future perspectives}

In this review, we have described the role of laparoscopy from the beginning in 1992 until now. As we have seen, there are several aspects in laparoscopic hiatal hernia repair that are still subject of debate. With improving technology, new techniques such 
as $3 \mathrm{D}$ and robotic surgery are coming more and more available in the field of minimal invasive surgery. In theory, these techniques may reduce operative time, complication rate and may improve patient outcomes. A recent pilot study investigating the advantage of 3D visualization during laparoscopic hiatal hernia repair compared with $2 \mathrm{D}$ visualization, proved that the operative time is significantly reduced by $22 \%$ when $3 \mathrm{D}$ vision is used. ${ }^{89}$ Furthermore, robotic surgery is becoming more available in many institutions, starting a whole new era. However, the advantage of robot surgery in hiatal hernia repair still has to be discovered. Initial reports seem promising, however a high recurrence rate of up to $42 \%$ after 2 years is seen. ${ }^{90}$ This might be due to the lack of experience with robot-assisted surgery and learning curve is still present. Therefore, results will most likely improve over time and further studies are needed to prove whether robot-assisted ITS and PEH repair is beneficial compared with traditional laparoscopic repair. ${ }^{91}$

\section{Conclusion}

This is an extensive review of the current literature and describes the role of laparoscopy in intrathoracic stomach repair. That are still many aspects of the treatment that are subject of debate and no gold standard for the treatment of an intrathoracic stomach or large para-oesophageal hernia repair is achieved. It is widely accepted that laparoscopy is superior to laparotomy and leads to better postoperative outcome. Furthermore, the transabdominal approach is standard treatment. However, the thoracic approach should be kept in mind when patients have a complex abdominal history and abdominal approach seems not possible. Since acute incarceration comes with increased morbidity and mortality, elective repair of intrathoracic stomach is recommended, even for the elderly with minimal complaints. However, the decision to perform a laparoscopic hiatal hernia repair should be tailored made, since not every octogenarian is suitable for surgery.

When the hernia content is reduced, is recommended to excise the hernia sac completely to minimize the risk of recurrence. True short oesophagus is rare when adequate mobilization of the oesophagus is performed, but when still present, Collis gastroplasty should be performed to minimize traction on the stomach and to reduce recurrence rate. Mesh reinforcement of the cruroplasty reduces recurrence rate, however there is a small risk of mesh related complications. There are several types of mesh available, but a synthetic mesh seems superior tot biological meshes, based on costs and recurrence rate. Fundoplication should not routinely be performed, only when severe acid reflux is present. When a fundoplication is needed, a partial or complete fundoplication should be considered based on the preference of the operating surgeon. An anterior gastropexy however, seems to reduce recurrence rate, 
leads to less dysphagia and provides good acid reflux control and might therefore be superior to a fundoplication. Laparoscopic hiatal hernia surgery is complex and requires advanced laparoscopic skills to minimize the risk of complications. The pleural cavity is almost always opened, but does not require chest tube drainage in most cases. Vagal nerve injury is an underdiagnosed complication, but results in increased acid reflux, increased reoperation rate and a worse quality of life. Surgeons should be careful with mobilization of the oesophagus to minimize the risk of this complication. Increased hernia size leads to a higher recurrence rate, where other patient's factors as BMI, gender, smoking, pulmonary disease have no proven effect on the postoperative outcome. As novel techniques are still being developed and robotic surgery and 3D vision is more widely available, this might result into another approach of hiatal hernia. The first results of these novel techniques seem promising, but the advantage of robotassisted surgery and 3D vision has yet to be proved. 


\section{References}

1. Hochberg LA. Thoracic surgery before the 20th century, Vantage Press, New York 1960.

2. Cuschieri A, Shimi S, Nathanson LK. Laparoscopic reduction, crural repair, and fundoplication of large hiatal hernia. Am J Surg 1992;163:425-30.

3. Athanasakis H, Tzortzinis A, Tsiaoussis J, Vassilakis JS, Xynos E. Laparoscopic repair of paraesophageal hernia. Endoscopy 2001;33:590-4.

4. Hill LD, Tobias JA. Paraesophageal hernia. Arch Surg 1968;96:735-44.

5. Sugerbaker DJ, Bueno R, Colson YL, Jaklitsch MT, Krasna MJ, Mentzer SJ, et al. Adult chest surgery, 2nd Edition, http://www.accessurgery.com/

6. Soresi AL. Diaphragmatic Hernia: Its Unsuspected Frequency: Its Diagnosis: Technic for Radical Cure. Ann Surg 1919;69:254-70.

7. Harrington SW. The Surgical Treatment of the More Common Type of Diaphragmatic Hernia : Report of 404 Cases. Ann Surg 1945;122:546-68.

8. Sweet RH. Esophageal hiatus hernia of the diaphragm; the anatomical characteristics, technic of repair, and results of treatment in 111 consecutive cases. Ann Surg 1952;135:1-13.

9. Allison PR. Reflux esophagitis, sliding hiatal hernia, and the anatomy of repair. Surg Gynecol Obstet 1951;92:419-31.

10. Stylopoulos N, Rattner DW. The history of hiatal hernia surgery: from Bowditch to laparoscopy. Ann Surg 2005;241:185-93.

11. Hiebert CA. Surgical management of esophageal reflux and hiatal hernia. Ann Thorac Surg 1961;52: 159-60.

12. Collis JL. An operation for hiatus hernia with short oesophagus. Thorax 1957;12:181-8.

13. Thal AP. A unified approach to surgical problems of the esophagogastric junction. Ann Surg 1968;168:542-50.

14. Hill LD. An effective operation for hiatal hernia: an eight year appraisal. Ann Surg 1967;166:681-92.

15. Dor J, Humbert P, Dor V, et al. The role of the modified Nissen procedure in the prevention of reflux following Heller's extramucosal cardiomyotomy. Mem Acad Chir 188:877-82.

16. Toupet A. Technique d'eosophago-gastroplastie avec phreno-gastropexie dans la cure radicales des hernies hiatales et comme complement de l'operation de Heller dans les cardiospasmes. Mem Acad Chir 1963;89:394-9.

17. Watson DI, Davies N, Devitt PG, Jamieson GG. Importance of dissection of the hernial sac in laparoscopic surgery for large hiatal hernias. Arch Surg 1999134:1069-73.

18. Edye M, Salky B, Posner A, Fierer A. Sac excision is essential to adequate laparoscopic repair of paraesophageal hernia. Surg Endosc '1998;12:1259-63.

19. Mitiek MO, Andrade RS. Giant hiatal hernia. Ann Thorac Surg 2010;89:S2168-73.

20. Diez Tabernilla M, Ruiz-Tovar J, Grajal Marino R, Calero Garcia P, Pina Hernandez JD, Chames Vaisman A, et al. Paraesophageal hiatal hernia. Open vs. laparoscopic surgery. Rev Esp Enferm Dig 2009;101:70611.

21. Karmali S, McFadden S, Mitchell P, Graham A, Debru E, Gelfand G, et al. Primary laparoscopic and open repair of paraesophageal hernias: a comparison of short-term outcomes. Dis Esophagus 2008;21:63-.

22. Klinginsmith M, Jolley J, Lomelin D, Krause C, Heiden J, Oleynikov D. Paraesophageal hernia repair in the emergency setting: is laparoscopy with the addition of a fundoplication the new gold standard? Surg Endosc 2016;30:1790-5.

23. Peters MJ, Mukhtar A, Yunus RM, Khan S, Pappalardo J, Memon B, et al. Meta-analysis of randomized clinical trials comparing open and laparoscopic anti-reflux surgery. Am J Gastroenterol 2009;104:154861; quiz 1547, 1562.

24. Soot SJ, Eshraghi N, Farahmand M, Sheppard BC, Deveney CW. Transition from open to laparoscopic fundoplication: the learning curve. Arch Surg 1999;134:278-81; discussion 282.

25. Hwang $\mathrm{H}$, Turner LJ, Blair NP. Examining the learning curve of laparoscopic fundoplications at an urban community hospital. Am J Surg 2005;189:522-6; discussion 526. 
26. Antiporda M, Veenstra B, Jackson C, Kandel P, Daniel Smith C, Bowers SP. Laparoscopic repair of giant paraesophageal hernia: are there factors associated with anatomic recurrence? Surg Endosc 2018; 32(2):945-54.

27. Whealon MD, Blondet JJ, Gahagan JV, Phelan MJ, Nguyen NT. Volume and outcomes relationship in laparoscopic diaphragmatic hernia repair. Surg Endosc 2017;31(10):4224-30.

28. Castelijns PSS, Ponten JEH, Van de Poll MCG, Nienhuijs SW, Smulders JF. Subjective outcome after laparoscopic hiatal hernia repair for intrathoracic stomach. Langenbecks Arch Surg 2017;402:521-30.

29. Karim MA, Maloney J, Ali A (2016) Laparoscopic Repair of Intrathoracic Stomach: Clinical and Healthrelated Quality of Life Outcomes. Surg Laparosc Endosc Percutan Tech 2016;26:484-7.

30. Wirsching A, El Lakis MA, Mohiuddin K, Pozzi A, Hubka M, Low DE. Acute vs. elective paraesophageal hernia repair: Endoscopic gastric decompression allows semi-elective surgery in a majority of acute patients. J Gastrointest Surg 2018;22(2):194-202.

31. Jassim H, Seligman JT, Frelich M, Goldblatt M, Kastenmeier A, Wallace J, et al. A population-based analysis of emergent versus elective paraesophageal hernia repair using the Nationwide Inpatient Sample. Surg Endosc 2014;28:3473-8.

32. Kaplan JA, Schecter S, Lin MY, Rogers SJ, Carter JT. Morbidity and Mortality Associated With Elective or Emergency Paraesophageal Hernia Repair. JAMA Surg 2015;150:1094-6.

33. Stylopoulos N, Gazelle GS, Rattner DW. Paraesophageal hernias: operation or observation? Ann Surg 2002;236:492-500; discussion 500-491.

34. Poulose BK, Gosen C, Marks JM, Khaitan L, Rosen MJ, Onders RP, et al. Inpatient mortality analysis of paraesophageal hernia repair in octogenarians. J Gastrointest Surg 2008;12:1888-92.

35. Jay AP, Watson DI. Changing work patterns for benign upper gastrointestinal and biliary disease: 19942007. ANZ J Surg 2010;80:519-25.

36. Grotenhuis BA, Wijnhoven BP, Bessell JR, Watson DI. Laparoscopic antireflux surgery in the elderly. Surg Endosc 2008;22:1807-12

37. El Lakis MA, Kaplan SJ, Hubka M, Mohiuddin K, Low DE. The Importance of Age on Short-Term Outcomes Associated With Repair of Giant Paraesophageal Hernias. Ann Thorac Surg 2017;103: 1700-9.

38. Parker DM, Rambhajan AA, Horsley RD, Johanson K, Gabrielsen JD, Petrick AT. Laparoscopic paraesophageal hernia repair is safe in elderly patients. Surg Endosc 2017;31:1186-91.

39. Paul S, Nasar A, Port JL, Lee PC, Stiles BC, Nguyen AB, et al. Comparative analysis of diaphragmatic hernia repair outcomes using the nationwide inpatient sample database. Arch Surg 2012;147:607-12.

40. Kohn GP, Price RR, DeMeester SR, Zehetner J, Muensterer OJ, Awad Z, et al. Guidelines for the management of hiatal hernia. Surg Endosc 2013;27:4409-28.

41. Migliore M, Arcerito M, Vagliasindi A, Puleo R, Basile F, Deodato G. The place of Belsey Mark IV fundoplication in the era of laparoscopic surgery. Eur J Cardiothorac Surg 2003;24:625-30.

42. Molena D, Mungo B, Stem M, Lidor AO. Novel combined VATS/laparoscopic approach for giant and complicated paraesophageal hernia repair: description of technique and early results. Surg Endosc 2015;29:185-91.

43. Wiechmann RJ, Ferguson MK, Naunheim KS, McKesey P, Hazelrigg SJ, Santucci TS, et al. Laparoscopic management of giant paraesophageal herniation. Ann Thorac Surg 2001;71:1080-6; discussion 1086-7.

44. Pierre AF, Luketich JD, Fernando HC, Christie NA, Buenaventura PO, Litle VR, et al. Results of laparoscopic repair of giant paraesophageal hernias: 200 consecutive patients. Ann Thorac Surg 2002;74:1909-15; discussion 1915-6.

45. Lugaresi M, Mattioli S, Aramini B, D'Ovidio F, Di Simone MP, Perrone O. The frequency of true short oesophagus in type II-IV hiatal hernia. Eur J Cardiothorac Surg 2013;43:e30-6.

46. Migaczewski M, Zub-Pokrowiecka A, Grzesiak-Kuik A, Pedziwiatr M, Major P, Rubinkiewicz M, et al. Incidence of true short esophagus among patients submitted to laparoscopic Nissen fundoplication. Wideochir Inne Tech Maloinwazyjne 2015;10:10-4.

47. Horvath KD, Swanstrom LL, Jobe BA. The short esophagus: pathophysiology, incidence, presentation, and treatment in the era of laparoscopic antireflux surgery. Ann Surg 2000;232:630-40.

48. Puri V, Jacobsen K, Bell JM, Crabtree TD, Kreisel D, Krupnick AS, et al. Hiatal hernia repair with or without esophageal lengthening: is there a difference? Innovations (Phila) 2013;8:341-7. 
49. Lin E, Swafford V, Chadalavada R, Ramshaw BJ, Smith CD. Disparity between symptomatic and physiologic outcomes following esophageal lengthening procedures for antireflux surgery. J Gastrointest Surg 2004;8:31-9; discussion 38-9.

50. Antoniou SA, Koch OO, Antoniou GA, Pointner R, Granderath FA. Mesh-reinforced hiatal hernia repair: a review on the effect on postoperative dysphagia and recurrence. Langenbecks Arch Surg 2012;397: 19-27.

51. Puri V, Kakarlapudi GV, Awad ZT, Filipi CJ. Hiatal hernia recurrence: 2004. Hernia 2004;8:311-7.

52. Targarona EM, Bendahan G, Balague C, Garriga J, Trias M. Mesh in the hiatus: a controversial issue. Arch Surg 2004;139:1286-96; discussion 1296.

53. Furnee E, Hazebroek E. Mesh in laparoscopic large hiatal hernia repair: a systematic review of the literature. Surg Endosc 2013;27:3998-4008.

54. Muller-Stich BP, Kenngott HG, Gondan M, Stock C, Linke GR, Fritz F, et al. Use of Mesh in Laparoscopic Paraesophageal Hernia Repair: A Meta-Analysis and Risk-Benefit Analysis. PLoS One 2015;10: e0139547.

55. Stadlhuber RJ, Sherif AE, Mittal SK, Fitzgibbons RJ, Jr., Michael Brunt L, Hunter JG, et al. Mesh complications after prosthetic reinforcement of hiatal closure: a 28-case series. Surg Endosc 2009;23:1219-26.

56. Kemppainen E, Kiviluoto T. Fatal cardiac tamponade after emergency tension-free repair of a large paraesophageal hernia. Surg Endosc 2000;14:593.

57. Muller-Stich BP, Linke G, Leemann B, Lange J, Zerz A. Cardiac tamponade as a life-threatening complication in antireflux surgery. Am J Surg 2006;191:139-41.

58. Frantzides CT, Welle SN. Cardiac tamponade as a life-threatening complication in hernia repair. Surgery 2012;152:133-5.

59. Brown CN, Finch JG. Which mesh for hernia repair? Ann R Coll Surg Engl 2010;92:272-8.

60. Huddy JR, Markar SR, Ni MZ, Morino M, Targarona EM, Zaninotto G, et al. Laparoscopic repair of hiatus hernia: Does mesh type influence outcome? A meta-analysis and European survey study. Surg Endosc 2016;30:5209-21.

61. Castelijns PSS, Ponten JEH, van de Poll MCG, Nienhuijs SW, Smulders JF. A collective review of biological versus synthetic mesh-reinforced cruroplasty during laparoscopic Nissen fundoplication. J Minim Access Surg 2018;14(2):87-94.

62. Braghetto I, Korn O, Csendes A, Burdiles P, Valladares H, Brunet L. Postoperative results after laparoscopic approach for treatment of large hiatal hernias: is mesh always needed? Is the addition of an antireflux procedure necessary? Int Surg 2010;95:80-7.

63. Avidan B, Sonnenberg A, Schnell TG, Sontag SJ. Hiatal hernia and acid reflux frequency predict presence and length of Barrett's esophagus. Dig Dis Sci 2002;47:256-64.

64. Rakic S, Pesko P, Dunjic MS, Gerzic Z. Paraoesophageal hernia repair with and without concomitant fundoplication. Br J Surg 1994;81:1162-3.

65. Furnee EJ, Draaisma WA, Simmermacher RK, Stapper G, Broeders IA. Long-term symptomatic outcome and radiologic assessment of laparoscopic hiatal hernia repair. Am J Surg 2010;199:695-701.

66. Broeders JA, Sportel IG, Jamieson GG, Nijjar RS, Granchi N, Myers JC, et al. Impact of ineffective oesophageal motility and wrap type on dysphagia after laparoscopic .fundoplication. $\mathrm{Br} J$ Surg 2011;98:1414-21.

67. Granderath FA, Schweiger UM, Kamolz T, Asche KU, Pointner R. Laparoscopic Nissen fundoplication with prosthetic hiatal closure reduces postoperative intrathoracic wrap herniation: preliminary results of a prospective randomized functional and clinical study. Arch Surg 2005;140:40-8.

68. Hunter JG, Swanstrom L, Waring JP. Dysphagia after laparoscopic antireflux surgery. The impact of operative technique. Ann Surg 1996;224:51-7.

69. Svetanoff WJ, Pallati P, Nandipati K, Lee T, Mittal SK. Does the addition of fundoplication to repair the intra-thoracic stomach improve quality of life? Surg Endosc 2016;30:4590-7.

70. Muller-Stich BP, Achtstatter V, Diener MK, Gondan M, Warschkow R, Marra F, et al. Repair of Paraesophageal Hiatal Hernias-Is a Fundoplication Needed? A Randomized Controlled Pilot Trial. J Am Coll Surg 2015;221:602-10. 
71. Higashi S, Nakajima K, Tanaka K, Miyazaki Y, Makino T, Takahashi T, et al. Laparoscopic anterior gastropexy for type III/IV hiatal hernia in elderly patients. Surg Case Rep 2017;3:45.

72. Daigle CR, Funch-Jensen P, Calatayud D, Rask P, Jacobsen B, Grantcharov TP. Laparoscopic repair of paraesophageal hernia with anterior gastropexy: a multicenter study. Surg Endosc 2015;29:1856-61.

73. Leggett PL, Bissell CD, Churchman-Winn R. Aortic injury during laparoscopic fundoplication: an underreported complication. Surg Endosc 2002;16:362.

74. Baigrie RJ, Watson DI, Game PA, Jamieson GG. Vascular perils during laparoscopic dissection of the oesophageal hiatus. Br J Surg 1997;84:556-7.

75. Cano-Valderrama O, Marinero A, Sanchez-Pernaute A, Dominguez-Serrano I, Perez-Aguirre E, Torres AJ. Aortic injury during laparoscopic esophageal hiatoplasty. Surg Endosc 2013;27:3000-2.

76. Fernandez Mdel C, Diaz M, Lopez F, Marti-Obiol R, Ortega J. Cardiac complications after laparoscopic large hiatal hernia repair. Is it related with staple fixation of the mesh? -Report of three cases. Ann Med Surg (Lond) 2015;4:395-8.

77. Yang X, Hua R, He K, Shen Q, Yao Q. Laparoscopic hernioplasty of hiatal hernia. Ann Transl Med 2016;4:343.

78. Hamrick MC, Davis SS, Chiruvella A, Coefield RL, Waring JP, Sweeney JF, et al. Incidence of delayed gastric emptying associated with revisional laparoscopic paraesophageal hernia repair. J Gastrointest Surg 2013;17:213-7

79. van Rijn S, Roebroek YG, Conchillo JM, Bouvy ND, Masclee AA. Effect of Vagus Nerve Injury on the Outcome of Antireflux Surgery: An Extensive Literature Review. Dig Surg 2016;33:230-9.

80. van Rijn S, Rinsma NF, van Herwaarden-Lindeboom MY, Ringers J, Gooszen HG, van Rijn PJ, et al. Effect of Vagus Nerve Integrity on Short and Long-Term Efficacy of Antireflux Surgery. Am J Gastroenterol 2016;111:508-15.

81. Lidor AO, Kawaji Q, Stem M, Fleming RM, Schweitzer MA, Steele KE, et al. Defining recurrence after paraesophageal hernia repair: correlating symptoms and radiographic findings. Surgery 2013;154: 171-8.

82. Oelschlager BK, Petersen RP, Brunt LM, Soper NJ, Sheppard BC, Mitsumori L, et al. Laparoscopic paraesophageal hernia repair: defining long-term clinical and anatomic outcomes. J Gastrointest Surg 2012;16:453-9.

83. Lidor AO, Steele KE, Stem M, Fleming RM, Schweitzer MA, Marohn MR. Long-term quality of life and risk factors for recurrence after laparoscopic repair of paraesophageal hernia. JAMA Surg 2015;150:424-31.

84. Furtado RV, Vivian SJ, van der Wall H, Falk GL. Medium-term durability of giant hiatus hernia repair without mesh. Ann R Coll Surg Engl 2016;98:450-5.

85. Zaman JA, Lidor AO. The Optimal Approach to Symptomatic Paraesophageal Hernia Repair: Important Technical Considerations. Curr Gastroenterol Rep 2016;18:53.

86. Koch OO, Asche KU, Berger J, Weber E, Granderath FA, Pointner R. Influence of the size of the hiatus on the rate of reherniation after laparoscopic fundoplication and refundopilication with mesh hiatoplasty. Surg Endosc 2011;25:1024-30.

87. Morgenthal CB, Lin E, Shane MD, Hunter JG, Smith CD. Who will fail laparoscopic Nissen fundoplication? Preoperative prediction of long-term outcomes. Surg Endosc 2007;21:1978-84.

88. Lidor AO, Chang DC, Feinberg RL, Steele KE, Schweitzer MA, Franco MM. Morbidity and mortality associated with antireflux surgery with or without paraesophogeal hernia: a large ACS NSQIP analysis. Surg Endosc 2011;25:3101-8.

89. Leon P, Rivellini R, Giudici F, Sciuto A, Pirozzi F, Corcione F. 3D Vision Provides Shorter Operative Time and More Accurate Intraoperative Surgical Performance in Laparoscopic Hiatal Hernia Repair Compared With 2D Vision. Surg Innov 2017;24:155-61.

90. Galvani CA, Loebl H, Osuchukwu O, Samame J, Apel ME, Ghaderi I. Robotic-Assisted Paraesophageal Hernia Repair: Initial Experience at a Single Institution. J Laparoendosc Adv Surg Tech A 2016;26:290-5.

91. Sarkaria IS, Latif MJ, Bianco VJ, Bains MS, Rusch VW, Jones DR, et al. (2017) Early operative outcomes and learning curve of robotic assisted giant paraesophageal hernia repair. Int J Med Robot 2017;13(1). 



\title{
Chapter 3
}

\section{A collective review of biological versus synthetic mesh-reinforced cruroplasty during laparoscopic \\ Nissen fundoplication}

\author{
P.S.S. Castelijns \\ J.E.H. Ponten \\ M.C.G. van de Poll \\ S.W. Nienhuijs \\ J.F. Smulders
}




\section{Abstract}

\section{Background}

Laparoscopic cruroplasty and fundoplication have become the gold standard in the treatment of hiatal hernia and gastroesophageal reflux disease (GERD). The use of a mesh-reinforcement of the cruroplasty has been proven effective; although there is a lack of evidence considering which type of mesh is superior. The aim of this study was to compare recurrence rates after mesh reinforced cruroplasty using biological versus synthetic meshes.

\section{Methods}

We performed a systematic review of all clinical trials published between January 2004 and September 2015 describing the application of a mesh in the hiatal hernia repair during Nissen fundoplication for both GERD and hiatal hernia. The primary outcome was the recurrence rate, and secondary outcomes were complication rate, mortality and symptomatic outcome.

\section{Results}

We included 16 studies and extracted data regarding 1089 mesh operated patients of whom 385 received a biological mesh and 704 a synthetic mesh. The mean follow-up was 53.4 months. The recurrence rate in the synthetic mesh group was $6.8 \%$ compared to $16.1 \%$ in the biological mesh group $(P<0.05)$. The complication rate was $5.1 \%$ and $4.6 \%(P=0.694)$, respectively, and there were 12 mesh-related complications. No mesh-related mortality was reported.

\section{Conclusion}

Mesh reinforcement of hiatal hernia repair seems safe in the short-term follow-up. The available literature suggests no clear advantage of biological over synthetic meshes. Regarding costefficiency and short-term results, the use of synthetic non-absorbable meshes might be advocated. 


\section{Introduction}

In 1992, the first report on laparoscopic hiatal hernia repair was published, and over the subsequent years the laparoscopic approach has become standard treatment. ${ }^{1,2}$ Hiatal herniation is a common disorder of the digestive tract, which is defined by a protrusion of the stomach into the thoracic cavity through a widening of the right crus of the diaphragm. ${ }^{3}$ Anatomically, hiatal hernias can be divided into four categories. Type I, a sliding hernia, means that the gastroesophageal junction migrates into the thorax. This is the most common type (95\%) and it may predispose to gastroesophageal reflux. ${ }^{2,4}$ Type II, para-oesophageal hernia, is a defect of the diaphragm with herniation of the gastric fundus through the hiatus into the thorax. Type III is a mixed type of hernia with both aspects of a type I and type II hernia. Often more than $50 \%$ of the stomach is in the thorax. The most severe type of hernia is a type IV, in which not only the stomach, but also other viscera like colon or spleen herniate into the mediastinal sac. In this latter case it is also called an "upside-down stomach". ${ }^{5}$

The possible life-threatening aspects of a hiatal hernia, such as obstruction, acute dilatation, perforation, or bleeding of the stomach mucosa, make it important to diagnose and repair the hiatal hernia. ${ }^{6}$ The use of mesh to repair a hiatal hernia had already started in the era of the open surgery. ${ }^{7}$ However, there is growing interest in the use of a mesh during laparoscopic surgery as well. According to the Society of American Gastrointestinal and Endoscopic Surgeons (SAGES) guidelines, the laparoscopic Nissen fundoplication and cruroplasty is the gold standard for both gastroesophageal reflux disease (GERD) ${ }^{8}$ and hiatal hernia repair. ${ }^{9}$ Recent studies $^{10-12}$ have suggested that reinforcement of the cruroplasty with a mesh results in a reduction in the recurrence rate. Several different meshes are available, broadly categorised into synthetic or biological material, various shapes or the fixation method. ${ }^{13}$ Both biological and synthetic meshes have been applied. The theoretical advantages of a biological mesh are less mesh related complications such as erosion or migration of the mesh, infection of the mesh and development of fibrotic strictures. However, considering the considerably higher costs of biological meshes and a possible higher recurrence rate, these theoretical advantages should be supported by clinical evidence before the standard use of biological meshes for cruroplasty reinforcement can be advocated. Only one randomised clinical trial has been performed addressing the direct question whether biological meshes are indeed superior to synthetic meshes. ${ }^{14}$ However, this study only reports short term follow-up. We systematically reviewed the outcomes of mesh reinforced cruroplasty, comparing biological and synthetic meshes. By including the "mesh-arms" of randomised controlled "mesh vs. non-mesh-trials," we attempted to reduce selection bias. 
We evaluated the recurrence rate in the different mesh groups as the primary outcome. Complications, mortality and the symptomatic success rate are seen as secondary outcomes.

\section{Methods}

\section{Search strategy}

PubMed database, including an e-link to related articles, Embase, and the clinical trial registry for the Cochrane Collaboration (CENTRAL) were searched for relevant studies reporting a mesh-based hiatal hernia repair and the outcome of recurrence of hiatal hernias.

The first search was performed in PubMed with the following terms: $((()(($ "Hernia, Hiatal"[Mesh]) OR hiatal hernia) OR hiatus)) AND (((“Surgical Mesh"[Mesh]) OR mesh) OR mesh*)) AND (("Laparoscopy"[Mesh]) OR laparoscopic)) AND ((((“Fundoplication”[Mesh]) OR Nissen) OR Toupet) OR fundoplication). When searching in Embase, the following search was used to identify the related articles: (hiatal hernia and laparoscopic and mesh and fundoplication).

In 2005 a large review describeed the results of laparoscopic versus open hiatal hernia repair up to $2004 .{ }^{15}$ Therefore, studies from January 1, 2004 to September 30, 2015 were selected. Two reviewers independently reviewed the articles (BC/JP). In case of discrepancy between the two reviewers, a third party (JFS) was consulted. Restrictions were: at least $\mathrm{n}=15$ and minimum follow-up of 12 months, primary repairs only. There were no limitations on language or study design. Selection was based on title and abstract, and when in doubt, full text.

\section{Selection criteria}

All cohort studies, both retrospective and prospective, case-control studies and RCT, which reported recurrence rates of mesh-based repair of hiatal hernia were selected, and studies with a level of evidence $\geq 3 \mathrm{~B}$ were included in the study. Paediatric studies, reviews, meta-analyses, case reports and case-series were excluded. The recurrence rate and mesh characteristics were obligatory to be included; the symptomatic outcome, however, was not an inclusion criteria. Only non-absorbable synthetic meshes are included in this study. A recurrence is defined as an objectified recurrence, if a hiatal hernia is seen on endoscopy or a Barium swallow examination. Figure 3.1 gives an overview of the search strategy. 


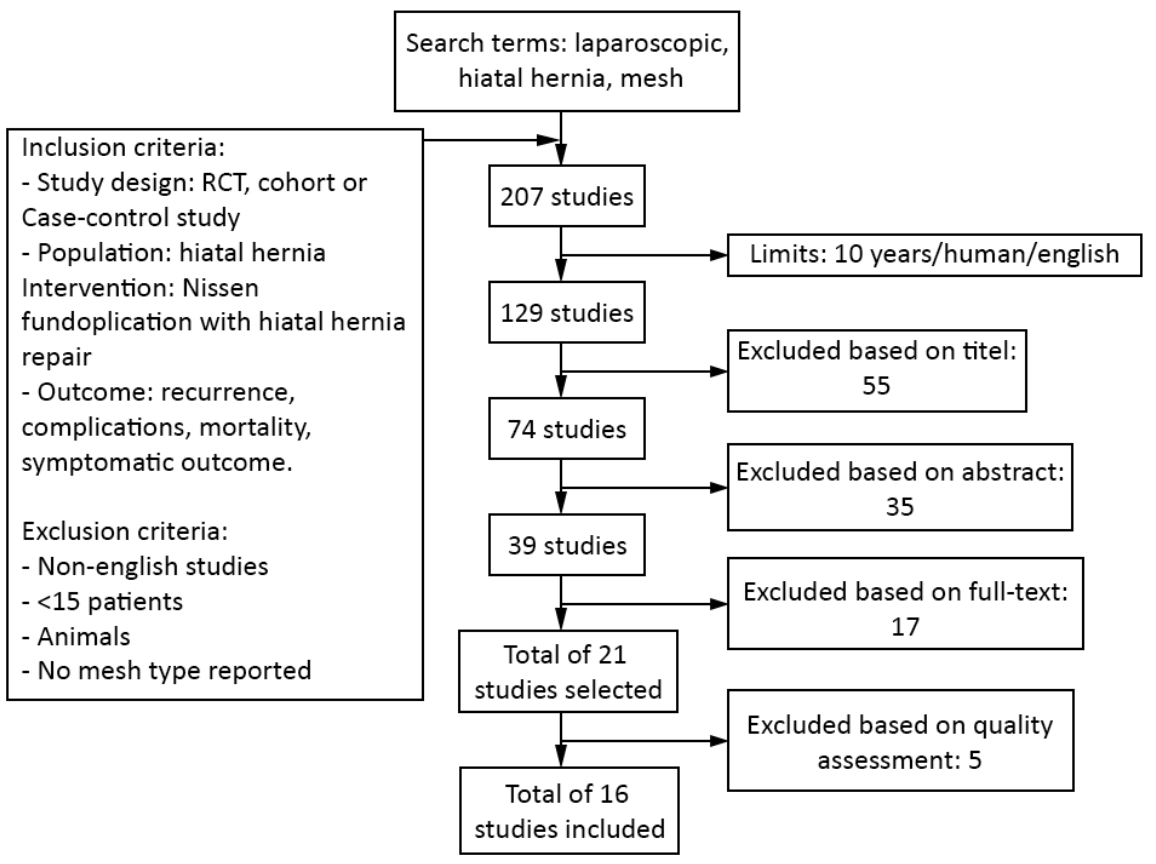

Figure $3.1 \quad$ Search strategy

\section{Data analysis}

A preform was used to extract study design, number of mesh operated patients, the size and type of hernia, the primary indication for the repair, details of the procedure, information about the type, configuration and fixation of the mesh, length of follow-up, recurrence rate, all complications and symptomatic outcome.

Some studies described both non-mesh based repair and mesh-based repair. Since this is a systematic review of mesh-based hiatal repair, all above mentioned data regarding mesh-operated patients were extracted. Total recurrence, complications and symptomatic outcome were calculated for the patients that underwent a mesh-based hiatal hernia repair. Data regarding a fundoplication other than Nissen were not extracted. Mean follow-up was extracted or the given median was used as the mean. Patient groups, in which the same type of mesh was used, were pooled.

All data were analysed using SPSS for MacOs version 21.0 (SPSS Inc., Chicago, IL, USA). Values are expressed as mean \pm standard deviation (SD). 


\section{Quality assessment}

All included studies were assessed regarding their methodological quality. The Jadad score was used to qualify the RCT's. ${ }^{16}$ In this score, the way of randomisation, the method of blinding and the amount of drop-outs lead to a minimum score of zero (a RCT of statistical inferior quality) and a maximum score of five (a RCT of statistical very good quality). To determine the methodological quality of the cohort studies and the case-control studies, the Newcastle-Ottawa Assessment Scale of the quality of nonrandomised studies in meta-analysis was used. ${ }^{17}$ The minimal score used is zero (very poor statistical quality) and the maximum score for the case-control series is nine (excellent statistical quality).

Consequently, a level of evidence was assigned to each article according to the Oxford Centre of Evidence Based Medicine Levels of Evidence (Table 3.1). ${ }^{18}$ A Jadad score $<4$ was graded as a level $2 B$ evidence and a score of four or five was level $1 B$ [10]. Cohort studies with a Newcastle-Ottawa Assessment score of $<6$ were graded a level of evidence of 4 and a score of $>5$ was graded level 2B. All case-control studies are assigned a level of 3B.

Table 3.1 Grades of evidence according to the oxford Centre for Evidence-bases Medicine Levels of Evidence

\begin{tabular}{ll}
\hline I & Evidence obtained from systematic reviews with homogeneity of randomized controlled trials \\
I-b & Evidence obtained from individual randomized controlled trials with narrow confidence interval \\
II-a & Evidence obtained from systematic reviews with homogeneity of well-designed cohort studies \\
II-b & Evidence obtained from individual cohort studies (including low-quality RCT"; e.g., <80\% follow-up) \\
II-c & Evidence obtained from "outcomes" research; ecological studies \\
III-a & Evidence obtained from systematic reviews with homogeneity of case-control studies \\
III-b & Evidence obtained from individual case-control studies \\
IV & Evidence obtained from case-series and poor-quality cohort and case-control studies \\
V & $\begin{array}{l}\text { Expert opinion without explicit critical appraisal, or based on physiology, bench research of "first } \\
\text { principles" }\end{array}$
\end{tabular}

\section{Results}

\section{Description of the studies}

The used search strategy generated a total of 207 articles eligible for selection. All articles were selected on title and abstract, based on the inclusion and exclusion criteria. Seventy-four articles underwent critical appraisal of the full text. Eventually 21 articles fulfilled the selection criteria and were selected for quality assessment. (Figure 3.1)

Four of the studies are case-control series, and all of them had a level of evidence 3B. Four of them are RCTs, all of them with a level of evidence $1 \mathrm{~B}$ and a mean Jadad score 
of $4.75 \pm 0.4$. The remaining 13 articles described cohort studies; eight of them had a level of evidence $2 \mathrm{~B}$ and the remaining five studies had a level of evidence 4 and were, therefore, excluded from this review. Finally, 16 articles were included in this review (Table 3.2). ${ }^{12,19-33}$

\section{Baseline characteristics}

In the 16 articles, a total of 2364 patients were included. All patients that underwent a mesh-based hiatal hernia repair were extracted. This led to the inclusion of 1089 patients in total. A total of 385 patients received a biological mesh (35.4\%) and 704 patients were operated on with a synthetic mesh (64.6\%). The gender was not described in five studies $(31.3 \%)^{20,26,31-33}$, and in the remaining studies the male: female ratio was 1:1.2. The weighted mean age of the population was 51.1 years and the weighted mean follow-up was 53.4 (range 12-97.7) months. Four studies included all hernia sizes, seven studies included large hernias defined by a defect larger than $5 \mathrm{~cm}$ or migration of $>50 \%$ of the stomach into the thorax. Three studies included only small defects defined by a hernia $<5 \mathrm{~cm}$ or $<50 \%$ of the stomach in the thorax. The remaining studies did not report their included hernia size.

\section{Mesh characteristics}

Several types of mesh were used in the included studies. Most studies described only one specific type of mesh, but in three studies, multiple types of synthetic or biological meshes were used, and these studies are referred to as the multiple mesh group. Polypropylene (Prolene ${ }^{\circledR}$; Ethicon) (synthetic mesh) and the Small Intestine Submucosa (SIS, 4-ply Surgisis; Cook Biotech Inc., Lafayette, IN) (biological mesh) are the most-used mesh types in this review - respectively, 540 (48.6\%) and 125 (11.3\%) patients. The methods of mesh fixation to the hiatus were suturing, stapling and/or the use of glue. In nearly all studies, except for one, the mesh was used as a reinforcement of the primary closure. ${ }^{26}$ In that study, the mesh was used to create a tension-free repair.

\section{Recurrence}

An accurate analysis of the recurrence rate appeared to be complex, as a standardised definition for recurrence was lacking in most studies. Some studies reported the return of symptoms as a recurrence and others reported an anatomical hiatal hernia at followup as a recurrence. The anatomical recurrence data were extracted and the definition we used for a recurrence was a hiatal hernia $>2 \mathrm{~cm}$ on barium swallow or on endoscopy. ${ }^{30}$ The anatomical recurrence rate in the biological mesh group was $16.1 \%$ compared with a recurrence of $6.8 \%$ in the synthetic mesh group $(P<0.05)$. 


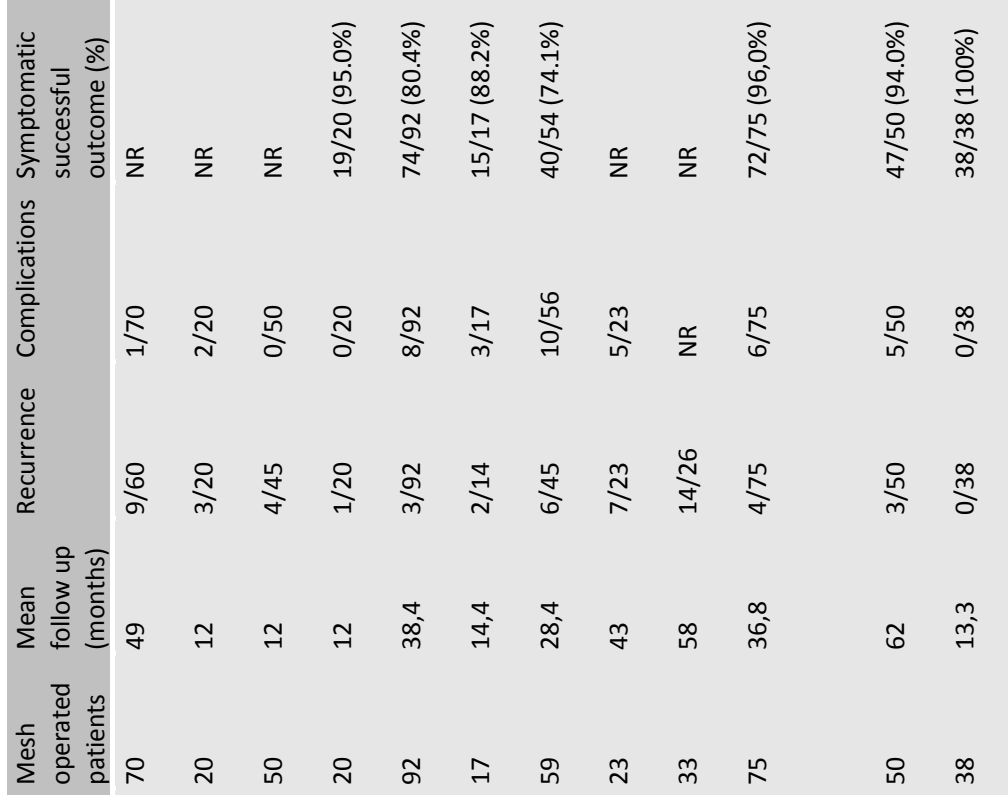

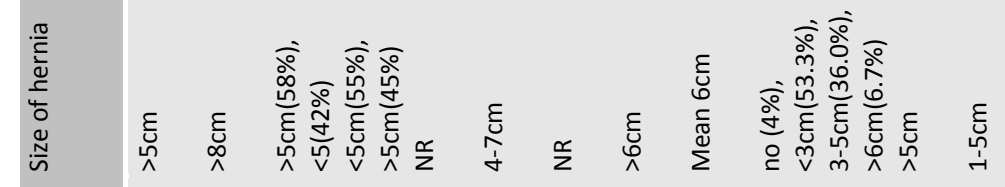

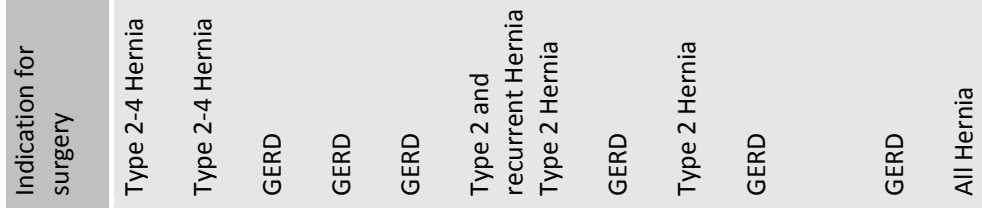

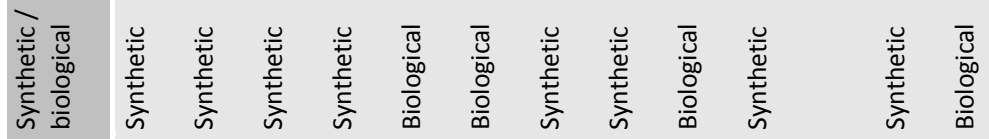

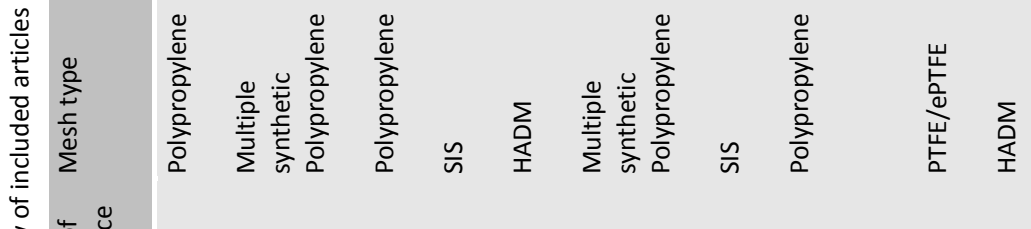




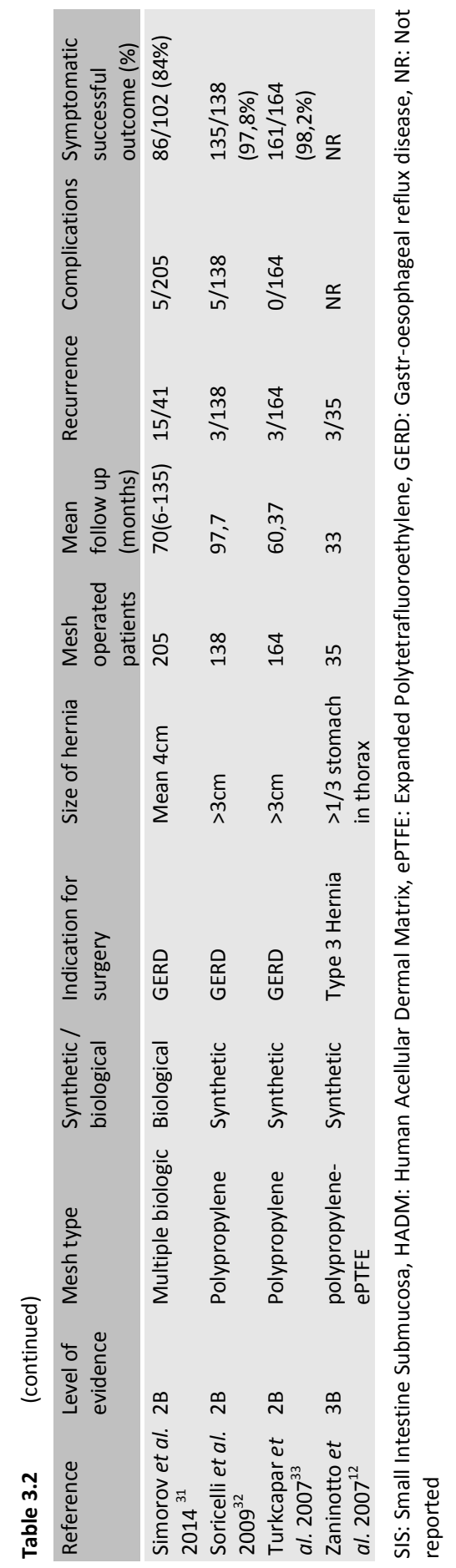


In the biological group two mesh types were used -a Human Acellular Dermal Matrix (HADM, Alloderm; LifeCell Corporation, Bridgewater, NJ, USA) and the SIS with an individual anatomical recurrence rate of $3.8 \%$ and $14.4 \%$, respectively. In the synthetic mesh group the lowest individual recurrence rate was seen for the polypropylene mesh, $5.9 \%$, and the highest recurrence rate was $7.1 \%$ for the polytetrafluoroethylene (PTFE) mesh.

\section{Complications}

There is no agreement between studies regarding which symptoms are classified as complications and which are not. Therefore, the reported complication rates were used, regardless of what the complications were. The most frequently reported complications were an intraoperative splenic lesion, post-operative dysphagia and a post-operative gasbloating syndrome. (Table 3.3a and 3.3b) Most complications appeared in the post-operative period, and 12 of the 1089 operated patients had a mesh-related complication. The most reported mesh-related complication was stenosis of the gastroesophageal junction. Only one mesh-related complication was in the biological mesh group compared with 11 events in the synthetic mesh group ( $P=0.065)$. The overall complication rate was $5.1 \%$ in the synthetic mesh group and $4.6 \%$ in the biological mesh group ( $P=0.694)$. The complication rates vary per type of mesh between $3.1 \%$ with a polypropylene mesh and $15.8 \%$ for the multiple synthetic group. In the biological group the lowest complication rate was seen for the HADM mesh with $5.5 \%$, where the upper limit was $8.7 \%$ for the SIS mesh.

Table 3.3a Reported post-operative complications

$\begin{array}{lcc} & \text { Studies } & \text { Number of patients } \\ \text { Complications post-operative } & 25,26 & 2 \\ \text { Oesophageal perforation } & 12 & 1 \\ \text { Cardiac arrest } & 12,23,29 & 6 \\ \text { Migration of the wrap } & 12,23,28 & 25 \\ \text { Dysphagia > 4 weeks } & 12,20,30 & 4 \\ \text { Hemorrhage from trocar site } & 20,41 & 3 \\ \text { Atelectasis } & 20 & 2 \\ \text { Hematome from trocar site } & 20 & 1 \\ \text { Infection of trocar site } & 20 & 1 \\ \text { Atrium fibrillation } & 31,41 & 9 \\ \text { Urine retention } & 41 & 2 \\ \text { Fever } & 25,41 & 4 \\ \text { Pneumothorax - resolved spontaneously } & 31 & 4 \\ \text { Pneumothorax - drain needed } & 28,32 & 22 \\ \text { Gas bloat } & 23 & 1 \\ \text { Gastroparesis, patient died } & 25 & 2 \\ \text { Pleural bleeding } & 29 & 1 \\ \text { Pulmonary embolism, patient died } & 19 & 1\end{array}$

This table presents all reported post-operative complications with the number of patients that underwent the specific complication 
Table 3.3b Reported operative and mesh-related complications

\begin{tabular}{|c|c|c|c|}
\hline \multirow{2}{*}{\multicolumn{2}{|c|}{ Complications during surgery }} & Studies & Number of patients \\
\hline & & & \\
\hline \multicolumn{2}{|c|}{ Gastric lesion } & 12 & 1 \\
\hline \multicolumn{2}{|l|}{ Gastric perforation } & 24,32 & 2 \\
\hline \multicolumn{2}{|l|}{ Pleural tear } & 32 & 1 \\
\hline \multicolumn{2}{|l|}{ Pleural lesion } & 32 & 3 \\
\hline \multicolumn{2}{|l|}{ Conversion to open } & 25,29 & 5 \\
\hline \multicolumn{2}{|l|}{ Pneumothorax } & $25,29,30$ & 9 \\
\hline \multicolumn{2}{|l|}{ Splenic lesion } & $12,23,28,29,32$ & 11 \\
\hline \multicolumn{4}{|c|}{ Mesh-related complications } \\
\hline \multirow[t]{3}{*}{ Synthetic mesh } & Not further specified & 32 & 1 \\
\hline & Erosion of mesh & 12,20 & 2 \\
\hline & Stenosis & 20,25 & 8 \\
\hline Biological mesh & Fibrosis & 24 & 1 \\
\hline
\end{tabular}

This table presents all reported operative and mesh-related complications with the number of patients that underwent the specific complication

\section{Symptomatic outcome}

All studies used different criteria for a symptomatic successful outcome. Some authors used the complete remission of symptoms as a successful outcome; others were satisfied when patients suffered less severe post-operative symptoms when compared with their pre-operative symptoms. The successful outcome reported in the individual articles is analysed in this review, regardless of the criteria that were used. Six studies did not report symptomatic outcomes. ${ }^{12,19-21,26,27}$ An overall symptomatic success rate of $85.5 \%$ was found in the biological mesh group, and a success rate of $94.6 \%$ in the synthetic mesh group. The highest success rate overall was in the Polypropylene group with $97.5 \%$ of the patients being relieved of their symptoms at a mean follow-up of 48.6 months. The lowest symptomatic success rate was found in the SIS group; $80.4 \%$ of these patients were relieved of their symptoms.

\section{Mortality}

Mortality after laparoscopic fundoplication and hiatal hernia repair is low. No meshrelated mortality was reported in the included studies (Table 3.4).

Table 3.4 Causes of death

\begin{tabular}{|c|c|c|c|c|c|}
\hline Study & Age & Gender & Type of mesh & Cause of death & Relation to mesh \\
\hline 19 & 74 & NR & Polypropylene & $\begin{array}{l}\text { Laceration of the fundoplication causing a } \\
\text { gastropleural fistula leading to respiratory } \\
\text { insufficiency }\end{array}$ & No \\
\hline 29 & NR & NR & PTFE-ePTFE & Pulmonary embolism & No \\
\hline 23 & NR & NR & SIS & Aspiration due to gastric paresis & No \\
\hline
\end{tabular}

This table presents the reported causes of death with the specific details. ePTFE: Expanded polytetrafluoroethylene, NR: Not reported, SIS: Small Intestine Submucosa 


\section{Discussion}

The aim of this study was to evaluate the recurrence rate in mesh repaired hiatal hernia. Recent studies have shown that a mesh-based hiatal hernia repair is superior to a non-mesh based repair. ${ }^{10-12}$ Until now, various recurrence rates have been reported for the use of synthetic meshes, varying between $0-44 \%$, with a median recurrence rate of $7 \%$ in a large review by Draaisma et al.. ${ }^{15,34,35}$ This spread may be caused by the difference in follow-up, since higher recurrence rates are found in studies with a longer follow-up. Another explanation for this wide spread is that different definitions for recurrence are available. One can define recurrence as the return of symptoms or as a radiological recurrence as well. If the latter one is used, recurrence rates up to $54 \%$ have been reported in patients that received a biological mesh-based repair. ${ }^{27}$ In 2006, Oelschlager et al. reported that a radiographic recurrence rate of $24 \%$ in patients in which the hiatal hernia was primarily closed compared with a recurrence rate of $9 \%$ in patients who received a biological mesh for a follow-up period of 6 months. ${ }^{36}$ However, when they describe the same cohort in 2011 and report the 5-year follow up, ${ }^{27}$ the recurrence rates are $59 \%$ and $54 \%$, respectively. It seems that the advantage in recurrence rate of the biological mesh disappears when the follow-up becomes longer. Unfortunately, it is very difficult to draw strong conclusions based on published studies, since there are only five studies describing a biological mesh and most studies only report short-term results. Nevertheless, we found a significantly higher recurrence rate in the absorbable mesh group. This finding is supported by Watson et al. ${ }^{14}$; however, there was no statistically significant difference in this study $(P=0.161)$. We believe that this result may be due to the small sample size, since the reported recurrence rates are $30.8 \%$ after biological absorbable mesh compared with 12.8 for the non-absorbable synthetic mesh. This study also reports a short-term follow-up of only 6 months.

The secondary outcomes of this review were the complication rate, mortality and the symptomatic success rate. There is a large heterogeneity among the studies regarding the different outcomes; nevertheless, the complication rates and symptomatic outcomes are pooled. Due to the large heterogeneity, it was not possible to apply an extensive statistical analysis on the data. If the complications are pooled, an overall complication rate of $4.9 \%$ is found (Table 3.5 ). There is a large diversity in the reported complications. This can probably be explained by the fact that some studies describe a symptom as a complication, for example dysphagia, where others report this as a common side effect of the procedure. Dysphagia is the main problem after antireflux surgery with an incidence of $3 \%-24 \%$ after Nissen fundoplication. ${ }^{21,37}$ Most complications are not related to the use of a mesh during the procedure, but there were 12 mesh-related complications. The mesh-related complication reported the most is a stenosis at the gastroesophageal junction. This is probably due to shrinkage of the mesh, which is more common in a synthetic mesh. The shrinkage rate can be up to $70 \%$ for a polypropylene mesh. ${ }^{38}$ Since the sample sizes of the individual series are rather 
small, there is a considerable risk of underreporting of complications due to publication bias.

Table 3.5 Pooled results of the studies

\begin{tabular}{|c|c|c|c|c|c|c|c|c|}
\hline $\begin{array}{l}\text { Mesh } \\
\text { type }\end{array}$ & $\begin{array}{c}\text { No of } \\
\text { studies }\end{array}$ & $\begin{array}{c}\text { No of } \\
\text { patient } \\
\text { s }\end{array}$ & $\begin{array}{c}\text { No of } \\
\text { mesh } \\
\text { operated } \\
\text { patients }\end{array}$ & $\begin{array}{l}\text { Weighted } \\
\text { mean } \\
\text { follow up } \\
\text { (months) }\end{array}$ & $\begin{array}{l}\text { Recurrence } \\
n / N(\%)^{*}\end{array}$ & $\begin{array}{c}\text { Complications } \\
n / N(\%)\end{array}$ & $\begin{array}{l}\text { Mortality } \\
n / N(\%)\end{array}$ & $\begin{array}{c}\text { Symptomatic } \\
\text { succesful } n \text { / } \\
N(\%)\end{array}$ \\
\hline Synthetic & $\begin{array}{c}11^{12,19-22} \\
25,26,28,29 \\
32,33\end{array}$ & 1652 & 704 & 53.4 & $\begin{array}{c}46 / 675 \\
(6.8)\end{array}$ & $34 / 666$ (5.1) & $\begin{array}{l}2 / 704 \\
(0.28)\end{array}$ & $\begin{array}{c}474 / 501 \\
(94.6)\end{array}$ \\
\hline Biologic & 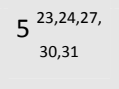 & 712 & 385 & 53.4 & $\begin{array}{c}34 / 211 \\
(16.1)\end{array}$ & $16 / 352(4.6)$ & $\begin{array}{l}1 / 385 \\
(0.26)\end{array}$ & $\begin{array}{c}213 / 249 \\
(85.5)\end{array}$ \\
\hline Overall & 16 & 2364 & 1089 & 53.4 & $\begin{array}{c}80 / 886 \\
(9.0)\end{array}$ & $50 / 1018$ (4.9) & $\begin{array}{c}3 / 1018 \\
(0.29)\end{array}$ & $\begin{array}{c}687 / 750 \\
(91.6)\end{array}$ \\
\hline
\end{tabular}

Summary of the results of all included studies. Data marked with * are considered statistically significant

Theoretically, a biological mesh could show lower mesh-related complication rates, since this type of mesh is made of collagen, which will be absorbed by the body over time. Furthermore, the biological material may still contain some growth factors, which may induce the remodelling faster. In this review, there were no complications reported in the biological mesh-based hiatal hernia repairs. However, Stadlhuber et al. $^{39}$ described in 2009 a series of 28 case reports describing mesh-related complications. Seven of these cases described mesh-related complications in biological meshes, including stenosis, fibrosis and even one case of erosion of the mesh into the oesophagus. There is only one mesh-related complication found in the included studies, which was described by Soricelli et al.. ${ }^{32}$ This concerned a polypropylene mesh after a mean follow-up of $89 \pm$ SD 29.8 months. The specific follow-up in this case is not reported and further details on this specific case are not reported either. Still, hiatal hernia repair with the use of a mesh seems to be a safe procedure since low mortality rates were reported.

The overall mortality rate was $0.29 \%$, which is very low, and all deaths were due to nonmesh related causes (Table 3.4).

As demonstrated in Table 3.2, the symptomatic outcome is reported in 10 studies and the overall success rate is $687 / 750$ (91.6\%). The most common method to measuring the symptomatic outcome is by a $0-4$ point Likert scale, ${ }^{20,22,27,30}$ Visick score, ${ }^{26,28,33}$ or by a yes/no scoring system. ${ }^{23-25}$ The definition for a successful symptomatic outcome used in this review is an improvement of the previously mentioned scores. Since there is a large heterogeneity in the symptomatic outcome, the only conclusion that can be made is that there is an increasing need for a standardised method to report the symptomatic outcome of hiatal hernia repair. 
Another aspect that needs to be considered is the cost of the different mesh types. Unfortunately, the price of the meshes was not mentioned in any of the articles. However, there is one literature review done in 2011 by Shankaran et al.. ${ }^{40}$ They evaluated the cost of different mesh types. The conclusion of this review is that the price of a synthetic mesh is between $\$ 0.20$ and $\$ 1.00$ per $\mathrm{cm}^{2}$. The biological mesh is available for a price between $\$ 8.00$ and $\$ 26.00$ per $\mathrm{cm}^{2}$. Therefore, one can conclude that the biological mesh is on average far more expensive than a synthetic mesh.

\section{Conclusion}

This is the first review that gives an overview of performed studies between 2004 and September 2015 describing hiatal hernia repair with the use of a mesh in Nissen fundoplication. Despite the large heterogeneity, some differences were found in recurrence, complications and symptomatic outcomes between a synthetic and a biological mesh. The use of a synthetic mesh showed a significant lower recurrence rate. Regarding the complication rate, there is no advantage of one mesh over the other; however, it seems that with the use of a synthetic mesh more mesh-related complications occur. For both synthetic and biological meshes, the mortality rate is very low. Mesh repair of a hiatal hernia seems safe in the short-term; however, more longterm studies are needed to analyse the mesh-related complications. Since the biological mesh is more expensive and does not show better results, a synthetic mesh seems a good choice to use for hiatal hernia repair.

In the synthetic mesh group, the polypropylene shows a very low recurrence rate and the lowest complication rate. This type of mesh might be superior to the other synthetic meshes. There is a lot of heterogeneity among the studies so far, and only few studies report on a biological mesh. There is a need for more RCTs comparing synthetic meshes with biological meshes with a long-term follow up, and a standardised method to report the success ratio of the procedure, both symptomatic and anatomic. 


\section{References}

1. Watson DI. Evolution and development of surgery for large paraesophageal hiatus hernia. World J Surg 2011;35:1436-41.

2. Cuschieri A, Shimi S, Nathanson LK. Laparoscopic reduction, crural repair, and fundoplication of large hiatal hernia. Am J Surg 1992;163:425-30.

3. Andujar JJ, Papasavas PK, Birdas T, Robke J, Raftopoulos Y, Gagne DJ, et al. Laparoscopic repair of large paraesophageal hernia is associated with a low incidence of recurrence and reoperation. Surg Endosc 2004;18:444-7.

4. Athanasakis H, Tzortzinis A, Tsiaoussis J, Vassilakis JS, Xynos E. Laparoscopic repair of paraesophageal hernia. Endoscopy 2001;33:590-4.

5. Hill LD, Tobias JA. Paraesophageal hernia. Arch Surg 1968;96:735-44.

6. Tsuboi K, Tsukada K, Nakabayashi T, Kato H, Miyazaki T, Masuda N, et al. Paraesophageal hiatus hernia, which has progressed for 8 years: report of a case. Hepatogastroenterology 2002;49:992-4.

7. Carlson MA, Condon RE, Ludwig KA, Schulte WJ. Management of intrathoracic stomach with polypropylene mesh prosthesis reinforced transabdominal hiatus hernia repair. J Am Coll Surg 1998; 187:227-30

8. Stefanidis D, Hope WW, Kohn GP, Reardon PR, Richardson WS, Fanelli RD, et al. Guidelines for surgical treatment of gastroesophageal reflux disease. Surg Endosc 2010;24:2647-69.

9. Peters JH. SAGES guidelines for the management of hiatal hernia. Surg Endosc 2013;27:4407-8.

10. Furnee E, Hazebroek E. Mesh in laparoscopic large hiatal hernia repair: a systematic review of the literature. Surg Endosc 2013;27:3998-4008.

11. Chilintseva N, Brigand C, Meyer C, Rohr S. Laparoscopic prosthetic hiatal reinforcement for large hiatal hernia repair. J Visc Surg 2012;149:e215-20.

12. Zaninotto G, Portale G, Costantini M, Fiamingo P, Rampado S, Guirroli E, et al. Objective follow-up after laparoscopic repair of large type III hiatal hernia. Assessment of safety and durability. World J Surg 2007;31:2177-83.

13. Herbella FA, Patti MG, Del Grande JC. Hiatal mesh repair--current status. Surg Laparosc EndosC Percutan Tech 2011;21:61-6.

14. Watson DI, Thompson SK, Devitt PG, Smith L, Woods SD, Aly A, et al. Laparoscopic repair of very large hiatus hernia with sutures versus absorbable mesh versus nonabsorbable mesh: a randomized controlled trial. Ann Surg 2015;261:282-9.

15. Draaisma WA, Gooszen HG, Tournoij E, Broeders IA. Controversies in paraesophageal hernia repair: a review of literature. Surg Endosc 2005;19:1300-8.

16. Olivo SA, Macedo LG, Gadotti IC, Fuentes J, Stanton T, Magee DJ. Scales to assess the quality of randomized controlled trials: a systematic review. Phys Ther 2008;88:156-75.

17. Stang A. Critical evaluation of the Newcastle-Ottawa scale for the assessment of the quality of nonrandomized studies in meta-analyses. Eur J Epidemiol 2010;25:603-5.

18. CEBM. Oxford Centre for Evidence-based Medicine - Levels of Evidence. 2009.

19. Brandalise A, Aranha NC, Brandalise NA. The polypropylene mesh in the laparoscopic repair of large hiatal hernias: technical aspects. Arq Bras Cir Dig 2012;25:224-8.

20. Gouvas N, Tsiaoussis J, Athanasakis E, Zervakis N, Pechlivanides G, Xynos E. Simple suture or prosthesis hiatal closure in laparoscopic repair of paraesophageal hernia: a retrospective cohort study. Dis Esophagus 2011;24:69-78.

21. Granderath FA, Schweiger UM, Kamolz T, Asche KU, Pointner R. Laparoscopic Nissen fundoplication with prosthetic hiatal closure reduces postoperative intrathoracic wrap herniation: preliminary results of a prospective randomized functional and clinical study. Arch Surg 2005;140:40-8.

22. Granderath FA, Kamolz T, Schweiger UM, Pointner R. Impact of laparoscopic nissen fundoplication with prosthetic hiatal closure on esophageal body motility: Results of a prospective randomized trial. Arch Surg 2006;141:625-32.

23. Jacobs M, Gomez E, Plasencia G, Lopez-Penalver C, Lujan H, Velarde D, et al. Use of surgisis mesh in laparoscopic repair of hiatal hernias. Surg Laparosc Endosc Percutan Tech 2007;17:365-8. 
24. Lee E, Frisella MM, Matthews BD, Brunt LM. Evaluation of acellular human dermis reinforcement of the crural closure in patients with difficult hiatal hernias. Surg Endosc 2007;21:641-5.

25. Lubezky N, Sagie B, Keidar A, Szold A. Prosthetic mesh repair of large and recurrent diaphragmatic hernias. Surg Endosc 2007;21:737-41.

26. Morino M, Giaccone C, Pellegrino L, Rebecchi F. Laparoscopic management of giant hiatal hernia: factors influencing long-term outcome. Surg Endosc 2006;20:1011-6.

27. Oelschlager BK, Pellegrini CA, Hunter JG, Brunt ML, Soper NJ, Sheppard BC, et al. Biologic prosthesis to prevent recurrence after laparoscopic paraesophageal hernia repair: long-term follow-up from a multicenter, prospective, randomized trial. J Am Coll Surg 2011;213:461-8.

28. Parsak CK, Erel S, Seydaoglu G, Akcam T, Sakman G. Laparoscopic antireflux surgery with polyglactin (vicryl) mesh. Surg Laparosc Endosc Percutan Tech 2011;21:443-9.

29. Priego P, Ruiz-Tovar J, Perez de Oteyza J. Long-term results of giant hiatal hernia mesh repair and antireflux laparoscopic surgery for gastroesophageal reflux disease. J Laparoendosc Adv Surg Tech A 2012;22:139-41.

30. Schmidt E, Shaligram A, Reynoso JF, Kothari V, Oleynikov D. Hiatal hernia repair with biologic mesh reinforcement reduces recurrence rate in small hiatal hernias. Dis Esophagus 2014;27:13-7.

31. Simorov A, Ranade A, Jones R, Tadaki C, Shostrom V, Boilesen E, et al. Long-term patient outcomes after laparoscopic anti-reflux procedures. J Gastrointest Surg 2014;18:157-62; discussion 162-3.

32. Soricelli E, Basso N, Genco A, Cipriano M. Long-term results of hiatal hernia mesh repair and antireflux laparoscopic surgery. Surg Endosc 2009;23:2499-504.

33. Turkcapar A, Kepenekci I, Mahmoud H, Tuzuner A. Laparoscopic fundoplication with prosthetic hiatal closure. World J Surg 2007;31:2169-76.

34. Frantzides CT, Madan AK, Carlson MA, Stavropoulos GP. A prospective, randomized trial of laparoscopic polytetrafluoroethylene (PTFE) patch repair vs simple cruroplasty for large hiatal hernia. Arch Surg 2002;137:649-52.

35. Carlson MA, Richards CG, Frantzides CT. Laparoscopic prosthetic reinforcement of hiatal herniorrhaphy. Dig Surg 1999;16:407-10.

36. Oelschlager BK, Pellegrini CA, Hunter J, Soper N, Brunt M, Sheppard B, et al. Biologic prosthesis reduces recurrence after laparoscopic paraesophageal hernia repair: a multicenter, prospective, randomized trial. Ann Surg 2006;244:481-90.

37. Hunter JG, Swanstrom L, Waring JP. Dysphagia after laparoscopic antireflux surgery. The impact of operative technique. Ann Surg 1996;224:51-7.

38. Brown CN, Finch JG. Which mesh for hernia repair? Ann R Coll Surg Engl 2010;92:272-8.

39. Stadlhuber RJ, Sherif AE, Mittal SK, Fitzgibbons RJ, Jr., Michael Brunt L, Hunter JG, et al. Mesh complications after prosthetic reinforcement of hiatal closure: a 28-case series. Surg Endosc 2009;23:1219-26.

40. Shankaran V, Weber DJ, Reed RL, 2nd, Luchette FA. A review of available prosthetics for ventral hernia repair. Ann Surg 2011;253:16-26.

41. Ringley CD, Bochkarev V, Ahmed SI, Vitamvas ML, Oleynikov D. Laparoscopic hiatal hernia repair with human acellular dermal matrix patch: our initial experience. Am J Surg 2006;192:767-72. 


\section{Chapter 4}

Subjective outcome after laparoscopic hiatal hernia repair for intrathoracic stomach

P.S.S. Castelijns J.E.H. Ponten M.C.G. van de Poll

S.W. Nienhuijs

J.F. Smulders 


\section{Abstract}

\section{Purpose}

For decades, an intrathoracic stomach (ITS) has been a definite indication for surgery due to the perceived risk of an acute volvulus with perforation, gangrene, or haemorrhage. At the present time, elective laparoscopic repair is the first choice for treatment of ITS. There is a lack of evidence in the long-term quality of life after a hiatal hernia repair for an intrathoracic stomach.

\section{Methods}

A retrospective analysis was performed on all patients undergoing a hiatal hernia repair for an intrathoracic stomach between January 2004 and January 2015. Additionally, to a hiatal closure, the patients received an antireflux procedure. Outcome measures included patient characteristics, operative details, complications, and postoperative morbidity and mortality. All patients were sent a quality of life questionnaire to assess long-term quality of life and patient satisfaction. A higher quality of life score represents a better quality of life.

\section{Results}

Eighty-six patients underwent laparoscopic repair for ITS, from which, one patient died during surgery. Eighty-five patients were contacted and 81 completed the questionnaire, resulting in a response rate of $95.3 \%$. At a median follow-up of 2.7 years (range $0.1-9.6$ ) the mean quality of life score was 13.5 (standard deviation 2.8). The mean overall satisfaction was 8.4.

There were four recurrences: three in the first 12 days after surgery and one in 2.4 years.

\section{Conclusions}

Very good results in patient satisfaction and symptom reduction were achieved after a median follow-up of 2.7 years in this laparoscopic repair of the intrathoracic stomach single centre experience study. The symptomatic recurrence rate was very low. 


\section{Introduction}

For decades, an intrathoracic stomach (ITS) has been a definite indication for surgery due to the perceived risk of an acute volvulus with perforation, gangrene, or hemorrhage. ${ }^{1,2}$ Due to the increasing incidence of gastro oesophageal reflux disease (GERD), more people undergo diagnostic workups for reflux symptoms. One of the causes for the increasing incidence of GERD is the exponentially growing problem of obesity. In some of these patients the GERD symptoms are caused by the large hiatal hernia rather than by obesity itself. An intrathoracic stomach may also be found as an accidental finding. These developments resulted in an increased number of patients with an intrathoracic stomach. ${ }^{3}$

The increasing availability of minimal invasive surgery has lowered the threshold to perform surgery on these patients. However, whether these patients with minimal symptoms actually benefit from such surgical treatment of intrathoracic stomach is unclear.

The first laparoscopic para-oesophageal hernia (PEH) repair was reported in 1992 by Cuschieri et al.. ${ }^{4}$ Over the succeeding years, antireflux surgery with repair of the hiatal hernia has become the standard treatment for all types of hiatal hernias. ${ }^{5}$ The symptomatic outcome of antireflux surgery for GERD is well documented in a large series of cases and clinical trials. ${ }^{6}$ Nevertheless, only data regarding the recurrence rates for an intrathoracic stomach repair are available. There is a lack of substantial data describing the quality of life after elective surgery for intrathoracic stomach. The largest current series describes a cohort of 73 patients with a reported objective followup of 5 years. ${ }^{7}$ However, only 33 patients completed the 3 -year follow-up and only 12 patients completed the entire 5-year follow-up.

In this article, we reported on a large series of patients with intrathoracic stomachs who underwent an elective minimal invasive surgery. We presented long-term followup data with a special emphasis on symptomatic outcome and patient satisfaction. These factors were assessed by a standardized questionnaire.

\section{Materials and methods}

We included patients who underwent surgery for a primary intrathoracic stomach, defined as $>50 \%$ of the stomach into the thorax on barium swallow investigation or on CT-scan. ${ }^{5}$ All the data was retrieved from the hospital information system at our institution for patients who were operated on between January 1, 2004 and January 1, 2015. Parameters that were extracted included patient characteristics, preoperative symptoms, preoperative medication usage, and diagnostic workups. 
Patients received a standardized questionnaire by mail. This questionnaire was a modified version of one that was used by Mittal et al. ${ }^{7}$ (Appendix 4.1). Items on the questionnaire included heartburn, regurgitation, dysphagia, retrosternal pain, gas bloating, and the use of antacids. In addition to these questions, patients were requested to score the result of the procedure on a visual analogue scale (VAS). Patients who did not respond were contacted by phone up to three times to maximize the response rate.

\section{Surgical technique}

All procedures were performed laparoscopically. After repositioning the stomach and dissecting the hernia sac, the hiatus was closed using non-absorbable woven sutures (Ti-cron $^{\mathrm{TM}}$, Covidien, New Haven, CT, USA). In several cases the cruroplasty was reinforced using a prosthetic mesh (Parietex ${ }^{\mathrm{TM}}$, Covidien, New Haven, CT, USA) at the discretion of the operating surgeon. This was then followed by a 360-degree floppy Nissen fundoplication. We did not perform gastropexy or a gastrostomy. The most distal suture fixates the wrap to the wall of the oesophagus to prevent telescoping.

\section{Immediate postoperative period}

Patients were put on a liquid diet for 2 weeks. Operation time, complications during surgery, length of stay (LOS), in-hospital postoperative complications and re-admissions were retrieved from the hospital information system.

\section{Statistics}

A retrospective database was managed in Access 2010. (Microsoft, USA) All data was analysed using SPSS for MacOs version 21.0(SPSS Inc., Chicago, IL, USA).

\section{Results}

\section{Patient characteristics}

A total number of 86 patients were operated on. One patient died during the procedure. Out of the 85 patients that were contacted (20 were male), 81 (18 were male) responded, concluding a $95.3 \%$ response rate. Data are reported on respondents only.

The median age was 63 years (42-80). The median BMI was 27 (20-42). Twenty patients (24.7\%) received a mesh-based repair. The two most dominant symptoms prior to surgery were retrosternal pain and dysphagia. Baseline characteristics are summarized in Table 4.1. 
Table 4.1 Baseline characteristics

\begin{tabular}{|c|c|c|c|c|}
\hline & Overall $(n=81)$ & Mesh $(n=20)$ & Suture $(n=61)$ & $P$ value \\
\hline Male/Female ratio & $18 / 63$ & $5 / 15$ & $13 / 48$ & $0.761^{a}$ \\
\hline median age & $63(42-80)$ & $65(43-80)$ & $62.5(42-77)$ & $0.273^{b}$ \\
\hline median BMI & $27(20-42)$ & $28.5(22-42)$ & $27.0(20-41)$ & $0.343^{b}$ \\
\hline $\begin{array}{l}\text { Median ASA classification } \\
\text { (range) }\end{array}$ & $2(1-3)$ & $2(2-3)$ & $2(1-3)$ & $0.033^{\mathrm{a}}$ \\
\hline Diabetes & $5 / 81(6.2 \%)$ & $1 / 20(5 \%)$ & $4 / 61(6.6 \%)$ & $1.000^{\mathrm{a}}$ \\
\hline Smoking & $7 / 81(8.6 \%)$ & $2 / 20(10 \%)$ & $5 / 61(8.2 \%)$ & $1.000^{\mathrm{a}}$ \\
\hline Asthma/COPD & $16 / 81(19.8 \%)$ & $4 / 20(20 \%)$ & $12 / 61(19.7 \%)$ & $1.000^{\mathrm{a}}$ \\
\hline Heartburn & $24 / 81(29.6 \%)$ & $6 / 20(30 \%)$ & $18 / 61(29.5 \%)$ & $0.967^{c}$ \\
\hline Regurgitation & $12 / 81(14.8 \%)$ & $3 / 20(15 \%)$ & $9 / 61(14.8 \%)$ & $1.000^{\mathrm{a}}$ \\
\hline Dysphagia & $29 / 81(35.8 \%)$ & $7 / 20(35 \%)$ & $22 / 61(36.1 \%)$ & $0.931^{\mathrm{c}}$ \\
\hline Retrosternal pain & $29 / 81(35.8 \%)$ & $10 / 20(50 \%)$ & $19 / 61(31.1 \%)$ & $0.127^{c}$ \\
\hline Epigastric pain & $23 / 81(28.4 \%)$ & $4 / 20(20 \%)$ & $19 / 61(31.1 \%)$ & $0.337^{\mathrm{a}}$ \\
\hline Nausea/Vomiting & $24 / 81(29.6 \%)$ & $6 / 20(30 \%)$ & $18 / 61(29.5 \%)$ & $0.967^{c}$ \\
\hline PPI Usage & $58 / 81(71.6 \%)$ & $16 / 20(80 \%)$ & $42 / 61$ (68.9\%) & $0.337^{c}$ \\
\hline
\end{tabular}

\section{Quality of life}

After a median follow-up of 2.7 years ranging from 48 days to 9.6 years, overall satisfaction assessed by the VAS was 8.4 (Figure 4.1). Most patients experienced minor to no symptoms, providing a mean quality of life (QoL) score of 13.5 (SD 2.8). A score of 16 indicates maximum quality of life and no complaints (Figure 4.2). The mean QoL assessment score was 13.5 for mesh reinforced cruroplasty and 13.7 for non-mesh reinforced cruroplasty. $(P=0.875)$ The satisfaction on the VAS was 8.2 and 8.5 respectively. No statistically significant difference in QoL was found between both groups. Since one patient died during surgery, follow-up data of the remaining 80 patients are presented. All details regarding the quality of life are demonstrated in Table 4.2. In the analysis of the short-term results there were no statistically significant differences between both groups (Table 4.3). We did not find a difference in quality of life between the patients with short-term follow-up compared to the long-term results (Table 4.4). Since there were no patients with a mesh reinforcement in the long-term group, we compared this group with the patients that did not receive a mesh reinforcement as well in the short-term group. This in order to perform a more adequate analysis. 


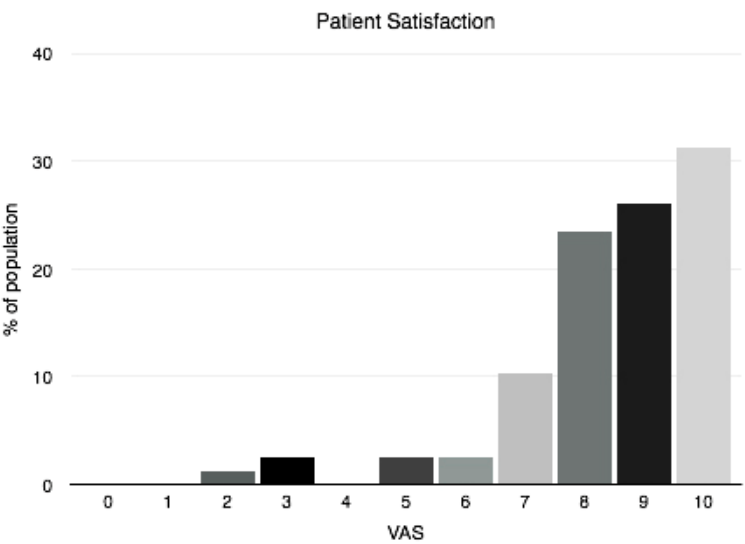

Figure 4.1 Patient satisfaction score

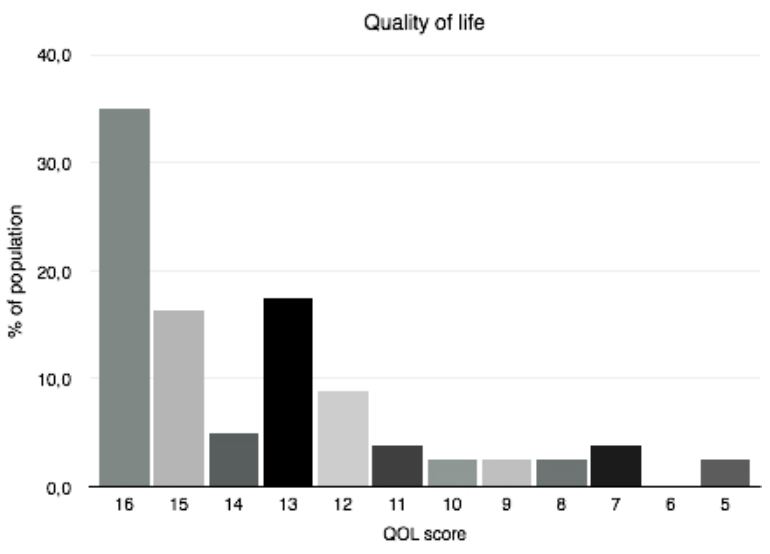

Figure 4.2 Quality of life score

Table 4.2 Symptoms and QoL at follow-up - Mesh vs non-mesh

\begin{tabular}{lcccc} 
Symptom & $\begin{array}{c}\text { Mean symptom score } \\
\mathrm{n}=80(\mathrm{SD})\end{array}$ & $\begin{array}{c}\text { Mesh } \\
\mathrm{n}=19 \text { Mean (SD) }\end{array}$ & $\begin{array}{c}\text { Suture } \\
\mathrm{n}=61 \text { Mean (SD) }\end{array}$ & $P$ value \\
\hline Dysphagia & $2.7(0.7)$ & $2.6(0.8)$ & $2.7(0.7)$ & $0.814^{\mathrm{a}}$ \\
Heartburn & $2.5(0.9)$ & $2.5(1.0)$ & $2.5(0.9)$ & $0.599^{\mathrm{a}}$ \\
Regurgitation & $2.6(0.8)$ & $2.7(0.8)$ & $2.5(0.8)$ & $0.247^{\mathrm{a}}$ \\
Retrosternal pain & $2,6(0.6)$ & $2.5(0.6)$ & $2.7(0.6)$ & $0.466^{\mathrm{a}}$ \\
Nausea/Vomiting & $2.5(0.8)$ & $2.6(0.7)$ & $2.5(0.8)$ & $0.911^{\mathrm{a}}$ \\
Gas Bloating & $26 / 80(32.5 \%)$ & $8 / 19(42.1 \%)$ & $18 / 61(29.5 \%)$ & $0.306^{\mathrm{c}}$ \\
Overall satisfaction & $8.4(1.7)$ & $8.2(1.6)$ & $8.5(1.7)$ & $0.253^{\mathrm{b}}$ \\
Total QOL score & $13.5(2.8)$ & $13.5(3.0)$ & $13.7(2.8)$ & $0.875^{\mathrm{b}}$ \\
PPI Usage & $33 / 79(41.8 \%)$ & $8 / 19(42.1 \%)$ & $25 / 60(41.7 \%)$ & $0.973^{\mathrm{c}}$
\end{tabular}

${ }^{a}$ Fisher exact, ${ }^{b}$ Mann-Whitney, ${ }^{c}$ Chi-square. QoL: Quality of Life, SD: Standard Deviation, PPI: Proton Pump Inhibitor 
Table 4.3 Symptoms and QoL at follow-up $<5$ years

\begin{tabular}{lcccc} 
Symptom & $\begin{array}{c}\text { Mean symptom score } \\
\mathrm{n}=66(\mathrm{SD})\end{array}$ & $\begin{array}{c}\text { Mesh } \\
\mathrm{n}=19 \text { Mean (SD) }\end{array}$ & $\begin{array}{c}\text { Suture } \\
\mathrm{n}=47 \text { Mean (SD) }\end{array}$ & $P$ value \\
\hline Dysphagia & $2.6(0.7)$ & $2.6(0.8)$ & $2.6(0.7)$ & $0.902^{\mathrm{a}}$ \\
Heartburn & $2.5(0.9)$ & $2.5(1.0)$ & $2.5(0.8)$ & $0.504^{\mathrm{a}}$ \\
Regurgitation & $2.6(0.8)$ & $2.7(0.8)$ & $2.6(0.7)$ & $0.550^{\mathrm{a}}$ \\
Retrosternal pain & $2.6(0.6)$ & $2.5(0.6)$ & $2.7(0.6)$ & $0.386^{\mathrm{a}}$ \\
Nausea/Vomiting & $2.5(0.8)$ & $2.6(0.7)$ & $2.5(0.8)$ & $1.000^{\mathrm{a}}$ \\
Gas Bloating & $22 / 66(33.3 \%)$ & $8 / 19(42.1 \%)$ & $14 / 47(29.8 \%)$ & $0.336^{\mathrm{b}}$ \\
Overall satisfaction & $8.4(1.8)$ & $8.2(1.6)$ & $8.5(1.9)$ & $0.539^{\mathrm{d}}$ \\
Total QOL score & $13.6(2.9)$ & $13.5(3.0)$ & $13.6(2.9)$ & $0.660^{\mathrm{c}}$ \\
(mean/range) & & & & \\
PPI Usage & $24 / 65(36.9 \%)$ & $8 / 19(42.1 \%)$ & $16 / 46(34.8 \%)$ & $0.578^{\mathrm{b}}$
\end{tabular}

${ }^{a}$ Fisher exact, ${ }^{b}$ Chi square, c Mann-Whitney U, ${ }^{d}$ Independent Sample T-test. QoL: Quality of Life, SD:

Standard Deviation, PPI: Proton Pump Inhibitor

Table 4.4 Symptoms and QoL $<5$ years vs $>5$ years for suture repair only

$\begin{array}{lccc}\text { Symptom } & \begin{array}{c}>\text { years } \\ \mathrm{n}=14 \text { Mean (SD) }\end{array} & \begin{array}{c}<5 \text { years } \\ \mathrm{n}=47 \text { Mean (SD) }\end{array} & P \text { value } \\ \text { Suture/mesh } & 14: 0 & 47: 0 & <0.05^{\mathrm{a}} \\ \text { Follow-up } & 7.0(1.7) & 2.6(1.4) & 1.000^{\mathrm{b}} \\ \text { Dysphagia } & 2.8(0.6) & 2.6(0.7) & 0.761^{\mathrm{b}} \\ \text { Heartburn } & 2.4(1.0) & 2.5(0.8) & 0.275^{\mathrm{b}} \\ \text { Regurgitation } & 2.3(0.8) & 2.6(0.7) & 0.756^{\mathrm{b}} \\ \text { Retrosternal pain } & 2.7(0.5) & 2.7(0.6) & 0.141^{\mathrm{b}} \\ \text { Nausea/Vomiting } & 2.4(0.6) & 2.5(0.8) & 1.000^{\mathrm{b}} \\ \text { Gas Bloating } & 4 / 14(28.6 \%) & 14 / 47(29.8 \%) & 0.827^{\mathrm{c}} \\ \text { Overall satisfaction (median/range) } & 8.7(1.1) & 8.5(1.9) & 0.317^{\mathrm{c}} \\ \text { Total QOL score (mean/range) } & 13.3(2.4) & 13.6(2.9) & 0.050^{\mathrm{d}} \\ \text { PPI Usage } & 9 / 14(64.3 \%) & 16 / 46(34.8 \%) & \end{array}$

${ }^{a}$ Independent Samples T-test, ${ }^{b}$ Fisher's exact, ${ }^{c}$ Mann-Whitney U, ${ }^{d}$ Chi-squared. QoL: Quality of Life, SD: Standard Deviation, PPI: Proton Pump Inhibitor

\section{Operative outcome}

All procedures were performed in a non-emergency setting by the senior author (JS) or under his supervision. The median operative time was 89 min (range 53-212 min). Twenty patients received a mesh-reinforced cruroplasty, whereas 61 patients received a pure suture repair of the hiatal hernia. The decision to use a mesh was made during the surgery at the discretion of the operating surgeon. The reason for using a mesh reinforcement was weakness of the right crus that was noticed in six patients and a very large defect $(>8 \mathrm{~cm})$ in 14 patients. Nine minor complications and two major complications were reported, resulting in a complication rate of $12.3 \%$. Minor complications included a serosa injury and opening of the pleura, while major complications included a laceration of the oesophagus and a perforation of the aorta. 
The laceration of the oesophagus was treated by an endoluminal stent. The perforation of the aorta occurred during the mobilization of the oesophagus, where there were adhesions between the aorta and the oesophagus. A conversion to open surgery was performed, however, the damage to the aorta was too extensive and the patient died during surgery. Autopsy revealed an aneurysm, which was unknown prior to surgery. Operative details are summarized in Table 4.5.

Table 4.5 Operative details $(n=82)$

\begin{tabular}{|c|c|c|}
\hline & & No. of patients \\
\hline \multicolumn{3}{|c|}{ Surgery type } \\
\hline & Open & 0 \\
\hline & Laparoscopic & 82 \\
\hline & Conversion & 1 \\
\hline & Elective & 82 \\
\hline & Emergency & 0 \\
\hline \multicolumn{3}{|c|}{ Antireflux surgery } \\
\hline & Nissen & 81 \\
\hline \multicolumn{3}{|c|}{ Hiatal closure } \\
\hline & Suture & 61 \\
\hline & Mesh based & 20 \\
\hline \multicolumn{3}{|c|}{ Number of Sutures (median/range) } \\
\hline & Suture & $3(2-6)$ \\
\hline & Mesh reinforcement & $4(0-6)$ \\
\hline \multicolumn{3}{|c|}{ Median operative time(range) } \\
\hline & Suture & $86.5(53-212)$ \\
\hline & Mesh & $95.0(68-126)$ \\
\hline \multicolumn{3}{|c|}{ Complications } \\
\hline & Opening pleura & 6 \\
\hline & Serosa damage & 2 \\
\hline & Bleeding & 2 \\
\hline & Laceration of the oesophagus & 1 \\
\hline Mortality & & 1 \\
\hline
\end{tabular}

\section{Postoperative period}

Postoperative complications were reported in $12.5 \%$ of the patients. Most reported postoperative complaints were nausea and chest pain, but these were not classified as complications. Five pneumothoraces occurred of which two were treated by chest tube drainage and three resolved with supportive therapy. The one patient that suffered from an intraoperative oesophageal perforation developed a sepsis due to persistent leakage and subsequently underwent an oesophageal resection with a gastro-thoracic reconstruction. Three recurrences were seen within 12 days and all were reoperated on. Two of them within the same admission. The median hospital stay was 2 days (range 1-48 days). 


\section{Mortality}

One patient died during the procedure due to perforation of the aorta. Emergency laparotomy was performed, but the patient could not be saved.

\section{Reoperation}

Apart from the three early recurrences mentioned above, five other patients underwent a reoperation during their follow-up. The total percentage of reoperation was therefore $9.9 \%$. Two patients were operated on because of persistent dysphagia. Two other patients were operated on for GERD due to failure of the fundoplication, while the last one underwent a reoperation for a late recurrent hiatal hernia (868 days after the initial procedure). No symptomatic recurrences were seen after the meshreinforced cruroplasty. All causes for reoperation along with their corresponding follow-ups are presented in Table 4.6. Median quality of life after reoperation was 12 compared to a median of 15 in patients that did not undergo reoperation ( $P=0.098)$.

Table 4.6 Reoperations

$\begin{array}{lc}\text { Causes of re-operation } & \text { Follow-up (days) } \\ \text { Failure wrap, crus intact } & 252 \\ \text { Torsion wrap, crus intact } & 1164 \\ \text { Early recurrence, due to vomit } & 2 \\ \text { Wrap in thorax } & 5 \\ \text { Rupture crus suture } & 868 \\ \text { Persistent dysphagia, redo Toupet, remove one suture from crus } & 439 \\ \text { Persistent dysphagia, redo Toupet } & 238 \\ \text { Wrap in thorax, failure crus sutures } & 12\end{array}$

\section{Discussion}

In this paper, we report one of the largest single centre experiences on laparoscopic repair of an intrathoracic stomach accompanied by a great response rate. We found very good results in patient satisfaction and quality of life after a median follow-up of 2.7 years.

Nissen fundoplication in patients with GERD is proven effective and leads to a great symptomatic outcome. ${ }^{8}$ The quality of life in patients with GERD is measured by the HRQL-GERD questionnaire, which is a validated list of questions regarding the most common symptoms. However, since patients with ITS reported different symptoms at baseline, this questionnaire is not suitable in our population. There is still no validated questionnaire available that represents the quality of life in patients with an intrathoracic stomach. Therefore, we used a modified standardized questionnaire that 
was previously published by Mittal et al. ${ }^{7}$ (Appendix 4.1). In this questionnaire, the most common symptoms in patients with an intrathoracic stomach were scored. The quality of life we found in our large cohort of patients was in line with the great results described previously. ${ }^{7}$

Due to the retrospective aspect of this study, we did not have the preoperative quality of life assessment. For this reason, we were unable to compare our postoperative results with the preoperative data that we retrieved from the patient information system. This is one of the most limiting aspects of this study. Nonetheless, if we compared our results with the data reported by Mittal et al., who used the same questionnaire, we would see comparable results. They reported a mean satisfaction score of 9.0 at a 3-year follow-up compared to a mean satisfaction of 8.4 for our cohort. The individual symptom scores were also comparable at the 3-year follow-up. ${ }^{7}$

Three patients had an early recurrence in our study. This is probably due to persistent postoperative vomiting which increases the intra-abdominal pressure, leading to reherniation of the wrap into the thorax. Iqbal et al has described a relation between failure of the procedure and postoperative nausea and vomiting (PONV) prevention after a Nissen fundoplication in 2006. ${ }^{9}$ They concluded that it is important to prescribe antiemetics after the procedure. Antoniou et al. described that postoperative vomiting as a result of the procedure only occurred on the first postoperative day. ${ }^{10}$ However, we believe that antiemetics might need to be prescribed for a longer period of time, since we have seen early recurrences due to vomiting up to 12 days.

We noticed only one late recurrence after a follow-up of 2.4 years. The total recurrence rate is therefore $4.9 \%$ and is comparable with the reported median recurrence rate of $7 \%$ (range $0-42 \%$ ) reported by Draaisma et al. in a large review describing 32 studies. $^{11}$ Not all of our patients received a standard objective follow-up by means of radiology investigations. We therefore may have underestimated the anatomical recurrence rate, especially since several studies demonstrated a very poor relationship between symptoms and the presence of an anatomical recurrence. Most recurrences appeared to be asymptomatic. ${ }^{7,12}$

Other causes for re-operation were failure of the fundoplication and persistent dysphagia. Dysphagia is a common side effect of the procedure and an incidence of $13 \%$ is reported in the literature. ${ }^{13}$ This is in contrast with our findings in the quality of life questionnaires. Nineteen (23.8\%) patients in our study reported some kind of dysphagia after a median follow-up of 3 years. This difference can be explained by the fact that we operated on symptomatic patients with an ITS, whereas most studies reported results of patients with GERD symptoms. Another explanation for the high rate of persistent dysphagia might be due to a too tight wrap. Despite the high rate of dysphagia, the reported quality of life in this study was excellent and patients rated the overall procedure with a mean satisfaction of 8.4 on the VAS. This may be due to a reduction in severity of dysphagia rather than a complete relief of symptoms. It should be noted that this study described patients with an intrathoracic stomach and not with 
GERD. Therefore, these results may not be applicable to the population that receives a Nissen fundoplication for reflux disease, since this group of patients had other symptoms at baseline.

We found two major operative complications, which were a perforation of the oesophagus during manipulation and a bleeding of the aorta leading to the death of the patient. To repair the perforation of the oesophagus, an endoluminal stent was placed intraoperatively and the defect was closed with sutures. The leakage persisted due to partial necrosis of the oesophageal wall. Therefore, a re-operation was necessary and eventually the patients had to undergo an oesophageal resection and gastric-tube reconstruction. An oesophageal perforation or laceration is a feared yet known complication and has been reported previously in the literature. In all cases this complication did not result in death of the patient. ${ }^{14,15}$

The second major complication was a perforation of the aorta. Aortic injuries during laparoscopic fundoplication are very rare and have only been detected twice in the past according to the literature. ${ }^{16,17}$

Another common complication of the Nissen fundoplication is a pneumothorax. ${ }^{18}$ The reported incidence of this complication in the literature was $4 \%$ in all Nissen fundoplications. However, the true percentage may be even higher since patients did not receive a routine $\mathrm{X}$-thorax despite the fact that during surgery the pleura is often opened. Five of our patients (6.25\%) developed a symptomatic pneumothorax, which received a thorax drainage in two cases. The reason for this increased incidence of pneumothoraces is that we only operated on patients with an ITS, whereas most literature describes only patients with GERD who are less prone to develop a pneumothorax.

In 20 of our cases a mesh reinforced the cruroplasty. The choice for the use of a mesh application was made by individual preference of the operating surgeon. Although the small sample size and unequal groups prohibit proper statistical comparison between patients that were treated with or without a mesh. Nevertheless, it is striking to see that no recurrences occurred in patients that received a mesh-reinforced cruroplasty. In addition, the complication rate and symptomatic outcome were comparable. Mesh related complications reported in the literature included erosion of the oesophagus and migration or infection of the mesh. ${ }^{19}$ We did not see any of these complications in our study. This can be explained by the fact that we reinforced the cruroplasty with a mesh only in the past few years. This is due to our increasing experiences with intrathoracic stomach repair and the presence of early recurrences in our cohort. As a result, we do not have any long-term follow-up data describing the mesh-based hiatal hernia repairs. A large meta-analysis published by Müller-Stich et al. in 2015 described the effect of mesh augmentation in hiatal hernia repairs in patients with a para-oesophageal hernia. They concluded that the mesh reinforcement does reduce the recurrence rate without increasing the procedure related complications and mortality, at least for the mid-term follow-up. The reported mesh related complication rate in this meta-analysis was 
$1.7 \% .{ }^{20}$ We used a synthetic mesh, but biological meshes are also available. However, the type of mesh that is more suitable for hiatal hernia repair has not yet been researched and therefore further randomized studies are needed.

\section{Conclusion}

This large single centre experience on laparoscopic repair of an intrathoracic stomach resulted in a high response rate. Although we do not have a preoperative comparison, fairly good results in patient satisfaction and symptom reduction were achieved after a median follow-up of 2.7 years. The symptomatic recurrence rate was very low, especially in the mesh-based cruroplasty. 


\section{References}

1. Leeder PC, Smith G, Dehn TC. Laparoscopic management of large paraesophageal hiatal hernia. Surg Endosc. 2003;17(9):1372-5.

2. Polomsky M, Jones CE, Sepesi B, O'Connor M, Matousek A, Hu R, Raymond DP, Litle VR, Watson TJ, Peters $\mathrm{JH}$. Should elective repair of intrathoracic stomach be encouraged? Journal of gastrointestinal surgery : official journal of the Society for Surgery of the Alimentary Tract. 2010;14(2):203-10.

3. Boeckxstaens G, El-Serag HB, Smout AJ, Kahrilas PJ. Symptomatic reflux disease: the present, the past and the future. Gut. 2014;63(7):1185-93.

4. Cuschieri A, Shimi S, Nathanson LK. Laparoscopic reduction, crural repair, and fundoplication of large hiatal hernia. Am J Surg. 1992;163(4):425-30.

5. Peters JH. SAGES guidelines for the management of hiatal hernia. Surg Endosc. 2013;27(12):4407-8.

6. Engstrom C, Cai W, Irvine T, Devitt PG, Thompson SK, Game PA, Bessell JR, Jamieson GG, Watson DI. Twenty years of experience with laparoscopic antireflux surgery. Br J Surg. 2012;99(10):1415-21.

7. Mittal SK, Bikhchandani J, Gurney O, Yano F, Lee T. Outcomes after repair of the intrathoracic stomach: objective follow-up of up to 5 years. Surg Endosc. 2011;25(2):556-66.

8. Kappaz GT, Sallum RA, Szachnowicz S, Rocha JR, Cecconello I. Improvement in quality-of-life after laparoscopic Nissen fundoplication. Arquivos de gastroenterologia 2014;51(3):212-6.

9. Iqbal A, Kakarlapudi GV, Awad ZT, Haynatzki G, Turaga KK, Karu A, Fritz K, Haider M, Mittal SK, Filipi CJ. Assessment of diaphragmatic stressors as risk factors for symptomatic failure of laparoscopic nissen fundoplication. J Gastrointest Surg. 2006;10(1):12-21.

10. Antoniou SA, Delivorias P, Antoniou GA, Natsiopoulos I, Kalambakas A, Dalenback J, Makridis C. Symptom-focused results after laparoscopic fundoplication for refractory gastroesophageal reflux disease--a prospective study. Langenbecks Arch Surg. 2008;393(6):979-84.

11. Draaisma WA, Gooszen HG, Tournoij E, Broeders IA. Controversies in paraesophageal hernia repair: a review of literature. Surg Endosc. 2005;19(10):1300-8.

12. Kang $\mathrm{T}$, Urrego $\mathrm{H}$, Gridley A, Richardson WS. Pledgeted repair of giant hiatal hernia provides excellent long-term results. J Laparoendosc Adv Surg Tech A. 2014;24(10):684-7.

13. Targarona EM, Grisales S, Uyanik O, Balague C, Pernas JC, Trias M. Long-term outcome and quality of life after laparoscopic treatment of large paraesophageal hernia. World J Surg. 2013;37(8):1878-82.

14. Lubezky N, Sagie B, Keidar A, Szold A. Prosthetic mesh repair of large and recurrent diaphragmatic hernias. Surg Endosc. 2007;21(5):737-41.

15. Morino M, Giaccone C, Pellegrino L, Rebecchi F. Laparoscopic management of giant hiatal hernia: factors influencing long-term outcome. Surg Endosc. 2006;20(7):1011-6.

16. Leggett $\mathrm{PL}$, Bissell $\mathrm{CD}$, Churchman-Winn R. Aortic injury during laparoscopic fundoplication: an underreported complication. Surg Endosc. 2002;16(2):362.

17. Yano F, Omura N, Tsuboi K, Kashiwagi H, Yanaga K. Thoracic aortic injury during laparoscopic fundoplication for reflux esophagitis. Int J Surg. 2008;6(6):490-2.

18. Thomas $\mathrm{H}$, Agrawal S. Systematic review of day-case laparoscopic fundoplication. J Laparoendosc Adv Surg Tech A. 2011;21(9):781-8.

19. Stadlhuber RJ, Sherif AE, Mittal SK, Fitzgibbons RJ, Jr., Michael Brunt L, Hunter JG, Demeester TR, Swanstrom LL, Daniel Smith C, Filipi CJ. Mesh complications after prosthetic reinforcement of hiatal closure: a 28-case series. Surg Endosc. 2009;23(6):1219-26.

20. Muller-Stich BP, Kenngott HG, Gondan M, Stock C, Linke GR, Fritz F, Nickel F, Diener MK, Gutt CN, Wente M, Buchler MW, Fischer L. Use of Mesh in Laparoscopic Paraesophageal Hernia Repair: A MetaAnalysis and Risk-Benefit Analysis. PLoS One 2015;10(10):e0139547. 


\section{Appendix 4.1}

\section{Quality of life questionnaire}

Name:

Date:

Date of birth:

Gender: M / F

Are you on anti-acid medication?

yes, what type of medication?

$\square$ No, for how long?

Months/days

How severe is your heartburn?

Times a day / week / month

$\square 0$ - none

$\square 1$ - Minimal - episodic, no treatment required

$\square 2$ - Moderate - controlled with medication

$\square 3$ - Severe - Interferes with daily activity or not controlled with medication

How severe is your dysphagia?

$\square 0$ - No dysphagia

$\square 1$ - Once a week or less

$\square 2$ - More than once a week, requiring dietary adjustment

$\square 3$ - Severe, preventing ingestion of solid food

How severe is your regurgitation of food?

Times a day / week / month

0 - No regurgitation

$\square 1$ - Mild - after straining or a large meal

$\square 2$ - Moderate - position dependent

$\square 3$ - Severe - constant regurgitation with or without aspiration

How severe is your chest pain?

Times a day / week / month

0 - None

$\square 1$ - Minimal - Episodic

$\square 2$ - Moderate - Reason to contact a doctor

$\square 3$ - Severe - interference with daily activity 
How severe is your nausea/vomiting?

Times a day / week / month

$\square 0$ - None

$\square 1$ - Minimal - episodic

$\square 2$ - Moderate - Reason to contact a doctor

$\square 3$ - Severe - interference with daily activity

Do you experience abdominal bloating?
$\square 1$ - Yes
$\square 0$ - No

Do you use other medications?

$\square$ No

$\square$ Yes, which?

Space for medications:

Do you have other symptoms?

How satisfied are you with your surgical outcome? (Scale 1-10, 1-worse/10-best)

Would you recommend this procedure to a friend?

$\square$ yes

$\square$ No 



\title{
Chapter
}

\section{Quality of life after Nissen fundoplication in patients with GERD - Comparison between long-and \\ short-term follow-up}

\author{
P.S.S. Castelijns \\ J.E.H. Ponten \\ M.C.G. van de Poll \\ N.D. Bouvy \\ J.F. Smulders
}




\section{Abstract}

\section{Introduction}

Nissen fundoplication is the golden standard for surgical treatment of gastroesophageal reflux disease (GERD). Numerous studies report excellent short-term results. However, data regarding long-term quality of life are lacking. The aim of this study is to investigate the long-term quality of life after Nissen fundoplication in patients with GERD and to compare this with the short-term results.

\section{Patients and methods}

We retrospectively analysed all patients who underwent laparoscopic Nissen fundoplication for GERD between January 2004 and January 2016. All patients received a validated GERD-HRQL questionnaire by mail to assess postoperative quality of life. Maximum quality of life is represented by a score of 75 . Secondary outcome measures were complications and recurrence rate.

\section{Results}

One hundred and seventy-five of the 227 operated patients returned the questionnaire $(77.1 \%)$. The median follow-up was 3.7 (0.1-10.3) years. Mean age was 51.6 (range 15-85) and 72 patients were male. We report an excellent quality of life with a median total score of 70 (range 2-75). Reoperation rate was $13.6 \%$ (23/169), in 12 patients the reoperation was due to recurrent reflux and in 11 patients due to persistent dysphagia. $91.3 \%$ of the re-operations were performed within the first 5 years after surgery. Mortality rate was zero.

\section{Conclusion}

We report a large series of single centre, single surgeon laparoscopic Nissen fundoplication. Despite the reoperation rate of $13.6 \%$ we found excellent long-term symptomatic outcome. There was no difference between short-term and long-term results. 


\section{Introduction}

Laparoscopic antireflux surgery (LARS) is considered the golden standard in the surgical treatment of gastroesophageal reflux disease (GERD). ${ }^{1,2}$ Since Cuschieri et al. performed the first laparoscopic Nissen fundoplication in 1992, this procedure gained increasing popularity over time. ${ }^{3}$ Many studies report good results after Nissen fundoplication with a successful symptomatic outcome in $80 \%-95 \%$ of the patients at a long-term follow-up of up of 5 years. ${ }^{4-7}$ Despite the good symptomatic results there are still many patients that report recurrent reflux or new symptoms that were not present before surgery. This may negatively influence the quality of life.

The GERD-Health Related Quality of Life (GERD-HRQL) is a validated instrument to measure the quality of life after LARS for patients with GERD. ${ }^{8,9}$ The questionnaire assesses most common symptoms and their impact on daily life. Many studies report symptomatic outcome after Nissen fundoplication. However, very few studies report on the long-term quality of life. Therefore, the aim of this study is to report on the quality of life after Nissen fundoplication at a long-term follow-up of up to 10.3 years. We compared the long-term results with the short-term outcome. This is a single-centre, single surgeon study.

\section{Patients and methods}

For this study, we included patients who underwent antireflux surgery for GERD. Initially patients were diagnosed by 24-h PH-metry of by endoscopy with proven oesophagitis. Since the introduction of the SAGES guideline for GERD in 2010, patients were diagnosed according this guideline ${ }^{2}$. All data were retrieved from the hospital information system for patients who were operated at our institution between January $1^{\text {st }} 2004$ and January $1^{\text {st }}$ 2016. Parameters that were extracted included patient characteristics, pre-operative symptoms, medication usage, diagnostic workup and operative outcome.

All patients were sent the GERD-HRQL questionnaire by mail. This is a validated and standardized questionnaire that is proven effective in reporting quality of life for patients with GERD. ${ }^{8,9}$ A maximum score of 75 represents excellent overall quality of life and a score of 0 reports a very poor quality of life. To make the results easier to compare, we classified this wide score into three groups. A score of 0-25 is classified as a poor outcome, $25-50$ as a medium outcome and a quality of life score of $\geq 50$ was classified as a good outcome. Specific items on heartburn and regurgitation both result in a score with a maximum of 30 , which represents no burden at all. A score of 0 is associated with a high rate of complaints of the specific symptom. A heartburn or regurgitation score $>18$ represents elimination of the particular symptom. The 
questionnaire is attached as Appendix 5.1. Non-responders were contacted by phone up to 3 times to maximize the response rate. Only follow-up data regarding respondents are presented.

\section{Surgical technique}

All procedures were performed laparoscopically. In all patients, the hiatus was dissected completely and a posterior cruroplasty was performed using non-absorbable

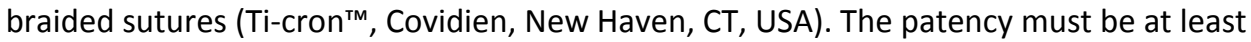
$10 \mathrm{~mm}$ besides the oesophagus. If a large hiatal hernia was present, the cruroplasty was reinforced using a non-absorbable prosthetic mesh (Parietex ${ }^{\mathrm{TM}}$, Covidien, New Haven, CT, USA) at the discretion of an operating surgeon. After dissection of the short gastric vessels, a $360^{\circ}$ floppy Nissen fundoplication was created. We did not use a boogie to calibrate the fundoplication. The most distal suture fixates the wrap to the wall of the oesophagus to prevent telescoping. We did not perform any gastropexy. The patients did receive neither a post-operative drain, nor epidural analgesia.

\section{Immediate postoperative period}

Patients were prescribed a semi-liquid diet for 2 weeks after the operation. Operation time, complications during surgery, length of stay (LOS), in-hospital post-operative complications and re-admissions were retrieved from the hospital information system.

\section{Postoperative follow-up}

Patients were examined by the surgeon in the outpatient clinic 8 weeks after discharge. Proton pump inhibitor (PPI) was continued until the first appointment. If no complications were found, the patients were referred to a general practitioner (GP) or gastroenterologist for further follow-up. The medical treatment was evaluated by the GP or gastroenterologist. We did not perform routine PH-studies or endoscopy. We performed additional diagnostics for both pre-operative workup in the case of a reoperation and for persistent or recurrent complaints after the initial procedure.

\section{Statistical analysis}

A retrospective database was managed in Access 2010. (Microsoft, USA) All data were analysed using SPSS for MacOS version 21.0 (SPSS Inc., Chicago, IL, USA).

\section{Ethical approval}

No ethical approval was required for this study and permission was granted by the institutional review board of our institution to perform this retrospective study. 


\section{Results}

\section{Patients characteristics}

A total of 231 patients were operated on. Four patients died during follow-up due to cancer, cardiac disease or a car crash. The remaining 227 patients were contacted, of which 175 patients returned the questionnaire, resulting in a response rate of $77.1 \%$. Six patients returned the questionnaire without completing it entirely. No reason was given. Of the remaining 169 operated patients, 72 were male (42.6\%). The mean age was 51.6 (range 15-85). The mean follow-up was 3.7 years with a maximum of 10.3 years.

The most common pre-operative reported complaints were heartburn (82.8\%), regurgitation (26.0\%) and chest pain (23.7\%). At baseline, $90.5 \%$ of the patients used a PPI for heartburn. All baseline characteristics are demonstrated in Table 5.1.

Table 5.1 Baseline characteristics

\begin{tabular}{lc}
\hline Characteristics & $\mathrm{N}(\%)$ \\
Response rate (\%) & $169 / 227(74.4)$ \\
Male: Female & $72: 97$ \\
Mean age (range) & $51.6(15-85)$ \\
Mean follow-up(range) & 3.7 years (0.1-10.3) \\
BMI (range) & $27.2(17.8-40.4)$ \\
ASA status (\%) & \\
$\quad$ ASA 1 & $51(30.2)$ \\
ASA 2 & $86(50.9)$ \\
$\quad$ ASA 3 & $4(2.4)$ \\
$\quad$ Missing & $28(16.6)$ \\
Heartburn (\%) & $140 / 169(82.8)$ \\
Regurgitation (\%) & $44 / 169(26.0)$ \\
Chest pain (\%) & $40 / 169(23.7)$ \\
Nausea (\%) & $28 / 169(16.6)$ \\
Vomiting (\%) & $18 / 169(10.7)$ \\
Ructus (\%) & $32 / 169(18.9)$ \\
Gastric asthma (\%) & $24 / 169(14.2)$ \\
Abdominal pain (\%) & $27 / 169(16.0)$ \\
Dysphagia (\%) & $15 / 169(8.9)$ \\
PPI (\%) & \\
Yes & \\
No & $153 / 169(90.5)$ \\
Unknown & $2 / 169(1.2)$ \\
\hline B & $14 / 169(8.3)$ \\
\hline
\end{tabular}

BMI: Body Mass Index, ASA: The American Society of Anaesthesiologists, PPI: Proton Pump Inhibitor 


\section{Operative outcome}

Almost all patients underwent a laparoscopic Nissen fundoplication with posterior cruroplasty. Only one patient received a Toupet fundoplication, the reason was a specific desire from the patient to receive a Toupet and not a Nissen. In five patients, the operation was performed for recurrent GERD after previous antireflux surgery. On five patients (3.0\%), a mesh was used for reinforcement of the cruroplasty because of an unexpected large hiatal hernia. A total of 23 patients underwent re-operation during follow-up. Reasons for re-operation were persistent dysphagia (47.8\%) or recurrent heartburn (52.8\%). None of the patients were diagnosed with delayed gastric emptying due to vagal nerve injury. The mean length of stay (LOS) was 2 days, with a maximum of 18 days. Mortality rate of the operated patients was zero.

Details regarding operative outcomes are summarized in Table 5.2.

\section{Complications}

In this study, we found a complication rate of $7.1 \%$. Complications included perforation of the stomach, bleeding and opening of the pleura. All complications could be managed during surgery without any further sequelae. However, in a number of cases this resulted in an extended length of hospital stay. Details regarding the complications can be found in Table 5.2.

Table 5.2 Operative outcome

\begin{tabular}{|c|c|}
\hline & $\mathrm{N}(\%)$ \\
\hline \multicolumn{2}{|l|}{ Technique } \\
\hline Nissen & $168(99.4)$ \\
\hline Toupet & $1(0.6)$ \\
\hline Laparoscopic & $169(100)$ \\
\hline \multicolumn{2}{|l|}{ Indication } \\
\hline Primary & $164(97.0)$ \\
\hline Recurrence & $5(3.0)$ \\
\hline \multicolumn{2}{|l|}{ Mean operative time (min) } \\
\hline & $78.8(38-379)$ \\
\hline \multicolumn{2}{|l|}{ Hiatal hernia repair } \\
\hline Suture only & $158(93.5)$ \\
\hline Suture with pledgets & $5(2.9)$ \\
\hline Mesh reinforced & $4(2.4)$ \\
\hline Mesh only & $1(0.6)$ \\
\hline None & $1(0.6)$ \\
\hline \multicolumn{2}{|l|}{ Complications } \\
\hline Bleeding & $2(1.2)$ \\
\hline Opening pleura & $4(2.4)$ \\
\hline Stomach perforation & $1(0.6)$ \\
\hline Bleeding spleen & $5(2.9)$ \\
\hline Overall & $12(7.1)$ \\
\hline Mortality & 0 \\
\hline Median LOS (days) & $2(1-18)$ \\
\hline
\end{tabular}

LOS: Length of Stay 


\section{Quality of life}

The median overall quality of life score was 70 (range 2-75) at a mean follow-up of 3.7 years. There was no difference in quality of life among patients with a follow-up longer than 5 years, compared with patients with follow-up of $<5$ years ( $P=0.447)$ Both the heartburn score and the regurgitation score are comparable between short- and long-term follow-up, no statistically significant differences were found. At follow-up $50.3 \%$ of the patients were on PPI compared with $90.9 \%$ at baseline $(P<0.05)$ A complete overview of the quality of life scores is demonstrated in Table 5.3 and Figure 5.1. In an extensive analysis to find predictors for quality of life, we only found that the presence of pre-operative belching results in a lower quality of life. (Table 5.4)

Table 5.3 Quality of life

\begin{tabular}{|c|c|c|c|c|}
\hline & \multirow[t]{2}{*}{ All patients $(n=169)$} & \multicolumn{2}{|c|}{ Follow-up } & \multirow[t]{2}{*}{$P$} \\
\hline & & $<5$ years $(n=115)$ & $>5$ years $(n=54)$ & \\
\hline Quality of life (median; range) & $70(2-75)$ & $70(9-75)$ & $70.5(2-75)$ & $0.447^{*}$ \\
\hline $\begin{array}{l}\text { Heartburn score } \\
\text { (median; range) }\end{array}$ & $29(0-30)$ & $29(2-30)$ & $29.5(0-30)$ & $0.928 *$ \\
\hline $\begin{array}{l}\text { Resolution of heartburn (score }>18 \text { ), } \\
n(\%)\end{array}$ & $129 / 169(76.3)$ & $86 / 115(74.8)$ & $43 / 54(79.6)$ & $0.489+$ \\
\hline $\begin{array}{l}\text { Regurgitation score } \\
\text { (median; range) }\end{array}$ & $30(0-30)$ & $30(0-30)$ & $30(0-30)$ & $0.616^{*}$ \\
\hline $\begin{array}{l}\text { Resolution of regurgitation (score } \\
>18), n(\%)\end{array}$ & $144 / 168(85.7)$ & $98 / 115(85.2)$ & $46 / 54(85.2)$ & $0.996+$ \\
\hline On PPI, n (\%) & $85 / 169$ (50.3) & $61 / 115(53.0)$ & $24 / 54(44.4)$ & $0.297+$ \\
\hline
\end{tabular}

* Mann-Whitney U, + chi-square. PPI: Proton Pump Inhibitor

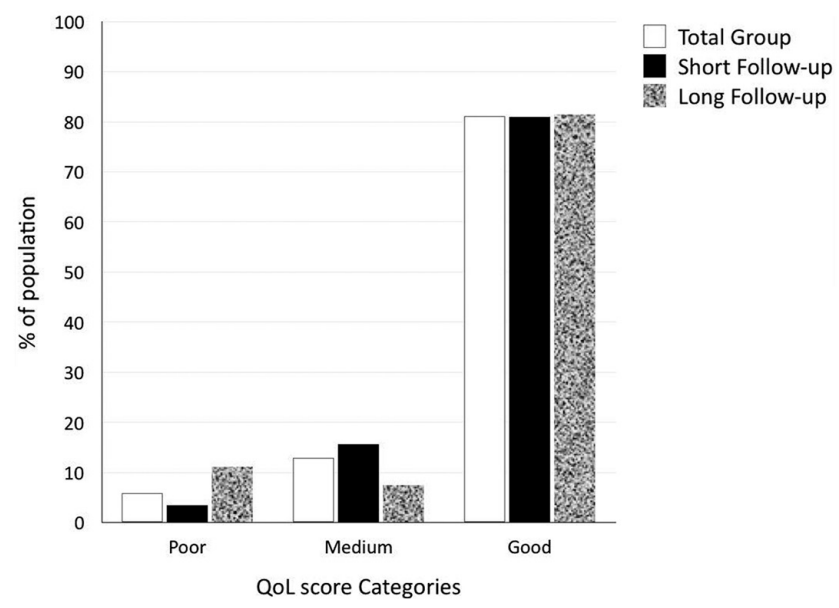

Figure 5.1 Quality of life score organized by categories. A Score of 0-25 is classified as 'Poor', 25-50 is classified as 'Medium' and a quality of life score of 50-75 is classified as 'Good' 
Table 5.4 Pre-operative predictors for quality of life

\begin{tabular}{lccc} 
Symptom & $\begin{array}{c}\text { QoL if symptom present } \\
\text { (median, range) }\end{array}$ & $\begin{array}{c}\text { QoL if symptom not } \\
\text { present (median, range) }\end{array}$ & $P$ \\
\hline Heartburn & $70(2-75)$ & $71(30-75)$ & $0.660^{*}$ \\
Regurgitation & $70(2-75)$ & $70(7-75)$ & $0.782^{*}$ \\
Dysphagia & $74(9-75)$ & $70(2-75)$ & $0.574^{*}$ \\
Chest pain & $65.5(7-75)$ & $71(2-75)$ & $0.115^{*}$ \\
Nausea & $63.5(2-75)$ & $71(3-75)$ & $0.109^{*}$ \\
Vomiting & $72(3-75)$ & $70(2-75)$ & $0.842^{*}$ \\
Ructust & $63(2-75)$ & $71(3-75)$ & $0.026^{*}$ \\
Abdominal pain & $67(22-75)$ & $70(2-75)$ & $0.997^{*}$ \\
BMI & & & \\
$\geq 25$ & $71(2-75)$ & $64(7-75)$ & $0.241^{*}$ \\
$\geq 30$ & $72(2-75)$ & $67(7-75)$ & $0.263^{*}$
\end{tabular}

* Mann-Whitney U. QoL: Quality of Life, BMI: Body Mass Index. Data marked with + are considered statistically significant

\section{Long-term versus short- term quality of life}

Short-term follow-up was defined as $<5$ years. A total of 115 patients had a follow-up of $<5$ years, with a median of 1.9 years (range 0.1-4.6). The remaining 54 patients reported a median follow-up of 7.1 years (range 5.1-10.3). The median quality of life was 70.0 for the short-term group, compared with 70.5 for the long-term group $(P=0.447)$. If we compare post-operative heartburn, regurgitation or usage of PPI, we did not find any statistically significant differences. Results are demonstrated in Table 5.3.

\section{Re-operation}

A total of 23 patients underwent a re-operation during follow-up (13.6\%). Eleven patients were re-operated due to persistent dysphagia (47.8\%) and 12 due to recurrent heartburn (52.2\%) (Figure 5.2) The median time to re-operation was 380 days (75-3488 days), 21 (91.3\%) re-operations occurred within the first 5 years after the initial operation.

If dysphagia was the reason for re-operation, the initial Nissen fundoplication was converted to a Toupet. When recurrent heartburn was present, we re-constructed the Nissen fundoplication. In most cases the wrap seemed to lose, or the sutures were ruptured.

Mean quality of life was 62.7 for patients who did not require re-operation compared to 53.1 for patients who did undergo re-operation $(P=0.196)$. This latter quality of life is measured after the re-operation was performed. 


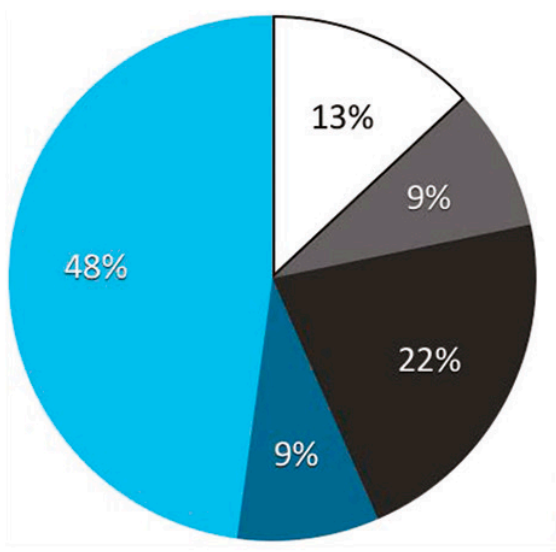

Recurrent heartburn

Recurrent heartburn, sliding HD

Recurrent heartburn, failure of fundoplication

Recurrent heartburn, fundoplication in thorax

Persistent dysphagia

Figure 5.2 Overview of causes for re-operation. A total of 23 re-operations occurred during follow-up

\section{Discussion}

We present a large single surgeon, single-centre series of patients who underwent laparoscopic Nissen fundoplication for GERD. We demonstrated a great response rate of $77.1 \%$ with a mean follow-up of 3.7 years. In this study, we found excellent quality of life after Nissen fundoplication.

Nissen fundoplication has been proven effective in reducing GERD and preventing recurrence, even at the long-term follow-up. ${ }^{10}$ However, only a few studies demonstrate quality of life after Nissen fundoplication. Several instruments to measure quality of life have been developed over time. There is no consensus which instrument is superior, however the GERD-HRQL questionnaire has been proven effective in measuring quality of life after Nissen fundoplication for GERD. ${ }^{9,11}$ Since this is a retrospective study, we do not have pre-operative quality of life data. However, we did find a median quality of life score of 70 which is in line with results demonstrated by a large study of Gee et al.. ${ }^{8}$ They describe a large series with a response rate of $54 \%$ and a median follow-up of 60 months. Interestingly, we did find that patients who underwent a re-operation did report a lower quality of life score. This result was also found in previously published studies. ${ }^{8,12,13}$ This is probably due to vagal nerve damage, either during the primary procedure or during the re-operation. It is known from the literature that patients with vagal nerve damage have a higher re-operation rate and report less quality of life at the long-term follow-up. ${ }^{14}$ Besides it seems important to perform proper patient selection in determining who will receive a Nissen fundoplication to prevent re-operation. Based on current literature it is recommended to have at least manometry to exclude diseases as achalasia and a 24-h PH-measurement in case no 
reflux oesophagitis is present on endoscopy. Besides, it is preferred that patients should have a good response to anti-acid medication. ${ }^{15,16}$ Unfortunately, due to the retrospective aspect of this study, we could not find all data describing the complete performed pre-operative workup. Furthermore, a total of 55 patients was operated before the introduction of the SAGES guidelines for GERD and therefore not all of them did undergo a manometry. We were also unable to find data regarding pre-operative response to anti-acid medication in all patients. We did find that pre-operatively $90.5 \%$ of the patients were on $\mathrm{PPI}$, which was reduced to $50.3 \%$ at follow-up $(P<0.05)$ The high percentage of patients who are on PPI on follow-up may contribute to the good reported quality of life. However, we do think that it is more important that patients report good quality of life, rather than being completely free of PPI. Especially since before surgery they were not satisfied with their situation on PPI.

We found a re-operation rate of $13.6 \%$, from which $7.1 \%$ was due to recurrent heartburn. A Heartburn score on the GERD-HRQL of $>18$ is classified as resolution of symptoms. Based on this score we found a recurrence in heartburn of $23.7 \%$. This is in contrast with current literature, since the reported recurrent heartburn is about 10$20 \%$ and the actual re-operation rate for recurrent complaints is about $3-6 \%{ }^{17,18}$ Reported causes for recurrent heartburn are an inadequate indication for surgery due to incomplete pre-operative work-up and failure to execute proper technical steps. ${ }^{19}$ Furthermore it is known that with increasing experience from the surgeon, the complication and re-operation rate will decrease. ${ }^{20,21}$ As mentioned before, it is known that patients with vagal nerve damage receive more frequent re-operations. ${ }^{14}$ Since this was a retrospective study, we were unable to determine whether the patients who underwent a re-operation, indeed had vagal nerve injury. Our higher re-operation rate is most likely due to a combination of above mentioned factors.

Eleven of the 23 re-operation were due to persistent dysphagia. This is a common sideeffect of Nissen fundoplication and a large meta-analysis by Tian et al. in 2015 demonstrates a post-operative dysphagia rate of $12.6 \%$ in patients who underwent Nissen fundoplication. ${ }^{22}$ In this study, $8.9 \%$ of the patients had moderate to severe dysphagia, which might be an indication for re-operation. This is comparable with the $6.5 \%$ re-operations for dysphagia in our study. Post-operative dysphagia is a known and major problem and re-operation rates between $1.8 \%$ and $10.8 \%$ for dysphagia have been reported in literature. ${ }^{2}$ To reduce dysphagia some authors advocate to perform a Toupet fundoplication. Despite the lower dysphagia rate, this technique seems to be inferior in controlling GERD symptoms at the long term. ${ }^{23}$ However, there are also studies that report comparable control of GERD symptoms with less post-operative complications and therefore advocate to perform a Toupet fundoplication. ${ }^{22} \mathrm{We}$ believe that it is important to perform the technique in which the surgeon has the most experience. In case of persistent post-operative dysphagia a Nissen can be converted to a Toupet and in case of insufficient reflux control after a Toupet, this can be 
converted to a Nissen. The final decision to perform either Nissen or Toupet should be tailored made.

Another outcome measurement in this study was the complication rate. We found a complication rate of $7.1 \%$ which is in line with the overall complication rate of $6.3 \%$ that is reported in a large meta-analysis by Memon et al in $2015 .{ }^{24}$ All complications were minor and could be managed during surgery without any further sequelae. The median time to re-operation was 380 days.

Some authors report the relevance of long-term results after antireflux surgery. However, if we compare quality of life after a follow-up of $<5$ years with results after $>5$ years, we do not see any statistically significant difference. This may suggest that most complications and recurrences occur within the first 5 years after initial surgery. This hypothesis is supported by the fact that almost all re-operations $21 / 23$ (91.3\%) were performed within 5 years after the primary procedure. Therefore, we might conclude that follow-up of 5 years after Nissen fundoplication might be sufficient to evaluate its effectiveness. This is supported by the study of Kelly et al. where they report that most re-operations are performed within the first 2 years and that they did not see any difference in symptomatic outcome between 5 and 10 years of follow-up. ${ }^{7}$

\section{Conclusion}

We report a large series of single-centre, single surgeon laparoscopic Nissen fundoplication. Despite the re-operation rate of $13.6 \%$ we found excellent symptomatic outcome at a median follow-up of 3.7 years. We did not find any difference between short-term and long-term results, therefore follow-up of 5 years might be sufficient to evaluate the results of Nissen fundoplication since $91.3 \%$ of the re-operations took place within 5 years. Patients who underwent re-operation experienced less quality of life, this might be due to vagal nerve injury, however this requires more research. 


\section{References}

1. Soricelli E, Basso N, Genco A, Cipriano M. Long-term results of hiatal hernia mesh repair and antireflux laparoscopic surgery. Surgical endoscopy. 2009;23(11):2499-504.

2. Stefanidis D, Hope WW, Kohn GP, Reardon PR, Richardson WS, Fanelli RD, et al. Guidelines for surgical treatment of gastroesophageal reflux disease. Surgical endoscopy. 2010;24(11):2647-69.

3. Cuschieri A, Shimi S, Nathanson LK. Laparoscopic reduction, crural repair, and fundoplication of large hiatal hernia. American journal of surgery. 1992;163(4):425-30.

4. Robertson AG, Patel RN, Couper GW, de Beaux AC, Paterson-Brown S, Lamb PJ. Long-term outcomes following laparoscopic anterior and Nissen fundoplication. ANZ journal of surgery. 2015.

5. Lundell L, Miettinen P, Myrvold HE, Pedersen SA, Liedman B, Hatlebakk JG, et al. Continued (5-year) followup of a randomized clinical study comparing antireflux surgery and omeprazole in gastroesophageal reflux disease. Journal of the American College of Surgeons. 2001;192(2):172-9; discussion 9-81.

6. Dallemagne B, Weerts J, Markiewicz S, Dewandre JM, Wahlen C, Monami B, et al. Clinical results of laparoscopic fundoplication at ten years after surgery. Surgical endoscopy. 2006;20(1):159-65.

7. Kelly JJ, Watson DI, Chin KF, Devitt PG, Game PA, Jamieson GG. Laparoscopic Nissen fundoplication: clinical outcomes at 10 years. Journal of the American College of Surgeons. 2007;205(4):570-5.

8. Gee DW, Andreoli MT, Rattner DW. Measuring the effectiveness of laparoscopic antireflux surgery: long-term results. Archives of surgery. 2008;143(5):482-7.

9. Velanovich V. The development of the GERD-HRQL symptom severity instrument. Diseases of the esophagus : official journal of the International Society for Diseases of the Esophagus / ISDE. 2007;20(2):130-4.

10. Simorov A, Ranade A, Jones R, Tadaki C, Shostrom V, Boilesen E, et al. Long-term patient outcomes after laparoscopic anti-reflux procedures. Journal of gastrointestinal surgery : official journal of the Society for Surgery of the Alimentary Tract. 2014;18(1):157-62; discussion 62-3.

11. Koetje JH, Nieuwenhuijs VB, Irvine T, Mayne GC, Watson DI. Measuring Outcomes of Laparoscopic Antireflux Surgery: Quality of Life Versus Symptom Scores? World journal of surgery. 2016;40(5):1137-44.

12. Khaitan L, Bhatt $P$, Richards W, Houston H, Sharp K, Holzman M. Comparison of patient satisfaction after redo and primary fundoplications. Surgical endoscopy. 2003;17(7):1042-5.

13. Draaisma WA, Rijnhart-de Jong HG, Broeders IA, Smout AJ, Furnee EJ, Gooszen HG. Five-year subjective and objective results of laparoscopic and conventional Nissen fundoplication: a randomized trial. Annals of surgery. 2006;244(1):34-41.

14. van Rijn S, Rinsma NF, van Herwaarden-Lindeboom MY, Ringers J, Gooszen HG, van Rijn PJ, et al. Effect of Vagus Nerve Integrity on Short and Long-Term Efficacy of Antireflux Surgery. The American journal of gastroenterology. 2016;111(4):508-15.

15. Campos GM, Peters JH, DeMeester TR, Oberg S, Crookes PF, Tan S, et al. Multivariate analysis of factors predicting outcome after laparoscopic Nissen fundoplication. Journal of gastrointestinal surgery : official journal of the Society for Surgery of the Alimentary Tract. 1999;3(3):292-300.

16. Bello B, Zoccali M, Gullo R, Allaix ME, Herbella FA, Gasparaitis A, et al. Gastroesophageal reflux disease and antireflux surgery-what is the proper preoperative work-up? Journal of gastrointestinal surgery : official journal of the Society for Surgery of the Alimentary Tract. 2013;17(1):14-20; discussion $p$

17. Carlson MA, Frantzides CT. Complications and results of primary minimally invasive antireflux procedures: a review of 10,735 reported cases. Journal of the American College of Surgeons. 2001;193(4):428-39.

18. Catarci M, Gentileschi P, Papi C, Carrara A, Marrese R, Gaspari AL, et al. Evidence-based appraisal of antireflux fundoplication. Annals of surgery. 2004;239(3):325-37.

19. Patti MG, Allaix ME, Fisichella PM. Analysis of the Causes of Failed Antireflux Surgery and the Principles of Treatment: A Review. JAMA Surg. 2015;150(6):585-90.

20. Watson DI, Baigrie RJ, Jamieson GG. A learning curve for laparoscopic fundoplication. Definable, avoidable, or a waste of time? Annals of surgery. 1996;224(2):198-203. 
21. Salminen $\mathrm{P}$, Hiekkanen $\mathrm{H}$, Laine $\mathrm{S}$, Ovaska J. Surgeons' experience with laparoscopic fundoplication after the early personal experience: does it have an impact on the outcome? Surgical endoscopy. 2007;21(8):1377-82.

22. Tian ZC, Wang B, Shan CX, Zhang W, Jiang DZ, Qiu M. A Meta-Analysis of Randomized Controlled Trials to Compare Long-Term Outcomes of Nissen and Toupet Fundoplication for Gastroesophageal Reflux Disease. PLoS One. 2015;10(6):e0127627.

23. Ma S, Qian B, Shang L, Shi R, Zhang G. A meta-analysis comparing laparoscopic partial versus Nissen fundoplication. ANZ journal of surgery. 2012;82(1-2):17-22.

24. Memon MA, Subramanya MS, Hossain MB, Yunus RM, Khan S, Memon B. Laparoscopic anterior versus posterior fundoplication for gastro-esophageal reflux disease: a meta-analysis and systematic review. World journal of surgery. 2015;39(4):981-96. 


\section{Appendix 5.1}

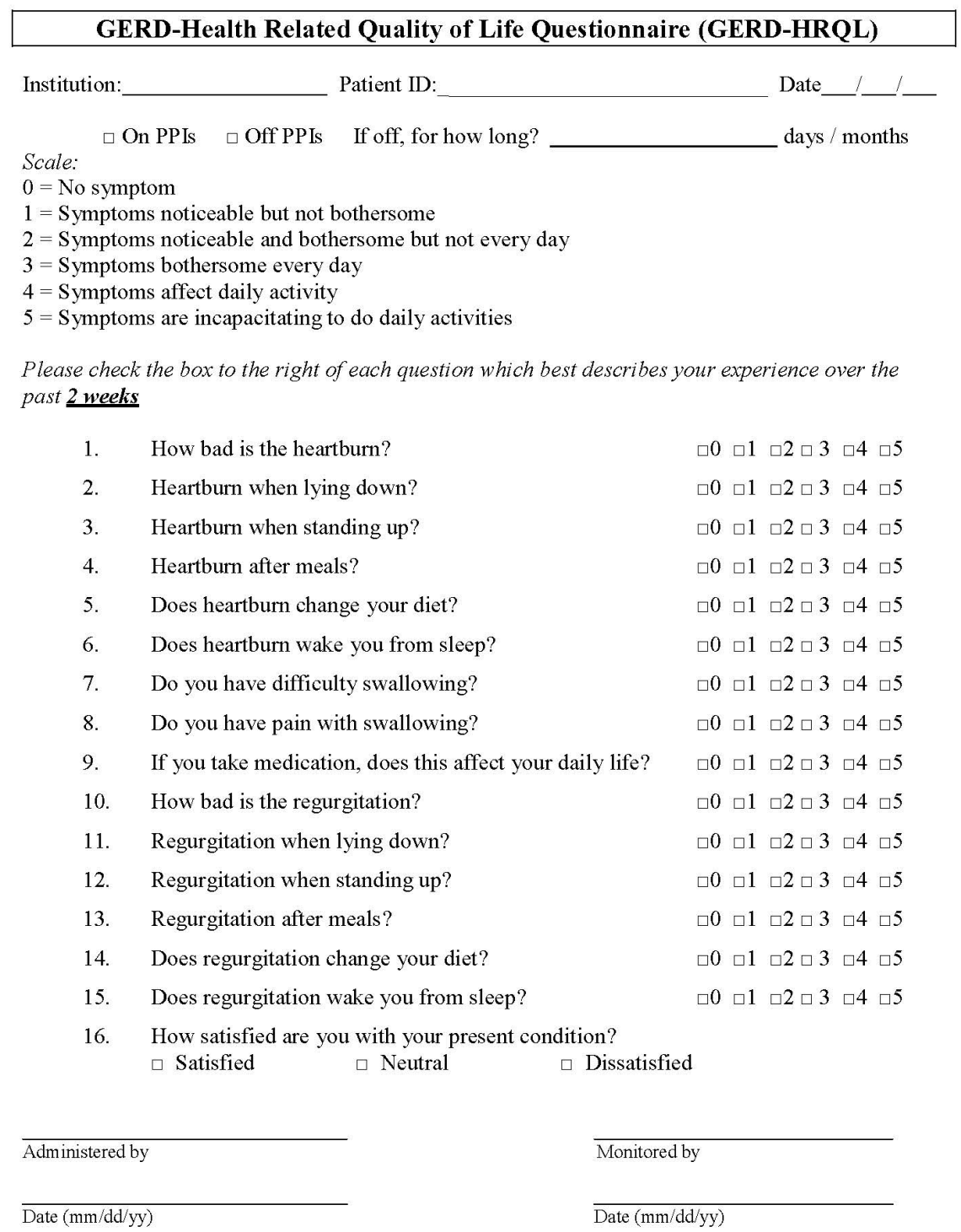




\section{GERD-HRQL Questionnaire -Instructions}

The GERD-HRQL questionnaire was developed and validated to measure changes of typical GERD symptoms such as heartburn and regurgitation in response to surgical or medical treatment. ${ }^{1}$

When comparing GERD-HRQL scores post-TIF to scores pre-TIF, it is important to take medication use into consideration. It is recommended to request patients take this questionnaire twice at screening (once off PPIs and the other time on PPIs) for fair comparison at follow-ups post-TIF

Total Score: Calculated by summing the individual scores to questions 1-15.

- Greatest possible score (worst symptoms) $=75$

- Lowest possible score (no symptoms) $=0$

Heartburn Score: Calculated by summing the individual scores to questions 1-6 .

- Worst heartburn symptoms $=30$

- No heartburn symptoms $=0$

- Scores of $\leq 12$ with each individual question not exceeding 2 indicate heartburn elimination. $^{2}$

Regurgitation Score: Calculated by summing the individual scores to questions 10-15.

- Worst regurgitation symptoms $=30$

- No regurgitation symptoms $=0$

- Scores of $\leq 12$ with each individual question not exceeding 2 indicate regurgitation elimination. $^{2}$

References Cited

${ }^{1}$ Velanovich V. The development of the GERD-HRQL symptom severity instrument. Dis Esophagus 2007;20:130-4.

${ }^{2}$ Hunter JG, Trus TL, Branum GD, Waring JP, Wood WC. A physiologic approach to laparoscopic fundoplication for gastroesophageal reflux disease. Ann Surg 1996;223:673-85. 



\section{Chapter 6}

7-year follow up after transoral incisionless fundoplication for treatment of gastroesophageal reflux disease; results of patients who participated in a randomized controlled trial 


\title{
Abstract
}

\begin{abstract}
Aims
Transoral incisionless fundoplication (TIF) is a minimally invasive endoscopic procedure for the treatment of gastroesophageal reflux disease (GERD) that mimics antireflux surgery, with the advantage of fewer side-effects. This procedure might be beneficial especially for patients who would like to avoid lifelong treatment with proton pump inhibitors (PPI's). Reports on long-term effects after TIF are very limited. The primary objective of this study was to report the 7-years results of patients who took part in a randomized controlled trial (RCT) comparing TIF (EsophyX-2 device) with PPI's. Because of a crossover option eventually all patients in the trial underwent TIF. Secondary objective was to identify pre-operative predictors for successful outcomes.
\end{abstract}

\section{Methods}

All patients who underwent TIF in the previously published randomized controlled trial (between 2008 and 2012) were contacted by mail and were sent a quality of life (GERD-HRQL) questionnaire. Additional questions regarding current PPI use and re-operations were added to the questionnaire. Also questions about the severity of regurgitation and overall satisfaction with health were included. A clinically significant improvement in quality of life was defined as $\geq 50 \%$ improvement in GERD-HRQL score. The original RCT database was used to perform multivariate analyses to identify potential predictors of a favourable outcome.

\section{Results}

All sixty patients from the original RCT were contacted. One patient died due to unrelated cause. 44 out of the remaining 59 patients, returned the questionnaire. The response rate was $74.6 \%$, however, three returned questionnaires were blank. The mean follow-up is 7.3 (SD 1.2) years. During the follow-up, 9 (22\%) patients underwent reoperation, 23 (56.1\%) patients resumed daily oral PPI intake. At 7 years, the median quality of life score was 6.0 (0-39) compared with 15.0 (3-42) at baseline $(P<0.05)$ (a lower quality of life score represents better outcome, with 0 as the maximum quality of life). 30 patients (73.2\%) had a $\geq 50 \%$ improvement in GERD-HRQL score compared to baseline. 31 patients $(75.6 \%)$ had relevant improvement in regurgitation score compared to baseline. The median regurgitation score was $2.0(0-24)$ compared to $11.0(0-28)$ at baseline $(P<0.001) .43 .9 \%$ of the patients reported to be satisfied with their health compared with $11.7 \%$ at baseline $(P<0.05)$. The presence of a hiatal hernia or oesophagitis were a negative predictor for successful outcome.

\section{Conclusions}

This is the first study reporting on 7-year follow-up results after TIF. It showed a significant improvement in quality of life scores and patient satisfaction. Despite the fact that some patients needed anti-reflux surgery in addition to TIF to control their symptoms and that $56 \%$ of patients resumed PPI usage, there is a group of patients who benefit optimally from the TIF procedure even in the long term. 


\section{Introduction}

The main purpose of gastroesophageal reflux disease (GERD) treatment is to achieve symptoms relief, improve quality of life, and to prevent oesophageal mucosal damage. ${ }^{1}$ It can be treated either by medication, surgery or transoral interventions. The first step in the treatment is usually with medication, specifically with proton pump inhibitors (PPI). ${ }^{2}$ However, this treatment is focused on symptom relief only and patients will have to continue to use PPI's lifelong. ${ }^{3,4}$ A long-term use of PPI's might be associated with an increased risk of dementia, pneumonia, rib fractures, magnesium deficiency, gastrointestinal infections and even a predisposition for upper gastrointestinal malignancies. ${ }^{5,6}$

The GERD treatment with medication is not optimal as some patients experience bothersome side-effects, some are 'unresponsive' to medical therapy or are not willing to take medication for a lifetime period. Besides, while the PPI treatment can provide reduction in acid reflux, it has minimal effect on regurgitation. For many years, laparoscopic antireflux surgery (LARS) has been the only treatment option for patients who did not respond well to medication or were not satisfied with the use of PPI's. However, LARS can cause serious side-effects. Several studies which reported the longterm results, showed a high degree of dysphagia, gas bloating, inability to belch, vagal nerve injury and even a re-operation rate of up to $15 \%{ }^{7,8}$ Literature shows recurrent heartburn in $10-20 \%$ of the patients after LARS for a median follow-up of 6.5 years. ${ }^{9-11}$ Therefore, alternative methods for controlling GERD have been developed. One of the most promising techniques is the transoral incisionless fundoplication (TIF). There are three devices for the performance of this intervention available by now, the EsophyX device (EndoGastric Solutions, Redmond, WA, United States), the Medigus Ultrasonic Surgical Endostapler system (MUSE ${ }^{\mathrm{TM}}$, Medigus Ltd., Omer; Israel) and the GERDX $^{\text {TM }}$ (G-SURG GmbH, Seeon-Seebruck, Germany). ${ }^{12,13}$ The transoral incisionless fundoplication (TIF) technique is minimally invasive and seems effective in controlling heartburn symptoms in a select group of patients, at least in the short term, which was demonstrated in several studies. ${ }^{12,14,15}$ In these studies TIF was compared with no treatment ${ }^{12,14}$ or a sham procedure. ${ }^{15}$ One randomized controlled trial has compared TIF with the standard PPI treatment. ${ }^{16}$ The results of this RCT showed an improved GERD-related quality of life and an improvement of the antireflux barrier in the short term. However, the results up to 1-year showed an increasing PPI dependence over time. There is only one prospective study published so far which gives the long-term results, up to 6 years after transoral incisionless fundoplication with EsophyX (Tif 2.0). ${ }^{17}$ In this study with 50 patients there was an elimination of daily dependence on PPI achieved in $75-80 \%$ of the patients after 6 -years. However, only 14 patients completed the 6-year follow-up. Therefore, the conclusions of this study must be viewed with care. 
The aim of the present study is to evaluate the 7 year's results of all patients who underwent a TIF procedure (by EsophyX device 2.0) after participating in a randomized trial comparing TIF with PPI's, the short-term outcomes of which we have published earlier. ${ }^{16}$ Also, we attempted to identify the pre-operative predictors for successful outcomes.

\section{Methods}

\section{Initial study design}

The initial study was designed as a prospective randomized controlled trial that was carried out at a university hospital in the Netherlands. A total of 60 patients with chronic GERD who were well controlled on daily PPI therapy were randomized 2:1, to either TIF (intervention) or continuation of treatment with PPI's (control group). After the baseline measurements were taken, the patients discontinued the PPI use and subsequently the measurements were taken again after a 14 days period without medication. Included were patients with hiatal hernia $\leq 2 \mathrm{~cm}$ who had proven reflux while off PPIs and recurrence of GERD symptoms after cessation of PPI's (GERD-HRQL score difference of $>10$ between on and off PPI's). After 6 months, patients in the control group had the possibility to switch to the TIF group and to undergo the intervention as well. All 60 patients underwent the TIF procedure. At 12 months, quality of life remained improved after TIF compared with baseline but there was no improvement in oesophageal acid exposure compared with baseline. Normalization of $\mathrm{pH}$ was accomplished in only $29 \%$ of patients and $61 \%$ of patients resumed the use of PPI's, from which $44 \%$ on daily basis.

\section{TIF procedure}

All procedures were performed under general anaesthesia and in left lateral decubitus position. The TIF procedure was performed by a team of two experienced physicians (surgeon and gastroenterologist) under continuous endoscopic visualization using the EsophyX-2 device with SerosaFuse fasteners (EndoGastric Solutions, Redmond, WA). Using a bite block, the lubricated EsophyX device was inserted over the endoscope, used as a guide wire. If present, a small hiatal hernia was reduced. PPI was continued for 14 days after the procedure to provide the mucosa time to heal. More details regarding the technical aspects of the used technique have been described before. ${ }^{16}$ 


\section{Present study}

For the present study, we contacted all 60 patients who underwent the TIF procedure and also consented to be approachable for further study. The patients were sent the quality of life questionnaires by post and by e-mail. Non-responders were contacted by phone once, to verify the address and to ask approval for sending the questionnaire again. The initial randomized study was approved by the Maastricht Medical Ethics Committee (METC 07-2-051, NL 17303.068.07) and was registered NCT0085759 (clinicaltrials.gov). The METC of Maastricht has confirmed that the Medical Research Involving Human Subjects Act (WMO) does not apply to the current long-term followup study and that official approval is not required. Primary objective of this study was to report the long-term quality of life after a TIF procedure, secondary outcome was to find predictors for successful outcomes regarding GERD symptoms.

\section{Quality of life questionnaires}

The GERD-HRQL (GERD related quality of life) questionnaire, is a validated tool that measures the symptom severity in GERD patients. ${ }^{18,19}$ Six out of the 10 questions assess the degree of heartburn, two questions address dysphagia, one question addresses regurgitation, and one question assesses the impact of medication use on daily living. We have added five other questions concerning regurgitation. These questions were included in the initial RCT study as well and are formulated in a similar way as the questions about heartburn. Each item is scored from 0 to 5 , with 0 representing no complaints at all, while a score of 5 represents very bothersome complaints. Based on study by Cadiere et al, a successful outcome was defined as an improvement of $\geq 50 \%$ of the quality of life score. ${ }^{20}$ The six questions about regurgitation have been furthermore analysed in an additional analysis to calculate a regurgitation score. Further, one additional question was added to evaluate the overall satisfaction with current health. In addition to the questionnaire, the patients were asked to report whether they have undergone additional surgery for GERD during follow-up and if they were currently using PPI's and/or other anti-acid drugs. In case of drug usage, the frequency and mode of delivery were questioned.

\section{Data handling}

The results of the questionnaires were added to the initial RCT database that was stored in an electronic database capture system (Microsoft Excel 97-2004). In this study only data regarding responders were analysed and are reported. 


\section{Statistical analysis}

Metric variables with normal distribution (tested by Shapiro-Wilk statistic) were univariately presented by their means and standard deviation and if not normally distributed the median and range (minimum - maximum) were used. Categorical variables were presented by frequencies and percentages. Standard univariable statistics were used to examine the differences between subgroups of patients or the association between particular parameters: Chi-square test or Fisher's exact test for categorical variables, Students t-test or Mann-Whitney $U$ test for continuous variables, and the Wilcoxon signed rank test or McNemar test for paired data. Multivariable analyses were performed by using backward logistic regression, whereby the odds ratio (OR) with 95\% confidence limits were estimated and tested with the Wald chi-square test. For the logistic regression, backward stepwise regression, based on Wald criteria, was used with the covariates presence of hiatal hernia and presence of oesophagitis were included together with the covariates with a p-value below 0.2 in univariate analyses. A $P$-value of $<0.05$ was considered statistically significant. All analyses were performed with SPSS, version 24.0 (IBM, Armonk, NY).

\section{Results}

\section{Patient characteristics}

A total of 60 patients underwent the TIF 2.0 procedure between 2008 and 2012. During follow-up 1 patient died, the cause of death was not related to the intervention. The remaining 59 patients were contacted. A total of 44 patients $(74.6 \%)$ returned the questionnaire. Three of the returned questionnaires were blank, the patients refused to answer the questions due to lack of time. Among the patients who returned the completed questionnaire $(n=41), 14(34.1 \%)$ are female and $27(65.9 \%)$ are male, with a median age of 48 (20-68). Median BMI is 24.9 (19.8-34.8) and the mean follow-up is 7.3 (SD 1.2) years.

\section{Quality of life and patient satisfaction}

Median quality of life score after 7 years is 6.0 (0-39) compared with 15.0 (3-42) at baseline $(P<0.01)$. The median regurgitation score is $2.0(0-24)$ at 7 years compared to $11.0(0-28)$ at baseline $(P<0.01)$. From one year after surgery until 7 years, the quality of life and regurgitation score remained constant (Table 6.1). After 7 years a total of $56.1 \%$ of the patients resumed daily use of proton pump inhibitors, after 12 months this was 34.1\% ( $P=0.267)$. (Table 6.2) Quality of life score of patients who resumed daily PPI usage was 12.0 (0-39) compared with $3.5(0-19)$ for patients who were still without PPI medication after 7 years of follow-up $(P=0.010)$ (Table 6.3). 
Table 6.1 Quality of life and regurgitation score at different moments of follow-up after TIF

\begin{tabular}{|c|c|c|c|c|c|c|c|c|}
\hline & \multirow[b]{2}{*}{ 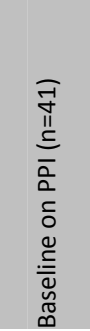 } & \multirow[b]{2}{*}{ 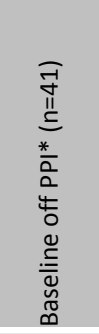 } & \multirow[b]{2}{*}{ 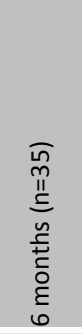 } & \multirow[b]{2}{*}{ 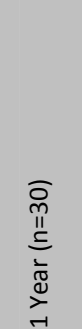 } & \multirow[b]{2}{*}{ 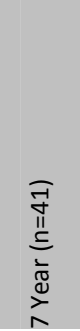 } & \multicolumn{3}{|l|}{ P-value } \\
\hline & & & & & & 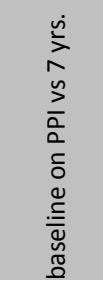 & 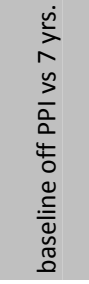 & 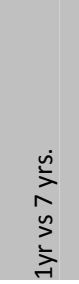 \\
\hline $\begin{array}{l}\text { Median GERD-HRQL } \\
\text { (range) }\end{array}$ & $\begin{array}{c}15.0 \\
(3-42)\end{array}$ & $\begin{array}{c}26.0 \\
(10-50)\end{array}$ & $\begin{array}{c}9.0 \\
(0-38)\end{array}$ & $\begin{array}{c}8.0 \\
(0-31)\end{array}$ & $\begin{array}{c}6.0 \\
(0-39)\end{array}$ & $0.000^{1}$ & $0.000^{1}$ & $0.242^{1}$ \\
\hline $\begin{array}{l}\text { Median Regurgitation score } \\
\text { (range) }\end{array}$ & $\begin{array}{c}11.0 \\
(0-28)\end{array}$ & $\begin{array}{c}16.0 \\
(0-30)\end{array}$ & $\begin{array}{c}4.0 \\
(0-25)\end{array}$ & $\begin{array}{c}3.0 \\
(0-22)\end{array}$ & $\begin{array}{c}2.0 \\
(0-24)\end{array}$ & $0.000^{1}$ & $0.000^{1}$ & $0.230^{1}$ \\
\hline
\end{tabular}

${ }^{1}$ Wilcoxon Signed Ranks Test, ${ }^{2}$ McNemar test. PPI: Proton Pump Inhibitor. * 14 days wash-out period

Table 6.2 PPI usage at different moments of follow-up

\begin{tabular}{|c|c|c|c|c|c|c|}
\hline & 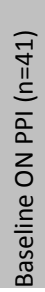 & 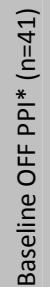 & 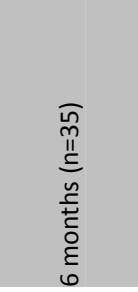 & $\begin{array}{l}\text { O } \\
\text { II } \\
\text { I } \\
\frac{1}{\pi} \\
\stackrel{1}{0} \\
-1\end{array}$ & 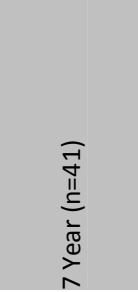 & 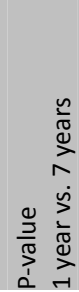 \\
\hline Yes & 41 & 0 & $8(19.5 \%)$ & 14 (34.1\%) & 23 (56.1\%) & \multirow{3}{*}{$0.267^{1}$} \\
\hline No & 0 & 41 & 27 (65.9\%) & 17 (41.5\%) & 18 (43.9\%) & \\
\hline Unknown & 0 & 0 & $6(14.6 \%)$ & $10(24.4 \%)$ & $0(0.0 \%)$ & \\
\hline
\end{tabular}

${ }^{1}$ McNemar test. PPI: Proton Pump Inhibitor. * 14 days wash-out period

\section{Re-operation}

During the 7-year follow-up period, 9 of the 41 (22.0\%) patients underwent reoperation for persistent heartburn complaints. Two of the 9 patients underwent a reoperation within the first year after the TIF procedure. Mean time to surgery was 14.2 (SD 8.4) months. One patient underwent a gastric bypass procedure, 5 patients underwent laparoscopic Nissen fundoplication and 3 patients a Toupet fundoplication. $33.3 \%$ of the 9 patients who underwent a re-operation reported to be satisfied with their quality of life at 7 years. From 32 patients who did not undergo a re-operation $46.9 \%$ of the patients reported to be satisfied with their quality of life. The median GERD-HRQL and the median regurgitation scores were better in patients after reoperation, however no statistical significance could be demonstrated. (Table 6.3). 
Table 6.3 The effect of re-operation and resumption of PPI usage on the quality of life and regurgitation score, 7 years after TIF

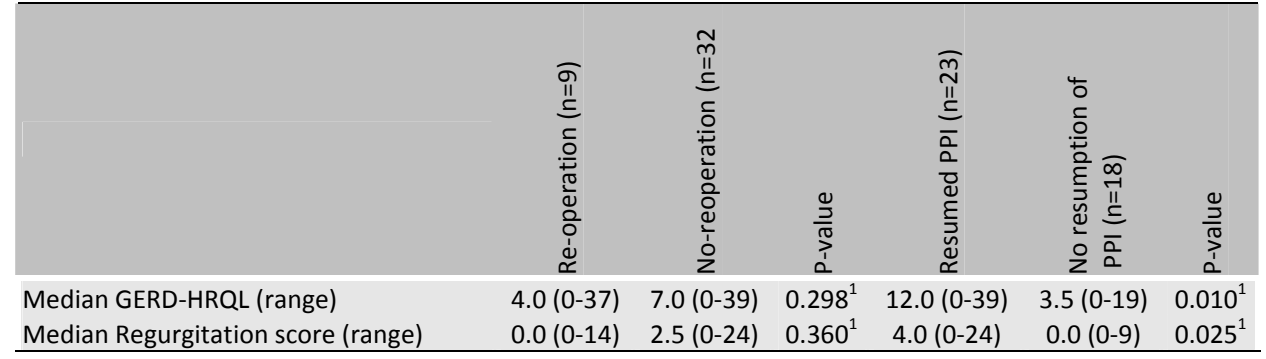

${ }^{1}$ Mann-Whitney $U$ test

\section{Pre-procedure and procedure related predictors for successful outcome}

Patients who reported an improvement of at least $50 \%$ on the GERD-HRQL score at 7-year follow-up, compared with baseline were defined as 'responders' to treatment. We have found $30(73.2 \%)$ responders when compared with baseline measurements taken in patients after a 14 days period of being off the PPI medication. When compared to baseline measurements when patients were still taking PPI's the proportion of responders is 21 (51.2\%).

Age, gender, BMI, median LES pressure, re-operation, presence of hiatal hernia, and presence of oesophagitis were included in the analyses as potential predictors for a successful treatment response measured with the GERD-HRQL questionnaire. None of these predictors showed a significant association with having a successful outcome. The results of the univariate analysis are summarized in Table 6.4. The multivariable analyses showed no significant results for the off-PPI comparison. However, in the comparison with the on-PPI period, multivariate analyses showed the patients with a hiatal hernia had a lower probability of being a responder to TIF treatment, OR $=0.12$ (95\% Cl 0.02-0.71), $P=0.020$. Also, the presence of oesophagitis lead to a lower probability of being a responder, $\mathrm{OR}=0.17$ (95\% $\mathrm{Cl} 0.030-0.942), P=0.043$.

Analogous analyses were performed for the improvement of at least $50 \%$ in the regurgitation score. When compared to baseline score when patients were off PPI we found $31(75.6 \%)$ responders and when compared with baseline score when patients were on PPI we found 24 (58.5\%) responders (Table 6.5). For this outcome, nonsignificant results in both the uni- and multivariate models were found. 
Table 6.4 Univariate analysis for predictors of a $\geq 50 \%$ improvement of the GERD-HRQL score, 7 years after TIF

\begin{tabular}{|c|c|c|c|c|c|c|}
\hline & \multicolumn{3}{|c|}{ on PPI at baseline } & \multicolumn{3}{|c|}{ off PPI at baseline* } \\
\hline & 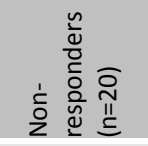 & 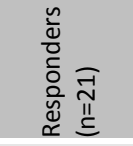 & $\frac{\stackrel{0}{2}}{\frac{\partial}{\pi}}$ & 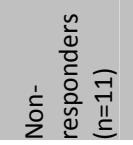 & 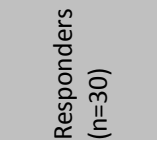 & $\begin{array}{l}\frac{0}{2} \\
\frac{2}{\pi} \\
\frac{1}{2}\end{array}$ \\
\hline Median age (range) & $42(20-68)$ & $49(33-67)$ & $0.341^{1}$ & $55(28-68)$ & $45.5(20-67)$ & $0.556^{1}$ \\
\hline Gender male (\%) & $15(75.0)$ & $12(57.1)$ & $0.228^{2}$ & $9(81.8)$ & $18(60.0)$ & $0.275^{3}$ \\
\hline $\mathrm{BMI} \geq 25(\%)$ & $11(55.0)$ & 9 (42.9) & $0.437^{2}$ & $7(63.6)$ & $13(43.3)$ & $0.249^{2}$ \\
\hline $\begin{array}{l}\text { Median LES } \\
\text { pressure (range) }\end{array}$ & $12.5(8-25)$ & $15(6-25)$ & $0.077^{1}$ & $13(8-25)$ & $15(6-25)$ & $0.222^{1}$ \\
\hline Re-operation (\%) & $3(15.0)$ & $6(28.6)$ & $0.454^{3}$ & $1(9.1)$ & $8(26.7)$ & $0.401^{3}$ \\
\hline Hiatal hernia (\%) & $17(85.0)$ & $11(52.4)$ & $0.025^{2}$ & $8(72.7)$ & $20(66.7)$ & $1.000^{3}$ \\
\hline Oesophagitis (\%) & $9(45.0)$ & $4(19.0)$ & $0.074^{2}$ & $4(36.4)$ & $9(30.0)$ & $0.719^{3}$ \\
\hline
\end{tabular}

${ }^{1}$ Mann-Whitney U, ${ }^{2}$ Pearson Chi-Square, ${ }^{3}$ Fisher's Exact Test. BMI: Body Mass Index $\left(\mathrm{kg} / \mathrm{m}^{2}\right)$, LES pressure: Lower Oesophageal Sphincter pressure. Oesophagitis is defined as the presence of any grade of Oesophagitis. Responders are patients that have an improvement of at least $50 \%$ on the GERD-HRQL score after a follow-up of 7 years compared with baseline. $* 14$ days wash-out period

Table 6.5 Univariate analysis for predictors of $a \geq 50 \%$ improvement of the regurgitation score, 7 years after TIF

\begin{tabular}{|c|c|c|c|c|c|c|}
\hline & \multicolumn{3}{|c|}{ on PPI at baseline } & \multicolumn{3}{|c|}{ off PPI at baseline* } \\
\hline & 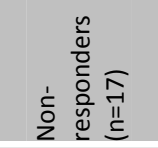 & 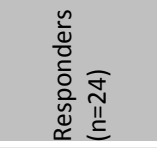 & 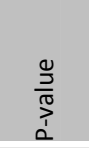 & 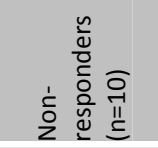 & 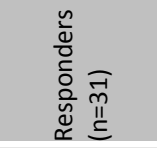 & $\frac{\frac{0}{3}}{\frac{\pi}{2}}$ \\
\hline Median age (range) & $43.0(20-68)$ & $49.0(33-67)$ & $0.278^{1}$ & $42.5(23-57)$ & $49.0(20-68)$ & $0.387^{1}$ \\
\hline Gender male (\%) & $11(64.7)$ & $16(66.7)$ & $0.896^{2}$ & $7(70.0)$ & $20(64.5)$ & $1.000^{3}$ \\
\hline $\mathrm{BMI} \geq 25(\%)$ & $8(47.1)$ & $12(50.0)$ & $0.853^{2}$ & $7(70.0)$ & 13 (41.9) & $0.159^{3}$ \\
\hline $\begin{array}{l}\text { Median LES } \\
\text { pressure (range) }\end{array}$ & $15(9-25)$ & $15(6-25)$ & $0.461^{1}$ & $14(9-25)$ & $15(6-25)$ & $0.560^{1}$ \\
\hline Re-operation (\%) & $4(23.5)$ & $5(20.8)$ & $1.000^{3}$ & $3(30.0)$ & $6(19.4)$ & $0.662^{3}$ \\
\hline Hiatal hernia (\%) & $11(64.7)$ & $17(70.8)$ & $0.678^{2}$ & $5(50.0)$ & $23(74.2)$ & $0.241^{3}$ \\
\hline Oesophagitis (\%) & $8(47.1)$ & $5(20.8)$ & $0.075^{2}$ & $4(40.0)$ & $9(29.0)$ & $0.698^{3}$ \\
\hline
\end{tabular}

${ }^{1}$ Mann-Whitney $U,{ }^{2}$ Pearson Chi-Square, ${ }^{3}$ Fisher's Exact Test. BMI: Body Mass Index $\left(\mathrm{kg} / \mathrm{m}^{2}\right)$, LES pressure: Lower Oesophageal Sphincter pressure. Oesophagitis is defined as the presence of any grade of Oesophagitis. Responders are patients that have an improvement of at least $50 \%$ on the regurgitation score after a followup of 7 years compared with baseline. $* 14$ days wash-out period 


\section{Discussion}

This is the first study reporting on 7-year follow-up results after TIF. This study reports the quality of life of patients who participated in a randomized controlled trial comparing TIF with PPI. The aim of this study was to evaluate the impact of TIF on quality of life, regurgitation, PPI usage and the need for re-operation. Secondary outcome was to identify predictors for a successful improvement in quality of life after a TIF procedure.

After a 7-year follow up, quality of life and regurgitation were statistically significant improved compared with baseline. When compared with the results at 12-month follow-up, we did not see a further deterioration of symptoms and good symptom control remained achieved. At 12 months after the initial TIF procedure, only 2 (5\%) patients underwent re-operation, but after 7 years a total of 9 re-operations have been reported in 41 patients that have completed the follow-up (22.0\%). This is higher than the re-operation rate reported in some studies after laparoscopic anti-reflux surgery, which is between 3 and $14 \%$ after a follow-up of 5 years. ${ }^{21-23}$

Previous studies have shown that the re-operation rate after a TIF procedure is approximately $7 \% .{ }^{24-26}$ These studies only report on the short-term follow-up and in the one study that reports a long-term follow-up after TIF, only 14 patients completed the entire follow-up. They found a re-operation rate of $8.1 \%$.

In this study, we included patients who were well controlled with PPI treatment, but were unwilling to continue PPI treatment for a lifelong period. They initially did not have an indication for laparoscopic anti-reflux surgery, however, some still underwent laparoscopic anti-reflux surgery after the TIF procedure due to insufficient effect of the TIF. Quality of life and regurgitation scores after 7 years were slightly better for patients who underwent re-operation compared with patients who did not. However, we could not detect a significant difference between these groups.

Despite the re-operation rate of $22 \%$ in our study, there are still patients who benefit from TIF procedure at 7 years of follow-up. $46.9 \%$ of the 32 patients who did not undergo a re-operation reported to be satisfied with their current quality of life. These patients also had an improvement of at least $50 \%$ on the quality of life score.

A disadvantage of laparoscopic antireflux surgery may be that it can lead to severe complications, such as dysphagia, gas bloating and other postoperative complications. ${ }^{7,8}$ TIF is a safe procedure with a low complication rate and if needed even after a previous TIF procedure, laparoscopic anti-reflux surgery can be performed without increased morbidity and mortality. ${ }^{27,28}$ It can be advocated that TIF might be performed as a safe minimally invasive technique for the treatment of GERD in patients who are not willing to take lifelong medication.

Testoni et al. tried to establish predictors for successful treatment with TIF and concluded that for patients with a hiatal hernia $<2 \mathrm{~cm}$ or a Hill grade I or II TIF might be 
a therapeutic option. ${ }^{17}$ In our study, we have performed a multivariate analysis to assess predictors for a successful outcome. We defined responders, patients who have a successful symptomatic outcome, as $\geq 50 \%$ improvement of GERD-HRQL score according to a common definition from the literature. ${ }^{16,20}$ We found that the presence of a hiatal hernia of any size (all hernia's $\leq 2 \mathrm{~cm}$ ) and the presence of oesophagitis of any degree had a negative correlation with the probability of having a successful symptomatic outcome after TIF. We have also evaluated the pre-operative Hill classification as a predictor for response to TIF therapy at long-term follow-up, but this information was missing in 8 of 41 patients (19.5\%). This large number of missing data in combination with the small sample size resulted in a non-significant result in the univariate analysis $(P=0.381)$. Since the Hill classification is closely related to the size of hiatal hernia we decided to report only the presence of hiatal hernia instead of Hill classification. $^{29}$

We also performed a multivariate analysis for the effect of TIF on regurgitation, however we could not detect any significant predictor for an improvement of at least $50 \%$ in regurgitation score. A BMI $>25$ might be a potential predictor, although in our analysis no statistical significance was reached $(P=0.159)$. It has been reported that an increased BMI is a predictor for increased severity of GERD complaints. ${ }^{30-32}$ The increased intra-abdominal pressure that comes with an increased BMI might have a negative impact on the regurgitation. Also, the presence of oesophagitis could have a negative effect on controlling the regurgitation symptoms $(P=0.075$ in the univariate analysis).

In a large meta-analysis with 18 studies, the number of patients that resumed PPI usage after 12 months was $40 \%$ and $60 \%$ after 5 years. However, the results for a follow-up longer than 3 years, were based on one study only with a very small number of patients that completed the follow-up $(n=24) .{ }^{33}$ We report a similar result of $56.1 \%$ of patients that resumed using PPI's after 7 years. We found that the patients who have resumed to use PPI's, reported a significant lower GERD-HRQL score compared with patients without the usage of PPI at 7 years. This underlines the negative impact that chronic PPI usage has on the quality of life in these patients.

In our study, we have decided to evaluate the long-term results after TIF by quality of life questionnaires only.

It is proven that GERD has a negative impact on quality of life of patients. ${ }^{34} \mathrm{PH}$-metry seems unreliable in detecting recurrent GERD. Up to $16 \%$ of the patients with a positive postoperative 24-h PH monitoring seem to have negative results in the follow-up $\mathrm{PH}$ metry. Moreover, about $25 \%$ of the patients with erosive oesophagitis present with a negative 24-h PH metry. ${ }^{35}$ Furthermore, endoscopy and 24-h PH monitoring are rather invasive procedures.

A limitation of this study might be that at the 12 months follow-up the patients who were using PPI's at that moment were asked to stop using PPI's 2 weeks before completing the quality of life questionnaires. This was done according to the protocol 
of the randomized controlled trial. At 7 years of follow-up we evaluated quality of life while some patients were using PPI's, therefore the quality of life comparison might be biased. However, the quality of life evaluation at 7 years represents better the daily practice.

One cost-effectiveness study has shown that EsophyX is more expensive and less efficacious than Nissen procedure for the treatment of GERD. ${ }^{36}$ However, this study did not evaluate the costs that came with additional medication usage after the intervention, which plays a major role in the long-term. Further studies are needed to establish the cost-effectiveness of TIF in the long-term.

\section{Conclusion}

In conclusion, this is the first study reporting long-term follow-up results 7 years after TIF. In patients, who had well controlled GERD symptoms with PPI medication at the start of the study, 22\% needed additional antireflux surgery within 7 years after TIF procedure. $56.1 \%$ of the patients resumed PPI usage. Quality of life score and regurgitation score were improved compared with baseline and good symptom control remained when compared with 1 year follow-up.

TIF could be performed as a first step in the treatment of GERD when patients are not willing to take PPI's for a lifelong period or when patients are not feasible for surgery. The presence of a hiatal hernia or oesophagitis was associated with a worse GERDHRQL score after 7 years. 


\section{References}

1. Vakil N, van Zanten SV, Kahrilas P, Dent J, Jones R, Global Consensus G. The Montreal definition and classification of gastroesophageal reflux disease: a global evidence-based consensus. Am J Gastroenterol. 2006;101(8):1900-20; quiz 43.

2. Tytgat GN, McColl K, Tack J, Holtmann G, Hunt RH, Malfertheiner P, et al. New algorithm for the treatment of gastro-oesophageal reflux disease. Aliment Pharmacol Ther. 2008;27(3):249-56.

3. El-Serag HB. Time trends of gastroesophageal reflux disease: a systematic review. Clin Gastroenterol Hepatol. 2007;5(1):17-26.

4. Metz DC. Managing gastroesophageal reflux disease for the lifetime of the patient: evaluating the longterm options. Am J Med. 2004;117 Suppl 5A:49S-55S.

5. Corsonello A, Lattanzio F, Bustacchini S, Garasto S, Cozza A, Schepisi R, et al. Adverse events of proton pump inhibitors: potential mechanisms. Curr Drug Metab. 2017.

6. de la Coba Ortiz C, Arguelles Arias F, Martin de Argila de Prados C, Judez Gutierrez J, Linares Rodriguez A, Ortega Alonso A, et al. Proton-pump inhibitors adverse effects: a review of the evidence and position statement by the Sociedad Espanola de Patologia Digestiva. Rev Esp Enferm Dig. 2016; 108(4):207-24.

7. Castelijns PSS, Ponten JEH, Vd Poll MCG, Bouvy ND, Smulders JF. Quality of life after nissen fundoplication in patients with gastroesophageal reflux disease: Comparison between long- and shortterm follow-up. J Minim Access Surg. 2018;14(3):213-20.

8. van Rijn S, Rinsma NF, van Herwaarden-Lindeboom MY, Ringers J, Gooszen HG, van Rijn PJ, et al. Effect of Vagus Nerve Integrity on Short and Long-Term Efficacy of Antireflux Surgery. Am J Gastroenterol. 2016;111(4):508-15.

9. Carlson MA, Frantzides CT. Complications and results of primary minimally invasive antireflux procedures: a review of 10,735 reported cases. J Am Coll Surg. 2001;193(4):428-39.

10. Catarci M, Gentileschi P, Papi C, Carrara A, Marrese R, Gaspari AL, et al. Evidence-based appraisal of antireflux fundoplication. Ann Surg. 2004;239(3):325-37.

11. Maret-Ouda J, Wahlin K, El-Serag HB, Lagergren J. Association Between Laparoscopic Antireflux Surgery and Recurrence of Gastroesophageal Reflux. JAMA. 2017;318(10):939-46.

12. Testoni PA, Mazzoleni G, Testoni SG. Transoral incisionless fundoplication for gastro-esophageal reflux disease: Techniques and outcomes. World J Gastrointest Pharmacol Ther. 2016;7(2):179-89.

13. von Renteln D, Schiefke I, Fuchs KH, Raczynski S, Philipper M, Breithaupt W, et al. Endoscopic fullthickness plication for the treatment of gastroesophageal reflux disease using multiple Plicator implants: 12-month multicenter study results. Surg Endosc. 2009;23(8):1866-75.

14. Witteman BP, Strijkers R, de Vries E, Toemen L, Conchillo JM, Hameeteman W, et al. Transoral incisionless fundoplication for treatment of gastroesophageal reflux disease in clinical practice. Surg Endosc. 2012;26(11):3307-15.

15. Hakansson B, Montgomery M, Cadiere GB, Rajan A, Bruley des Varannes S, Lerhun M, et al. Randomised clinical trial: transoral incisionless fundoplication vs. sham intervention to control chronic GERD. Aliment Pharmacol Ther. 2015;42(11-12):1261-70.

16. Witteman BP, Conchillo JM, Rinsma NF, Betzel B, Peeters A, Koek GH, et al. Randomized controlled trial of transoral incisionless fundoplication vs. proton pump inhibitors for treatment of gastroesophageal reflux disease. Am J Gastroenterol. 2015;110(4):531-42.

17. Testoni PA, Testoni S, Mazzoleni G, Vailati C, Passaretti S. Long-term efficacy of transoral incisionless fundoplication with Esophyx (Tif 2.0) and factors affecting outcomes in GERD patients followed for up to 6 years: a prospective single-center study. Surg Endosc. 2015;29(9):2770-80.

18. Velanovich V, Vallance SR, Gusz JR, Tapia FV, Harkabus MA. Quality of life scale for gastroesophageal reflux disease. J Am Coll Surg. 1996;183(3):217-24.

19. Velanovich V. The development of the GERD-HRQL symptom severity instrument. Dis Esophagus. 2007;20(2):130-4.

20. Cadiere GB, Buset M, Muls V, Rajan A, Rosch T, Eckardt AJ, et al. Antireflux transoral incisionless fundoplication using EsophyX: 12-month results of a prospective multicenter study. World J Surg. 2008;32(8):1676-88. 
21. Draaisma WA, Rijnhart-de Jong HG, Broeders IA, Smout AJ, Furnee EJ, Gooszen HG. Five-year subjective and objective results of laparoscopic and conventional Nissen fundoplication: a randomized trial. Ann Surg. 2006;244(1):34-41.

22. Anvari M, Allen C. Five-year comprehensive outcomes evaluation in 181 patients after laparoscopic Nissen fundoplication. J Am Coll Surg. 2003;196(1):51-7; discussion 7-8; author reply 8-9.

23. Pessaux P, Arnaud JP, Delattre JF, Meyer C, Baulieux J, Mosnier H. Laparoscopic antireflux surgery: fiveyear results and beyond in 1340 patients. Arch Surg. 2005;140(10):946-51.

24. Repici A, Fumagalli U, Malesci A, Barbera R, Gambaro C, Rosati R. Endoluminal fundoplication (ELF) for GERD using EsophyX: a 12-month follow-up in a single-center experience. J Gastrointest Surg. 2010;14(1):1-6.

25. Testoni PA, Corsetti M, Di Pietro S, Castellaneta AG, Vailati C, Masci E, et al. Effect of transoral incisionless fundoplication on symptoms, PPI use, and ph-impedance refluxes of GERD patients. World J Surg. 2010;34(4):750-7.

26. Muls V, Eckardt AJ, Marchese M, Bastens B, Buset M, Deviere J, et al. Three-year results of a multicenter prospective study of transoral incisionless fundoplication. Surgical Innov. 2013;20(4): 321-30.

27. Furnee EJ, Broeders JA, Draaisma WA, Schwartz MP, Hazebroek EJ, Smout AJ, et al. Laparoscopic Nissen fundoplication after failed EsophyX fundoplication. Br J Surg. 2010;97(7):1051-5.

28. Perry KA, Linn JG, Eakin JL, Onders RP, Velanovich V, Melvin WS. Transoral incisionless fundoplication does not significantly increase morbidity of subsequent laparoscopic Nissen fundoplication. J Laparoendosc Adv Surg Techn Part A. 2013;23(5):456-8.

29. Hansdotter I, Bjor O, Andreasson A, Agreus L, Hellstrom P, Forsberg A, et al. Hill classification is superior to the axial length of a hiatal hernia for assessment of the mechanical anti-reflux barrier at the gastroesophageal junction. Endosc Int Open. 2016;4(3):E311-7.

30. Ayazi S, Hagen JA, Chan LS, DeMeester SR, Lin MW, Ayazi A, et al. Obesity and gastroesophageal reflux: quantifying the association between body mass index, esophageal acid exposure, and lower esophageal sphincter status in a large series of patients with reflux symptoms. J Gastrointest Surg. 2009;13(8):1440-7.

31. Hajar N, Castell DO, Ghomrawi H, Rackett R, Hila A. Impedance pH confirms the relationship between GERD and BMI. Dig Dis Sci. 2012;57(7):1875-9.

32. Park SK, Lee T, Yang HJ, Park JH, Sohn Cl, Ryu S, et al. Weight loss and waist reduction is associated with improvement in gastroesophageal disease reflux symptoms: A longitudinal study of 15295 subjects undergoing health checkups. Neurogastroenterol Motil. 2017;29(5).

33. Huang $\mathrm{X}$, Chen $\mathrm{S}$, Zhao $\mathrm{H}$, Zeng $\mathrm{X}$, Lian J, Tseng $\mathrm{Y}$, et al. Efficacy of transoral incisionless fundoplication (TIF) for the treatment of GERD: a systematic review with meta-analysis. Surg Endosc. 2017;31(3): 1032-44.

34. Revicki DA, Wood M, Maton PN, Sorensen S. The impact of gastroesophageal reflux disease on healthrelated quality of life. Am J Med. 1998;104(3):252-8.

35. Swidnicka-Siergiejko A, Dabrowski A. Prolonged 2-day esophageal pH-metry with impedance monitoring improves symptom-reflux association analysis. Dig Dis Sci. 2013;58(9):2556-63.

36. Funk LM, Zhang JY, Drosdeck JM, Melvin WS, Walker JP, Perry KA. Long-term cost-effectiveness of medical, endoscopic and surgical management of gastroesophageal reflux disease. Surgery. 2015;157(1):126-36. 


\section{Chapter

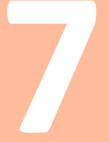

A modified technique to create a standardized floppy Nissen fundoplication without a bougie 


\section{Abstract}

\section{Introduction}

Nissen fundoplication is frequently applied in the surgical treatment of patients with gastroesophageal reflux disease (GERD). When the gastroesophageal junction remains too large or becomes too narrow persistent GERD or dysphagia may occur. To assure a correct size of the gastroesophageal junction the fundoplication can be created over a bougie. However, this increases the risk of oesophageal perforation. Therefore, we have modified a previously described technique to create a standardized fundoplication without the use of a bougie. In this paper, we describe this technique and demonstrate the initial results.

\section{Materials and methods}

We describe a technique to create a standardized Nissen fundoplication. After suture repair of the hiatal hernia, 3 marking sutures were placed on the gastric fundus, based on an equilateral triangle. The size of this triangle determines the final diameter of the fundoplication. With these measurements, we assure sufficient patency, minimize rotation and create a more reproducible fundoplication that may reduce postoperative dysphagia.

\section{Results}

We have operated 15 patients according this technique. Mean operative time was 69.5(SD 8.4) minutes, no complications occurred. There was no early dysphagia and the mean length of stay was 1.3 days. (1-2) Quality of life after 1 year was excellent.

\section{Conclusions}

This modified method for standardized Nissen fundoplication is safe and might reduce postoperative dysphagia. Quality of life after one year is excellent. The effect on postoperative dysphagia and the reproducibility of this technique should be established in a large prospective study. 


\section{Introduction}

Gastroesophageal reflux disease (GERD) is a common problem in the western world and approximately $10-28 \%$ of the europeans experience some degree of GERD. ${ }^{1}$ When conservative measures such as lifestyle interventions and proton-pump-inhibition fail, surgical fundoplication is indicated. In the year 1992, the first report on laparoscopic Nissen fundoplication was published and over the subsequent years, the laparoscopic approach has become standard treatment. ${ }^{2,3}$ For gastroesophageal reflux disease (GERD) the Nissen fundoplication is proven effective in reducing GERD related symptoms. ${ }^{4}$ However, this technique comes with different complications and side effects. Most reported complications are gas bloating and persistent dysphagia. Early dysphagia is reported up to $76 \%{ }^{5}$ and long-term dysphagia is described in approximately $8.0 \%$ of the patients. ${ }^{6,7}$ Dysphagia is a serious problem since $25 \%$ of the patients receive an endoscopic dilatation to reduce the dysphagia and even $1.8-10.8 \%$ of the patients undergo a re-operation for either recurrent reflux or persistent dysphagia. ${ }^{4}$ Different techniques have been developed over time, all with the aim to reduce postoperative dysphagia and to resolve the symptoms of GERD. A possible solution is to perform a partial-fundoplication. This technique reduces postoperative dysphagia, but seems less effective in controlling GERD related symtoms. ${ }^{8,9}$ During history some have tried to do not devide the gastric vessels, however this technique seems to result in more postoperative dysphagia. This might be due to the fact that this technique creates a fundoplication that has little rotation. ${ }^{10}$ Another technique to reduce postoperative dysphagia that is described in the literature is the use of a bougie to assure sufficient patency during the formation of the fundopication. However, the evidence is very little and there is no consensus regarding which size is best; reported bougies differ between $52 \mathrm{Fr}$ and $60 \mathrm{Fr} .{ }^{11-13}$ The use of a $56 \mathrm{Fr}$ bougie is a proven effective technique to reduce postoperative dysphagia, however application of such a large size bougie has been associated with an increased risk of oesophageal perforation. Perforation rates of $1.2 \%$ are reported; this complication may result in serious morbidity and even mortality for the patient. ${ }^{14,15}$

Therefore, we have developed a modification to the current technique for Nissen fundoplication to create a standardized and reproducible wrap without the use of a bougie. With this technique, we try to assure sufficient patency and to minimize the risk of damage to the oesophagus. This technique may minimize postoperative dysphagia. Aim of this study is to investigate whether this technique is feasible, safe and does not lead to a significant increased operating time. 


\section{Methods}

\section{Study design}

Based on previously published studies we know that an oesophagus with a $60 \mathrm{Fr}$ bougie in place has an outside diameter of approximately $2.7 \mathrm{~cm} .{ }^{16}$ For this study we used the measurements described by Reardon et al.. ${ }^{16}$ In order to create a 'floppy' fundoplication they added another $1.0 \mathrm{~cm}$ to this diameter resulting in a fundoplication with an ideal inside diameter of $3.70 \mathrm{~cm}$. According to the mathematical equation circumference $(c)=\pi^{*}$ diameter $(\mathrm{d})$, this results in a circumference of $11.6 \mathrm{~cm}$, rounded up to $12.0 \mathrm{~cm}$. (Figure 7.1.)

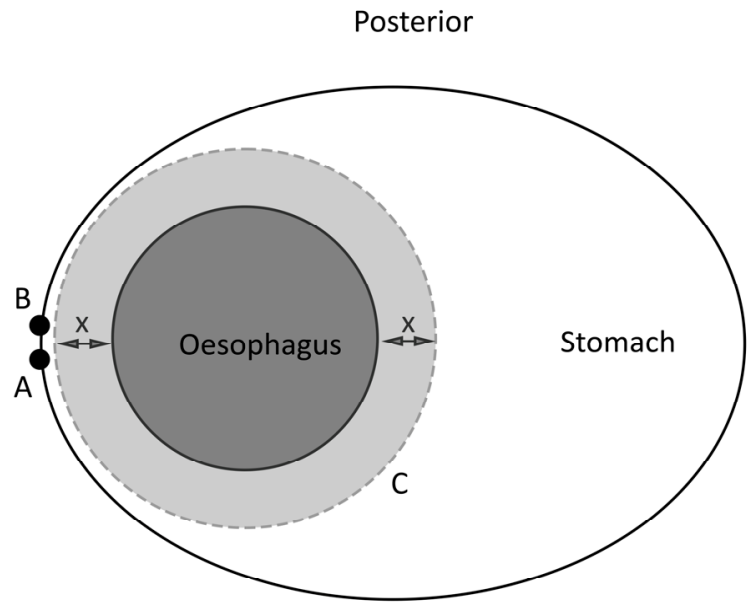

Anterior

Figure 7.1 Schematic overview of the calculated distances for the modified technique. A: point $A$, on the anterior side of the stomach wall, B: point B, on the posterior side of the stomach wall, C: circumference of fundoplication, represented by dotted line; $\mathrm{X}=$ distance between outside of oesophagus and the fundoplication, $0.5 \mathrm{~cm}$ on each side.

In order to create a fundoplication without any rotation, both point a (anterior side of the stomach) and point $b$ (posterior side of the stomach) need to be determined. The great curvature should be in the centre between these two points to prevent rotation of the fundoplication. (Figure 7.2) Measurements to locate these two points are depicted in Figure 7.3. Subsequently point $a$ and point $b$ are brought together behind the oesophagus and a 'shoeshine' movement is performed to prevent rotation of the wrap. Then the fundoplication is completed by placing 3 non-absorbable braided sutures (Ti-Cron ${ }^{\mathrm{TM}}$, Covidien, a Medtronic Company, New Haven, CT, USA). 


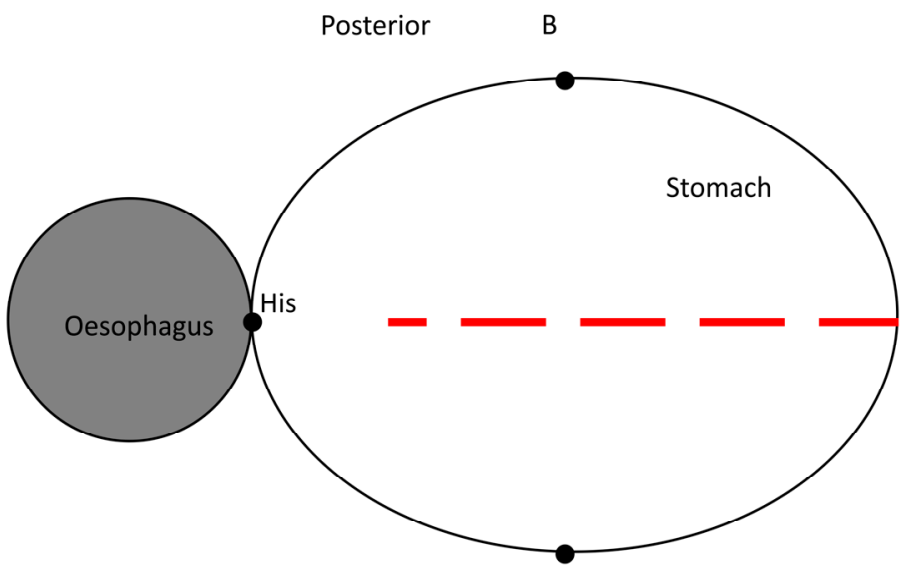

Anterior

A

Figure 7.2 Overview of both points $A$ and $B$ in relation to the short gastric vessels, demonstrating the symmetry of the fundoplication. A: point A on the stomach wall, B: point B on the stomach wall, red dotted line: the short gastric vessels, His: the angle of His, the junction between the greater curvature and the oesophagus

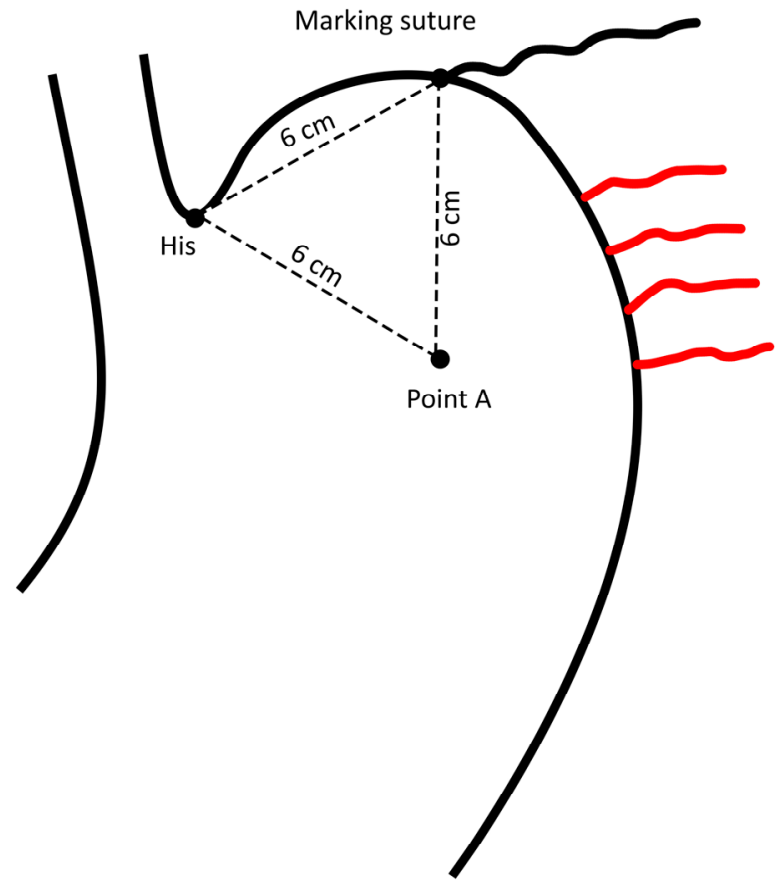

Figure 7.3 Anterior view the measurements taken during surgery. His: angle of His, A: point A on the anterior wall of the stomach, red lines: short gastric vessels 


\section{Patient selection}

For this modified technique, we retrospectively evaluated the first 15 consecutive patients that have been operated according this modified technique. All patients were diagnosed with GERD according to the SAGES guideline for GERD. Minimal age was 18 years and patients were not selected for this evaluation if they have had prior antireflux surgery.

\section{Outcome measurements}

To evaluate postoperative quality of life, all patients were sent a questionnaire by mail. Non-responders were contact up to three times by phone, to optimize response rate.

Primary outcome of this study was the safety of this procedure, and therefore the complication rate. Secondary outcomes were time of surgery, length of stay, postoperative dysphagia and short-term quality of life measured by the GERD-HRQL questionnaire.

\section{Operative technique}

The entire procedure will be performed laparoscopically, patients are in supine position with the surgeon between the legs and under general anaesthesia. Pneumoperitoneum is obtained using a Veress needle technique typically at Palmers point. Our preference, for safety reasons, is to place the first trocar under direct vision. We therefore use a $12 \mathrm{~mm}$ Visiport (Visiport ${ }^{\mathrm{TM}}$, Medtronic, North Haven, CT, USA) in the supra umbilical position. After inspection for adhesions and/or other abnormalities, two $5 \mathrm{~mm}$ trocars and one $8 \mathrm{~mm}$ trocars are inserted. Then the liver retractor placed in position to create enough space to perform the procedure.

The procedure starts with opening the lesser omentum and phrenoesophageal ligament, followed by dissection of the right and left limbs of the crus of the diaphragm. Then the short gastric vessels will be divided using an ultrasonic device. (Harmonic ace $^{\circledR}$, Ethicon, US)

The next step is to create a window behind the oesophagus and encircle the oesophagus with a silicon tube to retract the oesophagus without damage. At least $3 \mathrm{~cm}$ of the oesophagus is dissected and has to lay tension-free in the abdomen. The hernia sec is brought back into the abdomen and If a hiatal hernia is present, this is narrowed with braided sutures (Ti-Cron ${ }^{\mathrm{TM}}$, Covidien, a Medtronic Company, New Haven, CT, USA)

We pursue patency for a 10-mm instrument to pass besides the oesophagus. If a large hiatal hernia is present or in case of weakness of the crus, the cruroplasty is reinforced with a synthetic non-absorbable mesh. (Parietex ${ }^{\mathrm{TM}}$ Composite Mesh Hiatal, Sofradim, a Medtronic Company, Trevoux, France)

A large hiatal hernia is defined as migration of $>50 \%$ of the stomach into the thorax. ${ }^{17}$ 
We now measure $6 \mathrm{~cm}$ from the angle of His along the great curvature using the grasper, which has a length of $2.5 \mathrm{~cm}$, and place a marking suture. From this point, we will create an equilateral triangle with sides of $6 \mathrm{~cm}$. (Figure 7.2) We place a second marking suture on the anterior side of the stomach. The next step is to flip the stomach anteriorly and perform the same manoeuvre on the posterior side of the stomach and place a third marking suture. All marking sutures are braided absorbable sutures. (Polysorb $^{\mathrm{TM}}$, Covidien, a Medtronic Company, New Haven, CT, USA) In order to facilitate the mobilization of the stomach, the suture at the posterior side is kept a little longer. Then the silicone is removed and with a grasper the posterior suture is grabbed behind the oesophagus. A "shoeshine" movement is performed to make sure that there is no rotation. The surgeon brings the posterior suture together with the anterior suture and the assistant holds them in place. Then the procedure will be completed by placing 3 braided sutures (Ti-Cron ${ }^{\mathrm{TM}}$, Covidien, a Medtronic Company, New Haven, CT, USA) to fixate the fundoplication. The most distal suture is attached to the oesophagus to prevent telescoping. A video of the complete procedure can be found in the supplemental data of this article. (https://tinyurl.com/modified-nissen)

\section{Ethics}

Since it concerns the routine implementation of a modification of a previously described technique that is now routinely applied in our institution, informed consent was waived.

\section{Results}

\section{Patient characteristics}

A total of 15 patients were operated according this technique between March 2015 and January 2016. Mean age during surgery was 53.4(SD 11.8) years, $9(60 \%)$ of the patients were male and the mean BMI was 26.5 (SD 3.7). 93.3\% of the operated patients experienced pre-operative heartburn, $26.7 \%$ of the patients experienced regurgitation and dysphagia was present in $20 \%$ of the patients. A complete overview of the baseline characteristics for all patients is presented in Table 7.1.

All patients were diagnosed according to the SAGES guideline for GERD. An overview of the pre-operative work-up is demonstrated in Table 7.2.

\section{Operative results}

All patients underwent a primary laparoscopic Nissen fundoplication. Mean operative time was 69.5 (SD 8.4) minutes. We experienced no operative complications and there 
were no conversions to an open procedure. There were no re-operations during followup. Details regarding the procedures are summarized in Table 7.3.

Table 7.1 Demographic and clinical data of the modified Nissen fundoplication

\begin{tabular}{|c|c|c|}
\hline & & $\mathrm{MNF}^{\mathrm{a}}$ \\
\hline \multicolumn{2}{|l|}{ Number of patients } & 15 \\
\hline \multicolumn{2}{|l|}{ Response rate } & $9 / 15(60 \%)$ \\
\hline \multicolumn{2}{|l|}{ Sex } & $9 \mathrm{M} / 6 \mathrm{~F}$ \\
\hline \multicolumn{2}{|l|}{ Mean age $\left(\right.$ Years, $\left.S D^{\mathrm{b}}\right)$} & $53.4(11.8)$ \\
\hline \multicolumn{2}{|l|}{ Mean Body Mass Index (SD), $\mathrm{Kg} / \mathrm{m}^{2}$} & $26.5(3.7)$ \\
\hline \multirow[t]{3}{*}{ ASA $^{\mathrm{c}}$} & ASA $1, \mathrm{n}(\%)$ & $5(33.3 \%)$ \\
\hline & ASA 2, n (\%) & $10(66.7 \%)$ \\
\hline & ASA 3, n (\%) & $0(0 \%)$ \\
\hline \multirow[t]{9}{*}{ Pre-operative symptoms } & Heartburn & $14 / 15(93.3 \%)$ \\
\hline & Regurgitation & $4 / 15(26.7 \%)$ \\
\hline & Chest pain & $2 / 15(13.3 \%)$ \\
\hline & Nausea & $1 / 15(6.7 \%)$ \\
\hline & Vomiting & $0 / 15(0.0 \%)$ \\
\hline & Ructus & $2 / 15(13.3 \%)$ \\
\hline & Gastric asthma & $3 / 15(20.0 \%)$ \\
\hline & Abdominal pain & $2 / 15(13.3 \%)$ \\
\hline & Dysphagia & $3 / 15(20 \%)$ \\
\hline \multirow[t]{2}{*}{ PPI } & yes & $15 / 15(100 \%)$ \\
\hline & no & $0 / 15(0.0 \%)$ \\
\hline
\end{tabular}

Table 7.2 Pre-operative work-up of all patients that underwent the modified Nissen fundoplication

$\begin{array}{lll}\text { Study } & & \mathrm{n} / \mathrm{N}(\%) \\ \text { Endoscopy } & \text { None } & 0 / 15(0.0 \%) \\ \text { Oesophagitis } & \text { Performed } & 15 / 15(100 \%) \\ & \text { Grade A } & 2 / 15(13.3 \%) \\ & \text { Grade B } & 3 / 15(20.0 \%) \\ & \text { Grade C } & 1 / 15(6.7 \%) \\ \text { Banometry } & \text { Barret } & 3 / 15(20.0 \%) \\ \text { Barium swallow } & \text { None } & 7 / 15(46.7 \%) \\ & \text { Normal } & 7 / 15(46.7 \%) \\ \text { 24-h PH-study } & \text { None } & 8 / 15(53.3 \%) \\ & \text { Sliding hernia with reflux } & 13 / 15(86.7 \%) \\ & \text { Sliding hernia without reflux } & 1 / 15(6.7 \%) \\ & \text { None } & 1 / 15(6.7 \%) \\ & \text { Normal } & 4 / 15(26.7 \%) \\ & \text { Pathologic reflux } & 0 / 15(0.0 \%) \\ & \text { Mean DeMeester Score (Range) } & 11 / 15(73.3 \%) \\ \end{array}$




\section{Postoperative results}

Postoperative stay at the hospital was one or two days. No postoperative complications were seen and only one patient was re-admitted within the first 30 days. The reason for re-admission was general illness with fever. This appeared to be due to a urinary tract infection. The patient was treated with antibiotics and the patient was discharged after 3 days.

Table 7.3 Operative outcome after 1 year for patients that underwent the modified Nissen fundoplication

\begin{tabular}{|c|c|c|}
\hline Outcome measurement & & $\mathrm{n} / \mathrm{N}(\%)$ \\
\hline Mean operative time (minutes; SD) & & $69.5(8.4)$ \\
\hline \multirow[t]{2}{*}{ Operative technique } & Laparoscopic & $15 / 15(100 \%)$ \\
\hline & Open & $0 / 15(0.0 \%)$ \\
\hline \multirow[t]{2}{*}{ Hiatal hernia } & Type 1 & $9 / 15(60.0 \%)$ \\
\hline & None & $6 / 15(40.0 \%)$ \\
\hline \multirow[t]{2}{*}{ Hiatal hernia repair } & Suture & $15 / 15(100 \%)$ \\
\hline & Mesh & $0 / 15(0.0 \%)$ \\
\hline \multirow[t]{3}{*}{ Number of Sutures used } & 1 & $1 / 15(6.7 \%)$ \\
\hline & 2 & $10 / 15(66.7 \%)$ \\
\hline & 3 & $4 / 15(26.7 \%)$ \\
\hline Operative Complications & & $0 / 15(0.0 \%)$ \\
\hline Conversion & & $0 / 15(0.0 \%)$ \\
\hline Mean $\operatorname{LOS}^{\mathrm{b}}$ (range) & & $1.3(1-2)$ \\
\hline Postoperative complications & & $0 / 15(0.0 \%)$ \\
\hline 30-day mortality & & $0 / 15(0.0 \%)$ \\
\hline Re-admission within 30 days & & $1 / 15(6.7 \%)$ \\
\hline
\end{tabular}

\section{Quality of life}

A total of 9 patients $(60 \%)$ returned the quality of life questionnaire. This resulted in a median quality of life after one year of 69 out of a maximum score of 75. (Range 36-75) The median heartburn score was 30 , with a maximum score of 30 . Postoperative PPI usage was $44.4 \%$.

\section{Discussion}

In this paper, we present a modified technique to create a floppy Nissen fundoplication without the use of a bougie. The aim of this modification is to create a standardized and reproducible fundoplication without the risks that come with the use of a bougie and that is better teachable to surgeons in training. Theoretically, this technique might reduce postoperative dysphagia without increasing the rate of recurrent heartburn compared with the standard technique. 
Based on current literature we have found an incidence of early dysphagia up to $76 \%{ }^{5} \mathrm{~A}$ retrospective study performed by Lamb et al. investigates the results of revision surgery after prior anti-reflux surgery for GERD. ${ }^{18}$ This study demonstrates that persistent dysphagia is the most reported indication for revision surgery. (52\%) We also know from previous literature that patients who experience postoperative dysphagia report suboptimal outcomes after revision surgery. ${ }^{19-21}$ It is therefore important to reduce the risk of postoperative dysphagia and minimize the chance for revision surgery.

Our hypothesis is that postoperative dysphagia may be, among other causes, the result of both a too tight fundoplication and some sort of rotation in the wrap. A too tight wrap as a cause of postoperative dysphagia has been investigated previously. ${ }^{22}$ However, there is no consensus regarding the ideal diameter of the fundoplication and it is hard to feel the correct tightness of the wrap. Some authors therefore advocate the use of a bougie to assure sufficient patency. ${ }^{11,12}$ Nevertheless, different bougie sizes have been used varying between 52 and 60Fr, but the optimal size has yet to be found. The positive effect of a bougie on postoperative dysphagia was already demonstrated by DeMeester et al in $1986 .{ }^{23}$ This study showed a significant decrease in postoperative dysphagia for a $60 \mathrm{Fr}$ bougie compared with a 36Fr bougie, especially in the first three postoperative months. The use of a bougie comes, however, with the severe risk of oesophageal perforation, which comes with serious morbidity and even mortality. ${ }^{15}$ Despite these possible serious complications, an anonymous survey performed in 2005 by Huttl et al in Germany, showed that still $46 \%$ of the surgeons still routinely used a bougie during laparoscopic Nissen fundoplication at that time. ${ }^{24} \mathrm{~A}$ possible explanation might be that it is difficult, especially for the beginning surgeon, to create a proper fundoplication with a correct diameter. This hypothesis is supported by historical studies, that demonstrates a learning curve of approximately 25 procedures per surgeon. ${ }^{25-27}$ These studies also show a prior complication rate of $24-55 \%$ which decreases to approximately $10 \%$ when more experience is obtained. By this modified technique, we aim to aid surgeons who start performing laparoscopic Nissen fundoplication, to create a standard fundoplication which ensures sufficient patency. Further research is needed to investigate whether this technique indeed reduces the learning curve and reduces long-term dysphagia.

According to previously published literature, we believe that a common error made by surgeons is to create an asymmetrical fundoplication, resulting in a 'twist' in the fundoplication. ${ }^{16,28}$ With the above-mentioned technique we assured that the fundoplication that is created, is as symmetrical as possible. This leads to a reduced risk of shifting the line of the greater curvature to either anteriorly or posteriorly. (Figure 7.2.)

In this report, we demonstrate the first 15 patients that have been operated according to this modified technique. We are aware of the fact that this is a very small group and follow-up is short and only $60 \%$ returned the quality of life questionnaire. However, we did not see any perioperative complications, only one patient was admitted for an 
urinary tract infection on the third postoperative day. This is a minor complication and in our opinion not related to the modified technique.

Since the measurement of the exact points $a$ and $b$ does take some extra time, we compared the operative time with our retrospective cohort of the past 10 years. The mean operative time in this cohort was 78.8 (SD 39.2), ${ }^{29}$ where the mean operative time for this modified technique was 69.5 (SD 8.4) minutes. $(P=0.752)$ There is no statistically significant difference between both techniques in operating time. However, we do expect that especially beginning surgeons will benefit from this modified technique, which might even result in an even faster operating time. This hypothesis will be subject of further research.

\section{Conclusion}

The size of the gastric wrap, created during a Nissen fundoplication can be standardized using an atraumatic and minimal invasive approach. This modified technique is safe and leads to good results direct postoperatively and at 1 year follow up. The possible advantage regarding reproducibility, reduced learning curve and less postoperative dysphagia has yet to be established is further studies. 


\section{References}

1. El-Serag HB, Sweet S, Winchester CC, Dent J Update on the epidemiology of gastro-oesophageal reflux disease: a systematic review. Gut 2014:63:871-80.

2. Watson DI Evolution and development of surgery for large paraesophageal hiatus hernia. World J Surg 2011:35:1436-41.

3. Cuschieri A, Shimi S, Nathanson LK Laparoscopic reduction, crural repair, and fundoplication of large hiatal hernia. Am J Surg 1992:163:425-30.

4. Stefanidis D, Hope WW, Kohn GP, Reardon PR, Richardson WS, et al. Guidelines for surgical treatment of gastroesophageal reflux disease. Surg Endosc 2010:24:2647-69.

5. Balci D, Turkcapar AG Assessment of quality of life after laparoscopic Nissen fundoplication in patients with gastroesophageal reflux disease. World J Surg 2007:31:116-21.

6. Pessaux P, Arnaud JP, Delattre JF, Meyer C, Baulieux J, et al. Laparoscopic antireflux surgery: five-year results and beyond in 1340 patients. Arch Surg 2005:140:946-51.

7. Triponez F, Dumonceau JM, Azagury D, Volonte F, Slim K, et al. Reflux, dysphagia, and gas bloat after laparoscopic fundoplication in patients with incidentally discovered hiatal hernia and in a control group. Surgery 2005:137:235-42.

8. Ma S, Qian B, Shang L, Shi R, Zhang G A meta-analysis comparing laparoscopic partial versus Nissen fundoplication. ANZ J Surg 2012:82:17-22.

9. Sgromo B, Irvine LA, Cuschieri A, Shimi SM Long-term comparative outcome between laparoscopic total Nissen and Toupet fundoplication: Symptomatic relief, patient satisfaction and quality of life. Surg Endosc 2008:22:1048-53.

10. Leggett PL, Bissell CD, Churchman-Winn R, Ahn C A comparison of laparoscopic Nissen fundoplication and Rossetti's modification in 239 patients. Surg Endosc 2000:14:473-7.

11. Allaix ME, Herbella FA, Patti MG Laparoscopic total fundoplication for gastroesophageal reflux disease. How I do it. J Gastrointest Surg 2013:17:822-8.

12. Auyang ED, Pellegrini CA How I do it: laparoscopic paraesophageal hernia repair. J Gastrointest Surg 2012:16:1406-11.

13. Davis RE, Awad ZT, Filipi CJ Technical factors in the creation of a "floppy" Nissen fundoplication. Am J Surg 2004:187:724-7.

14. Patterson EJ, Herron DM, Hansen PD, Ramzi N, Standage BA, et al. Effect of an esophageal bougie on the incidence of dysphagia following nissen fundoplication: a prospective, blinded, randomized clinical trial. Arch Surg 2000:135:1055-61.

15. Lowham AS, Filipi CJ, Hinder RA, Swanstrom LL, Stalter K, et al. Mechanisms and avoidance of esophageal perforation by anesthesia personnel during laparoscopic foregut surgery. Surg Endosc 1996:10:979-82.

16. Reardon PR, Matthews BD, Scarborough TK, Preciado A, Marti JL, et al. Geometry and reproducibility in 360 degrees fundoplication. Surg Endosc 2000:14:750-4.

17. Peters JH SAGES guidelines for the management of hiatal hernia. Surg Endosc 2013:27:4407-8.

18. Lamb PJ, Myers JC, Jamieson GG, Thompson SK, Devitt PG, et al. Long-term outcomes of revisional surgery following laparoscopic fundoplication. Br J Surg 2009:96:391-7.

19. Iqbal A, Awad Z, Simkins J, Shah R, Haider M, et al. Repair of 104 failed anti-reflux operations. Ann Surg 2006:244:42-51.

20. Smith CD, McClusky DA, Rajad MA, Lederman AB, Hunter JG When fundoplication fails: redo? Ann Surg 2005:241:861-9.

21. Safranek PM, Gifford CJ, Booth MI, Dehn TC Results of laparoscopic reoperation for failed antireflux surgery: does the indication for redo surgery affect the outcome? Dis Esophagus 2007:20:341-5.

22. Bais JE, Bartelsman JF, Bonjer HJ, Cuesta MA, Go PM, et al. Laparoscopic or conventional Nissen fundoplication for gastro-oesophageal reflux disease: randomised clinical trial. The Netherlands Antireflux Surgery Study Group. Lancet 2000:355:170-4.

23. DeMeester TR, Bonavina L, Albertucci M Nissen fundoplication for gastroesophageal reflux disease. Evaluation of primary repair in 100 consecutive patients. Ann Surg 1986:204:9-20. 
24. Huttl TP, Hohle M, Wichmann MW, Jauch KW, Meyer G Techniques and results of laparoscopic antireflux surgery in Germany. Surg Endosc 2005:19:1579-87.

25. Salminen $\mathrm{P}$, Hiekkanen $\mathrm{H}$, Laine $\mathrm{S}$, Ovaska J Surgeons' experience with laparoscopic fundoplication after the early personal experience: does it have an impact on the outcome? Surg Endosc 2007:21:1377-82.

26. Watson DI, Baigrie RJ, Jamieson GG A learning curve for laparoscopic fundoplication. Definable, avoidable, or a waste of time? Ann Surg 1996:224:198-203.

27. Soot SJ, Eshraghi N, Farahmand M, Sheppard BC, Deveney CW Transition from open to laparoscopic fundoplication: the learning curve. Arch Surg 1999:134:278-81.

28. Peters JH, DeMeester TR, Crookes $P$, Oberg S, de Vos Shoop M, et al. The treatment of gastroesophageal reflux disease with laparoscopic Nissen fundoplication: prospective evaluation of 100 patients with "typical" symptoms. Ann Surg 1998:228:40-50.

29. Castelijns PSS, Ponten JEH, Vd Poll MCG, Bouvy ND, Smulders JF Quality of life after nissen fundoplication in patients with gastroesophageal reflux disease: Comparison between long- and shortterm follow-up. J Minim Access Surg. 2018;14(3):213-20. 



\section{Chapter}

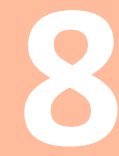

Standardized method for Nissen fundoplication: reproducibility and effect on learning curve

P.S.S. Castelijns M.C.G. van de Poll

B.P.A. de Greef N.D. Bouvy

J.F. Smulders 


\title{
Abstract
}

\begin{abstract}
Aims
Laparoscopic anti-reflux surgery requires advanced laparoscopic skills and is associated with a substantial learning curve leading to a large variability of the size and form of the fundoplication in inexperienced hands. We have developed a modified technique to create a standardized floppy Nissen fundoplication without the use of a bougie. The aim of this study was to determine the effect of this modified technique on the variability of fundoplication in a standardized ex-vivo model.
\end{abstract}

\section{Methods}

In an ex-vivo set-up, a laparoscopic fundoplication was performed in 20 porcine stomachs using a 2 -by-2 factorial design. Fundoplications were performed by either a $5^{\text {th }}$ year surgical resident or an experienced anti-reflux surgeon using a conventional or modified technique. Measurements regarding time, size, symmetry and reproducibility of the fundoplication were evaluated.

\section{Results}

Using the modified technique symmetry of the fundoplication increased whereas variability between different fundoplications decreased significantly. This effect was seen in both experienced as well as inexperienced operators. The positive effect of the modified technique on symmetry was more profound in the inexperienced operator. Symmetry of fundoplications created with the modified technique was comparable between both operators.

\section{Conclusions}

This modified technique is better reproducible than the standard technique for Nissen fundoplication and leads to a more symmetrical and more standardized wrap. It may facilitate both beginning and experienced surgeons to create a standardized fundoplication and may reduce the learning curve in anti-reflux surgery. 


\section{Introduction}

Laparoscopic Nissen fundoplication has been described for the first time in 1992 by Cushieri et al. ${ }^{1}$ Despite the broad experience with this technique, there is still a learning curve associated with this advanced laparoscopic technique. Watson et al described their experience of 280 fundoplications in 1996 and concluded that the risk of adverse outcomes did not stabilize until 20 procedures for each surgeon and even 50 procedures per institution was achieved. ${ }^{2}$ Another study in 1999 evaluated the laparoscopic learning curve for surgeons experienced in open Nissen fundoplication, but still the learning curve is approximately 20 procedures and even after 100 procedures there is still improvement in operation time, conversion rate and intraoperative complication rate. ${ }^{3}$ In 2005 , a similar result has been described. This study presents a re-operation rate for dysphagia of $22 \%$ in the early experience with laparoscopic anti-reflux surgery compared with $4 \%$ for the more experienced surgeon. ${ }^{4}$ Even in the current era, where laparoscopic surgery is gold standard for most treatments, the institutional experience in laparoscopic hiatal hernia repair of $<10$ procedures per year remains an independent risk factor for recurrence. ${ }^{5}$ Even if a resident is supervised by an experienced surgeon, the outcomes after anti-reflux surgery are slightly less. ${ }^{6}$ Several other studies report on the large learning curve of laparoscopic Nissen fundoplication. ${ }^{7-9}$

Dysphagia remains a serious complication of Nissen fundoplication and early dysphagia up to $76 \%$ has been reported, and even long-term dysphagia is present in $8.0 \%$ of the patients. ${ }^{10-12}$ Vagal nerve injury leads to delayed gastric emptying, which is closely related to the feeling of dysphagia. Also several technical aspects are of great importance in reducing dysphagia. ${ }^{13}$ In the history of anti-reflux surgery several techniques have been proposed, including partial fundoplications. Especially the early postoperative dysphagia is significantly less after partial fundoplication compared with Nissen fundoplication. ${ }^{14}$ Preservation of the gastric vessels has been attempted to reduce postoperative dysphagia, however in fact this has led to an increase of this complication. Possibly due to forced rotation of the fundoplication. ${ }^{15}$ This emphasizes the importance of the construction of an adequate and symmetric fundoplication.

To reduce the risk of postoperative dysphagia we have developed a technique to create a standardized floppy fundoplication with minimal rotation. Clinical results of this technique have been described earlier in detail. ${ }^{16}$ It is unknown whether this technique is indeed better reproducible, teachable and leads to a more standard fundoplication with sufficient patency. Furthermore, this technique may reduce the learning curve for laparoscopic Nissen fundoplication. The primary aim of this study was to investigate the reproducibility of this modified technique compared with the conventional method. Secondary outcome measure is the difference between an experienced surgeon and a resident in performing this technique. 


\section{Methods}

\section{Experimental setup}

For this study, we have created an ex-vivo laparoscopic set-up box. We used the stomach and esophagus of cadaver pigs obtained from the local abattoir. All procedures were recorded on video and analyzed afterwards. We only studied the creation of the fundoplication, the laparoscopic introduction, mobilization of the stomach, dissecting the gastric vessels and/or the hiatal hernia repair are not subject of this study.

\section{Conventional technique}

The conventional technique starts with grasping the fundus behind the gastroesophageal junction and performing the "shoe-shine maneuver" i.e. the tension free movement of the fundus dorsal of the esophageal-cardiac junction. Then the fundus is plicated around the esophagus and sutured to the anterior gastric wall with three sutures. These sutures are placed at a location that is deemed appropriate by the operating surgeon. In general, no Bougie is used in this method.

\section{Modified technique}

For the modified technique, a marking suture is placed at the greater curvature. Hereafter, 2 sutures are places at the anterior and posterior wall of the stomach, with $12 \mathrm{~cm}$ in between the sutures. Distances are measured using the laparoscopic grasper, which has a width of $2.5 \mathrm{~cm}$. Than the anterior and posterior marking sutures are brought together, a shoe-shine maneuver is performed and the fundoplication completed by placing 3 sutures. This modified technique is described in detail in a previous publication. ${ }^{16}$ The measurements that are needed to perform the modified technique are demonstrated in Figure 8.1.

\section{Experimental procedures}

The studies were performed using a 2-by-2 factorial design. Ten fundoplications were performed by an experienced anti-reflux with over 300 laparoscopic Nissen fundoplications and at least 50 procedures in the last year (JS) and 10 by a $5^{\text {th }}$ year resident (JP) with general experience in laparoscopic surgery. Both of them performed 5 fundoplications according the conventional method and 5 fundoplications according the modified technique.

Afterwards the fundoplication was dismantled by the principal investigator (PC) and several distances, including the circumference of the fundoplication, was measured. 
(Figure 8.1) All procedures were recorded digitally and pictures were taken from each dismantled fundoplication.

Conventional technique

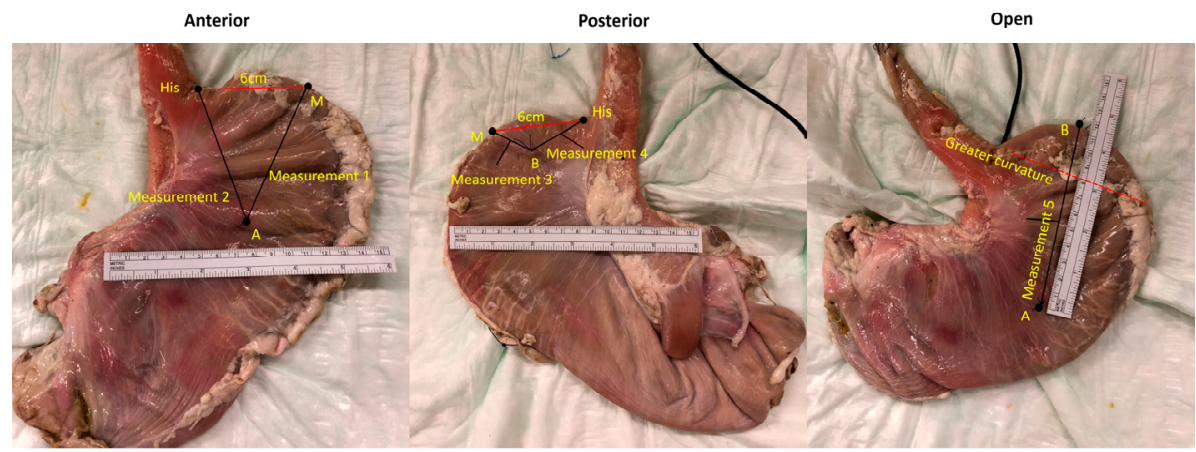

Modified technique

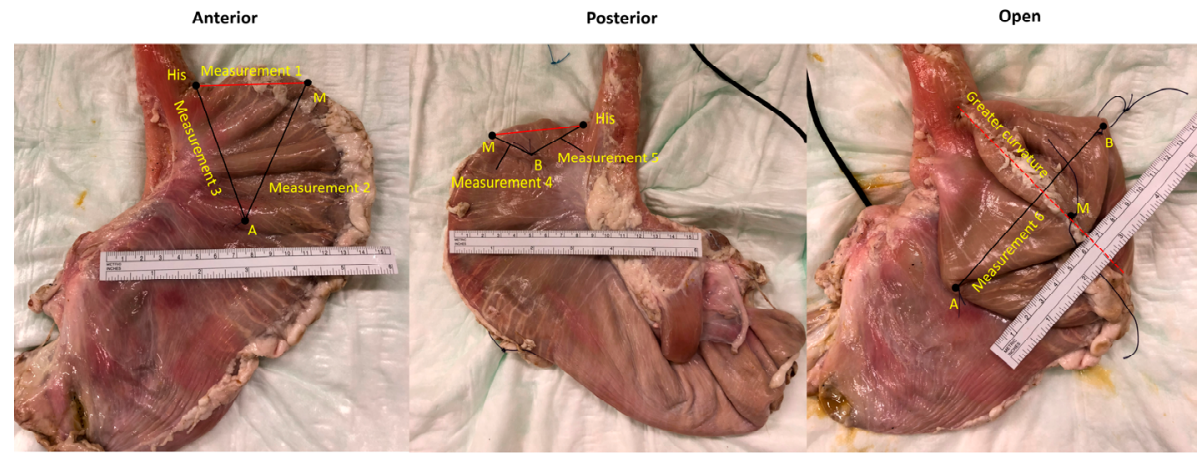

Figure 8.1 Measurements taken in both the conventional technique and the modified technique. A: Point a, anterior side of stomach, B: Point B, posterior side of stomach, M: point on greater curvature

\section{Measurements}

All measurements were performed with a standard ruler and distances were rounded up to 1 decimal. For the comparison of reproducibility, we calculated the average distance for each measurement. Then for each fundoplication the deviation towards this average is expressed as a percentage of the average. Figure 8.2 demonstrates an example of this calculation. We chose this method since the impact of a deviation becomes less when the distance becomes greater. To determine the symmetry of the fundoplication, we calculated the difference between 'the distance of the anterior point to the midline' and 'the distance of the posterior point to the midline'. When 
perfectly symmetrical, these distances should be equal and therefore the difference should be zero.

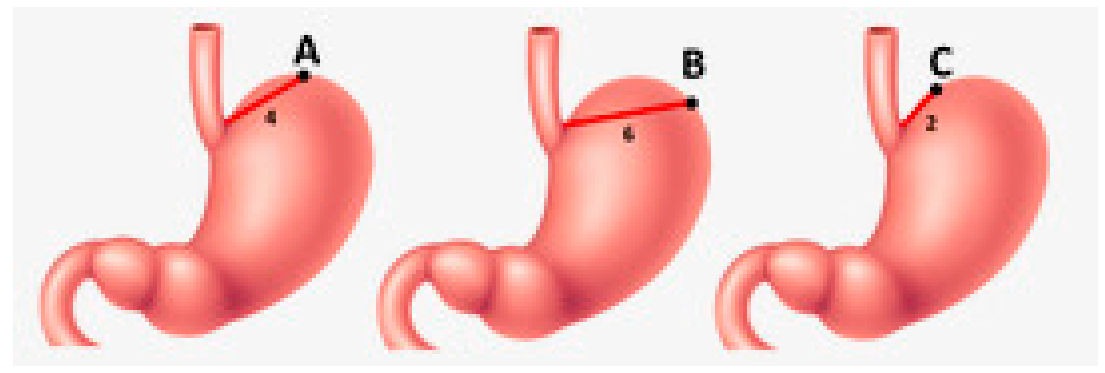

Figure 8.2 Example of calculation the variation in fundoplication. The average distance of His to point $A, B$ or $C$ is $(4+6+2) / 3=4$. To calculate deviation of point $B$ we calculate the difference with the average, which leads to $6-4=2$. This deviation is expressed as a percentage of the average, thus $2 / 4 * 100 \%=50 \%$ deviation

\section{Statistical analysis}

Since this is a 2x2 factorial design we performed a 2-way ANOVA. Metric variables with normal distribution (tested by Shapiro-Wilk statistic) were univariatly presented by their means and standard deviation (SD) and if not normally distributed the median and range were used. For sake of clarity, we chose to present all data in the $2 \times 2$ factorial design as median with range. A $P$ value of $<0.05$ was considered statistically significant. All analyses were performed with SPSS-pc, version 21.0 (IBM, Armonk, NY)

\section{Ethics}

Since the studies were performed using offal from commercial meat industry, no permission was required from the in ethical committee on animal experiments.

\section{Results}

Both surgeons performed each 10 fundoplications, from which 5 according the conventional technique and 5 according the modified technique. The median operative time was 5.9 (range 4.6-7.6) minutes for the conventional technique compared with 14.8 (11.5-19.4) minutes for the modified technique. $(P<0.05)$ When the operating times of the surgeon are compared with the resident, no significant difference is found in operating time. $(P=0.402)$ 


\section{Reproducibility}

When the deviation of all measurements is combined, this leads to an overall variation in technique. We found that there is a $14.4 \%$ (range 6.8-53.2) variation for the conventional technique, compared with a variation of $8.7 \%$ (range 3.9-16.7) for the modified technique. $(P=0.087)$ Approximately the same variation is found for resident and surgeon individually, however, this difference was not statistically significant. We found a median variation in total diameter of the fundoplication of $5.5 \%$ compared with $4.9 \%$, which was not statistically significant. $(P=0.764)$ When the variation of the individual distances was analyzed, we did not find a significant difference. However, when analyzed for surgeon and resident individually, we found in improvement in variation in determining the posterior point. ( $P=0.009$ and $P=0.049$ respectively) Data regarding reproducibility is summarized in Table 8.1 .

Table 8.1 Comparison between modified and original technique: Reproducibility

\begin{tabular}{|c|c|c|c|c|c|c|c|}
\hline & $\begin{array}{l}\text { Resident } \\
(n=10)\end{array}$ & $\begin{array}{l}\text { Surgeon } \\
(n=10)\end{array}$ & P-value* & $\begin{array}{l}\text { Conventional } \\
\qquad(n=10)\end{array}$ & $\begin{array}{l}\text { Modified } \\
\quad(n=10)\end{array}$ & $P$-value* & $\begin{array}{c}\text { Interaction } \\
P \text {-value* }\end{array}$ \\
\hline $\begin{array}{l}\text { Median operating time, } \\
\text { min (range) }\end{array}$ & $\begin{array}{c}9.4 \\
(4.7-16.2)\end{array}$ & $\begin{array}{c}10.2 \\
(4.6-19.4)\end{array}$ & 0.402 & $\begin{array}{c}5.9 \\
(4.6-7.6)\end{array}$ & $\begin{array}{c}14.8 \\
(11.5-19.4)\end{array}$ & 0.000 & 0.265 \\
\hline $\begin{array}{l}\text { Median variation in } \\
\text { distances compared with } \\
\text { own average, \% (range) }\end{array}$ & $\begin{array}{c}11.5 \% \\
(7.1-53.2)\end{array}$ & $\begin{array}{c}10.8 \% \\
(3.9-15.4)\end{array}$ & 0.227 & $\begin{array}{c}14.4 \% \\
(6.8-53.2)\end{array}$ & $\begin{array}{c}8.7 \% \\
(3.9-16.7)\end{array}$ & 0.087 & 0.426 \\
\hline $\begin{array}{l}\text { Median variation in total } \\
\text { diameter of } \\
\text { fundoplication, \% (range) }\end{array}$ & $\begin{array}{c}7.9 \% \\
(1.0-22.4)\end{array}$ & $\begin{array}{c}3.1 \% \\
(0-14.3)\end{array}$ & 0.170 & $\begin{array}{c}5.5 \% \\
(0.0-22.4)\end{array}$ & $\begin{array}{c}4.9 \\
(1.0-16.3)\end{array}$ & 0.764 & 0.838 \\
\hline $\begin{array}{l}\text { Median variation in } \\
\text { position of posterior } \\
\text { point, } \% \text { (range) }\end{array}$ & $\begin{array}{c}15.7 \% \\
(3.6-214.3)\end{array}$ & $\begin{array}{c}9.7 \% \\
(4.0-28.0)\end{array}$ & 0.270 & $\begin{array}{c}22.8 \% \\
(5.9-214.3)\end{array}$ & $\begin{array}{c}7.1 \% \\
(3.6-12.9)\end{array}$ & 0.111 & 0.295 \\
\hline
\end{tabular}

\section{Standardization}

Another outcome of this study was the standardization of the technique. When the total diameter of the fundoplication was measured, we found a median diameter of $10.0 \mathrm{~cm}$ (range 8.4-12.2) for the conventional technique compared with a diameter of $9.8 \mathrm{~cm}(8.6-11.7)$ for the modified technique. $(P=0.610)$ The calculated diameter is defined as the sum of the distance from the anterior point to the midline and the distance from the posterior point to the midline. We found no difference in calculated diameter between both techniques. $(P=0.138)$. When the median measured diameter of the modified technique $(9.8 \mathrm{~cm})$ is compared with the calculated diameter $(10.4 \mathrm{~cm})$, we found no statically significant discrepancy. $(P=0.057)$ We also analyzed the degree of symmetry of both techniques, and found that the symmetry improved from median 4.7 $\mathrm{cm}$ (range 1.7-7.6) to $0.6 \mathrm{~cm}(0.1-1.2)$. $(P=0.047)$ No difference was found between the resident and surgeon. All data regarding the standardization is summarized in Table 8.2. 
Table 8.2 Comparison between modified and original technique: Standardization

\begin{tabular}{|c|c|c|c|c|c|c|c|}
\hline & $\begin{array}{l}\text { Resident } \\
(n=10)\end{array}$ & $\begin{array}{l}\text { Surgeon } \\
(n=10)\end{array}$ & $P$-value* & $\begin{array}{l}\text { Conventional } \\
\qquad(n=10)\end{array}$ & $\begin{array}{l}\text { Modified } \\
(n=10)\end{array}$ & $P$-value* & $\begin{array}{c}\text { Interaction } \\
P \text {-value* }\end{array}$ \\
\hline $\begin{array}{l}\text { Measured diameter of } \\
\text { fundoplication (median } \\
\mathrm{cm} \text {; range) }\end{array}$ & $\begin{array}{c}10.2 \\
(8.5-12.2)\end{array}$ & $\begin{array}{c}9.8 \\
(8.4-10.4)\end{array}$ & 0.212 & $\begin{array}{c}10.0 \\
(8.4-12.2)\end{array}$ & $\begin{array}{c}9.8 \\
(8.6-11.7)\end{array}$ & 0.610 & 0.640 \\
\hline $\begin{array}{l}\text { Calculated diameter of } \\
\text { fundoplication }{ }^{\text {a }} \text { (median } \\
\mathrm{cm} \text {; range) }\end{array}$ & $\begin{array}{c}10.7 \\
(8.6-12.9)\end{array}$ & $\begin{array}{c}10.0 \\
(8.5-11.7)\end{array}$ & 0.242 & $\begin{array}{c}10.0 \\
(8.5-11.5)\end{array}$ & $\begin{array}{c}10.4 \\
(9.2-12.9)\end{array}$ & 0.138 & 0.583 \\
\hline $\begin{array}{l}\text { Degree of symmetry } \\
\text { (median } \mathrm{cm} \text {; range) }\end{array}$ & $\begin{array}{c}1.9 \\
(0.1-7.6)\end{array}$ & $\begin{array}{c}1.5 \\
(0.1-5.9)\end{array}$ & 0.061 & $\begin{array}{c}4.7 \\
(1.7-7.6)\end{array}$ & $\begin{array}{c}0.6 \\
(0.1-1.2)\end{array}$ & 0.000 & 0.047 \\
\hline
\end{tabular}

a Diameter is calculated by adding 'the distance from anterior point to greater curvature' to 'the distance from posterior point to greater curvature'; ${ }^{b}$ Degree of symmetry is calculated by calculating the difference between 'anterior point to midline' and 'posterior point to midline'. These distances should be equal; therefore, the difference should be close to zero when fundoplication is symmetrical; * Based on 2-way ANOVA

\section{Measurements}

To evaluate the accuracy of the measurements that were performed in the modified technique, we compared each distance with the targeted distance of $6 \mathrm{~cm}$. These results are demonstrated in Table 8.3. The only measurement that was statistically different compared with the aimed distance, was from the posterior point to the greater curvature. This distance should have been $6 \mathrm{~cm}$, however, we found a mean distance of $5.3 \mathrm{~cm}$ (SD 0.5). ( $P=0.001)$ For the surgeon and resident individually, this distance was not statically significant different.

Table 8.3 Correlation between measurements and actual distances for modified fundoplication

$\begin{array}{llcc} & & \text { Actual distances (cm) } & \begin{array}{c}P \text {-value (compared with the } \\ \text { ideal distance of } 6.0 \mathrm{~cm} \text { ) }\end{array} \\ \text { Measurement 1, median (range) } & \text { Overall } & 5.7 \mathrm{~cm}(4.9-6.8) & 0.419^{1} \\ & \text { Resident } & 6.3 \mathrm{~cm}(4.9-6.8) & 0.576^{1} \\ & \text { Surgeon } & 5.4 \mathrm{~cm}(4.9-6.1) & 0.095^{1} \\ \text { Measurement 2, median (range) } & \text { Overall } & 5.4 \mathrm{~cm}(4.5-6.7) & 0.214^{1} \\ & \text { Resident } & 6.0 \mathrm{~cm}(4.9-6.7) & 1.000^{1} \\ \text { Measurement 3, mean (SD }{ }^{3} \text { ) } & \text { Surgeon } & 4.8 \mathrm{~cm}(4.5-6.2) & 0.094^{1} \\ & \text { Overall } & 6.5 \mathrm{~cm}(0.8) & 0.090^{2} \\ \text { Measurement 4, mean (SD) } & \text { Resident } & 6.8 \mathrm{~cm}(0.9) & 0.140^{2} \\ & \text { Surgeon } & 6.2 \mathrm{~cm}(0.5) & 0.508^{2} \\ & \text { Overall } & 5.3 \mathrm{~cm}(0.5) & 0.001^{2} \\ \text { Measurement 5, mean (SD) } & \text { Resident } & 5.4 \mathrm{~cm}(0.6) & 0.061^{2} \\ & \text { Surgeon } & 5.2 \mathrm{~cm}(0.4) & 0.011^{2} \\ & \text { Overall } & 6.6 \mathrm{~cm}(1.1) & 0.110^{2} \\ & \text { Resident } & 6.9 \mathrm{~cm}(1.2) & 0.143^{2} \\ & \text { Surgeon } & 6.4 \mathrm{~cm}(1.1) & 0.482^{2}\end{array}$

This table demonstrates the actual distances and are compared with the aimed distance $(6.0 \mathrm{~cm}$ for each measurement). For description of the measurements we refer to Figure 8.1. ${ }^{1}$ Mann-Whitney $\mathrm{U}$, ${ }^{2}$ Independent-Samples T Test, ${ }^{3}$ SD; Standard deviation 


\section{Learning curve}

To evaluate whether the fundoplication that has been created according this technique is similar between the resident and the surgeon we have compared the measurements between both. As is seen in Table 8.1 and 8.2 there is no difference detected between both the resident and the surgeon. When sub-group analyses is performed for both the conventional and modified technique, there is still no significant difference. (Table 8.4).

Table 8.4 Comparison between resident and surgeon

\begin{tabular}{|c|c|c|c|}
\hline & Resident & Surgeon & P-value \\
\hline \multicolumn{4}{|c|}{ Median operating time, $\min$ (range) } \\
\hline Original & $6.2(4.7-443)$ & $5.6(4.6-7.6)$ & $0.754^{1}$ \\
\hline Modified & $14.4(11.5-16.2)$ & $16.7(12.7-19.4)$ & $0.347^{1}$ \\
\hline \multicolumn{4}{|c|}{ Median degree of symmetry, $\mathrm{cm}$ (range) } \\
\hline Original & $6.1 \mathrm{~cm}(2.8-7.6)$ & $3.0 \mathrm{~cm}(1.7-5.9)$ & $0.076^{1}$ \\
\hline Modified & $0.5 \mathrm{~cm}(0.1-0.9)$ & $0.6 \mathrm{~cm}(0.1-1.2)$ & $0.751^{1}$ \\
\hline \multicolumn{4}{|c|}{ Mean total diameter, cm (SD) } \\
\hline Original & $10.4 \mathrm{~cm}(1.4)$ & $9.6 \mathrm{~cm}(0.7)$ & $0.274^{2}$ \\
\hline Modified & $10.0 \mathrm{~cm}(1.2)$ & $9.6 \mathrm{~cm} \mathrm{0.7)}$ & $0.546^{2}$ \\
\hline \multicolumn{4}{|c|}{$\begin{array}{l}\text { Median variation in distances compared with } \\
\text { own average, \% (range) }\end{array}$} \\
\hline Original & $14.6 \%(10.2-53.2)$ & $14.1 \%(6.8-15.4)$ & $0.465^{1}$ \\
\hline Modified & $9.5 \%(7.1-16.7)$ & $6.7 \%(3.9-15.0)$ & $0.347^{1}$ \\
\hline
\end{tabular}

${ }^{1}$ Mann-Whitney $\mathrm{U},{ }^{2}$ Independent-Samples T Test

\section{Discussion}

Laparoscopic Nissen fundoplication comes with a substantial learning curve and one of the most reported causes for re-operation remains dysphagia or recurrent heartburn. Among the many reasons for these complications, we believe that an inappropriate construction of the fundoplication plays an essential role. To aid surgeons in performing a proper fundoplication without the use of a bougie, we have developed a modified technique, which is proven safe and leads to good results at the short term. ${ }^{16}$ For this paper we have studied the actual reproducibility and standardization of this technique in an ex-vivo experiment. Furthermore, we have compared the results of a resident with an experienced laparoscopic surgeon to assess whether this technique may reduce the learning curve. A recent publication established the relevance of training procedures to reduce the learning curve once again. ${ }^{17}$ When we compared the resident with the surgeon we did not find any significant differences. However, it seems that with the conventional technique the fundoplication of the resident is far more asymmetrical that the surgeon. This difference seems to disappear when the modified technique is used. ( $P=0.076$ vs $. P=0.751)$ This difference might not be significant due to 
small sample sizes, since only 10 fundoplications each were performed. The variation in the technique did not significantly differ between the surgeon and the resident.

We have found that the variation in distances of the fundoplication is reduced from 14.4 to $8.7 \%$ ( $P=0.087)$. For the individual distances no differences were found, even for the location of the posterior point of the fundoplication. Both the surgeon and the resident experienced that it was difficult to determine the proper location at the posterior side of the stomach. We noticed that in all cases, the distance from the midline to the posterior point was less than the distance from the midline to the anterior point. This resulted in a fundo-rotation instead of a fundoplication. The relevance of creating a symmetrical fundoplication is already mentioned in previous studies. $^{2,18}$ The median deviation from perfect symmetry was $4.7 \mathrm{~cm}$ in the conventional technique compared to $0.6 \mathrm{~cm}$ for the modified technique. $(P=0.000)$ There seems to be an interaction between the performer of the fundoplication and the method that is been used. Most likely the conventional fundoplication of the surgeon is more symmetrical than the one of the resident due to the experience of the surgeon. This therefore increases the effect that is found. However, we believe that the effect of the difference in technique is of such proportion, that this outweighs the possible effect of the performer.

Therefore, we conclude that this modified technique leads to a significant more symmetrical fundoplication. Since this is a technical study, we do not know whether this effect indeed reduces postoperative dysphagia and leads to better symptomatic outcome, but this might be subject of further study.

It is interesting that the actual diameter of the fundoplication for both techniques is similar. Thus, the size of the wrap is comparable with the conventional technique. We know from previous studies, that the size of the fundoplication influences postoperative outcome. We have also learnt from studies that use a bougie, that with a larger diameter of the fundoplication, postoperative dysphagia reduces. ${ }^{19}$ The same effect is seen when Nissen fundoplication is compared with the partial fundoplications. Especially the short-term dysphagia is significant more severe after Nissen when compared with Toupet fundoplication. ${ }^{14}$ Whether the demonstrated patency is the proper size has yet to be established, since no consensus has been reached regarding this subject. ${ }^{20}$ Despite the fact that it is unknown whether this technique leads to significant less dysphagia, a great advantage is that the surgeon knows the size of the fundoplication that is created. Therefore, when persistent dysphagia is present, it is possible to perform a re-do fundoplication, with an increased patency by measuring a larger distance.

This study is based on a theoretical model with mathematical equations to determine the distances from the midline to create a fundoplication with a diameter of approximately $12 \mathrm{~cm} .{ }^{16}$ We found that all measurements except the determination of the posterior point was accurate and no statically significant difference with the aimed distance was observed. This is supported by the fact that the variation regarding to 
location of the posterior point was very large. Therefore, special attention should be paid when determining the location of the posterior point.

The distances in this study are measured by an estimation with the laparoscopic grasper, which is $2.5 \mathrm{~cm}$. The accuracy can be further improved by introducing a sterile ruler, however this may lead to a further increasing operating time and we do not believe that this leads to statistically improvement compared with the technique mentioned above.

Another interesting finding in this study is the discrepancy between the calculated diameter of the fundoplication and the actual diameter. Based on the theoretical model, the diameter should be $12 \mathrm{~cm}$. However, we measured a median distance of $9.8 \mathrm{~cm}$ and the calculated distance was $10.4 \mathrm{~cm}$. This might be due to a standard error which is made in the measurement, either during surgery or during analysis of the distances by the investigator. Another explanation might be an error in the mathematical equation to determine the diameter of the fundoplication. Since we create 2 equilateral triangles with a base of $6 \mathrm{~cm}$, we may need to determine the height of these triangles, instead of the length of the sides. The result of this alternative calculation is a diameter of $10.4 \mathrm{~cm}$, which is more in line with the diameter that we have found. This should be kept in mind when functional outcomes of this techniques are evaluated.

Despite the possible advantages of this technique, which is better reproducible and leads to a more symmetrical fundoplication, the operating time is significant longer. The conventional technique requires a median of 5.9 minutes to complete compared with 14.8 minutes for the modified technique. However, this is only a difference of 6.9 minutes for a small part of the entire procedure. Based on a large retrospective cohort study of the same experience surgeon of 169 patients, we know that the mean operative time for the entire procedure is 78.8 minutes. ${ }^{21}$ Therefore, the operative time is only increased by $8.8 \%$ based on a mean operative time of an experienced surgeon. It might be that when a resident of unexperienced surgeon performs the entire procedure, the effect on operating time due to this modified technique is minimized. Furthermore, when this technique is more frequently performed, the operative time may further reduce and the difference may become even less.

This is this the first study that evaluates the standardization and reproducibility of a laparoscopic fundoplication with an ex vivo porcine model. Despite maximum effort to reduce bias and perform a reproducible concept, there are still some limitations of this study. We operated on porcine stomachs, which are comparable with the human stomach, but are slightly more rigid and more difficult to handle. Since this is our first experience with this concept, only one surgeon and one resident were included. It would be interesting to see what the results will be when more residents perform this experiment, to actually extrapolate the results to real life. Some data seems to provide an advantage of the modified technique over the conventional technique, but no significance is reached. This might be due to the very small sample size, and when more 
fundoplications are performed, these differences may become statistically significant. This study demonstrates possible advantages of this modified technique over the modified technique and shows that even an inexperience resident is capable of creating a proper fundoplication with this modified technique. Further studies are needed to evaluate patient outcomes of this technique and to establish whether the learning curve is further reduced by this technique.

\section{Conclusion}

This modified technique for Nissen fundoplication leads to a better reproducible and more standardized fundoplication which can easily be reproduced by an inexperienced surgeon. Further studies are need to evaluate the actual effect on patient outcomes and learning curve. 


\section{References}

1. Cuschieri A, Shimi S, Nathanson LK. Laparoscopic reduction, crural repair, and fundoplication of large hiatal hernia. Am J Surg 1992;163(4):425-30.

2. Watson DI, Baigrie RJ, Jamieson GG. A learning curve for laparoscopic fundoplication. Definable, avoidable, or a waste of time? Ann Surg 1996;224(2):198-203.

3. Soot SJ, Eshraghi N, Farahmand M, Sheppard BC, Deveney CW. Transition from open to laparoscopic fundoplication: the learning curve. Arch Surg 1999;134(3):278-81.

4. Hwang $\mathrm{H}$, Turner $\mathrm{L}$, Blair NP. Examining the learning curve of laparoscopic fundoplications at an urban community hospital. Am J Surg 2005;189(5):522-6.

5. Antiporda M, Veenstra B, Jackson C, Kandel P, Daniel Smith C, Bowers SP. Laparoscopic repair of giant paraesophageal hernia: are there factors associated with anatomic recurrence? Surg Endosc 2018;32(2):945-54.

6. Brown CN, Smith LT, Watson DI, Devitt PG, Thompson SK, Jamieson GG. Outcomes for trainees vs experienced surgeons undertaking laparoscopic antireflux surgery - is equipoise achieved? J Gastrointest Surg 2013;17(7):1173-80.

7. Zacharoulis D, O'Boyle CJ, Sedman PC, Brough WA, Royston CM. Laparoscopic fundoplication: a 10-year learning curve. Surg Endosc 2006;20(11):1662-70.

8. Gill J, Booth MI, Stratford J, Dehn TC. The extended learning curve for laparoscopic fundoplication: a cohort analysis of 400 consecutive cases. J Gastrointest Surg 2007;11(4):487-92.

9. Dagash H, Chowdhury M, Pierro A. When can I be proficient in laparoscopic surgery? A systematic review of the evidence. J Pediatr Surg. 2003;38(5):720-4.

10. Balci D, Turkcapar AG. Assessment of quality of life after laparoscopic Nissen fundoplication in patients with gastroesophageal reflux disease. World J Surg 2007;31(1):116-21.

11. Pessaux P, Arnaud JP, Delattre JF, Meyer C, Baulieux J, Mosnier H. Laparoscopic antireflux surgery: fiveyear results and beyond in 1340 patients. Arch Surg 2005;140(10):946-51.

12. Triponez F, Dumonceau JM, Azagury D, Volonte F, Slim K, Mermillod B, et al. Reflux, dysphagia, and gas bloat after laparoscopic fundoplication in patients with incidentally discovered hiatal hernia and in a control group. Surgery 2005;137(2):235-42.

13. van Rijn S, Roebroek YG, Conchillo JM, Bouvy ND, Masclee AA. Effect of Vagus Nerve Injury on the Outcome of Antireflux Surgery: An Extensive Literature Review. Dig Surg 2016;33(3):230-9.

14. Du X, Hu Z, Yan C, Zhang C, Wang Z, Wu J. A meta-analysis of long follow-up outcomes of laparoscopic Nissen (total) versus Toupet (270 degrees ) fundoplication for gastro-esophageal reflux disease based on randomized controlled trials in adults. BMC Gastroenterol 2016;16(1):88.

15. Leggett PL, Bissell CD, Churchman-Winn R, Ahn C. A comparison of laparoscopic Nissen fundoplication and Rossetti's modification in 239 patients. Surg Endosc 2000;14(5):473-7.

16. Castelijns PSS, van de Poll MCG, Smulders JF. A modified technique to create a standardized floppy Nissen fundoplication without a bougie. J Laparoendosc Adv Surg Tech A. 2018.

17. Ujiie $H$, Kato $T$, Hu HP, Bauer P, Patel P, Wada $H$, et al. Development of a novel ex vivo porcine laparoscopic Heller myotomy and Nissen fundoplication training model (Toronto lap-Nissen simulator). J Thorac Dis 2017;9(6):1517-24.

18. Reardon PR, Matthews BD, Scarborough TK, Preciado A, Marti JL, Kamelgard JI. Geometry and reproducibility in 360 degrees fundoplication. Surg Endosc 2000;14(8):750-4.

19. DeMeester TR, Bonavina L, Albertucci M. Nissen fundoplication for gastroesophageal reflux disease. Evaluation of primary repair in 100 consecutive patients. Ann Surg 1986;204(1):9-20.

20. Bais JE, Bartelsman JF, Bonjer HJ, Cuesta MA, Go PM, Klinkenberg-Knol EC, et al. Laparoscopic or conventional Nissen fundoplication for gastro-oesophageal reflux disease: randomised clinical trial. The Netherlands Antireflux Surgery Study Group. Lancet. 2000;355(9199):170-4.

21. Castelijns PSS, Ponten JEH, Vd Poll MCG, Bouvy ND, Smulders JF. Quality of life after nissen fundoplication in patients with gastroesophageal reflux disease: Comparison between long- and shortterm follow-up. J Minim Access Surg. 2018;14(3):213-20. 

Chapter 9 



\section{Laparoscopic treatment of intrathoracic stomach}

The first reports on diaphragmatic hernias date back as far as the 16 th century. ${ }^{1}$ During the second half of the 20th century, major advancements in the surgical treatment of this entity have been made. The increasing knowledge regarding the association between hiatal hernias and acid reflux lead to the first fundoplication, performed by Rudolph Nissen, in 1956 . $^{2}$ Several modifications to this technique were made, and with the development of laparoscopic surgery the outcome was further improved with fewer complications and lower morbidity and mortality. The postoperative hospital stay is reduced by half and the complication rate is further reduced from $20.6 \%$ to $8.5 \%$. We found the same results in chapter 4, where we evaluated the outcome of our retrospective cohort of 86 patients who underwent laparoscopic hiatal hernia repair for an intrathoracic stomach. Median follow-up was 2.7 years with a maximum of 9.6 years and complication rate was $12.5 \%$. As we described in chapter $\mathbf{2}$, one of the complications after intrathoracic stomach (ITS) and para-oesophageal (PEH) repair, is a bleeding from either large vessels or organs. ${ }^{5,6}$ We experienced one major bleeding of the aorta in our cohort of the past 10 years, which lead to the death of the patient. Aortic injury is rarely described in the literature, and only two cases have been described so far. ${ }^{7,8}$ Also pleural rupture is a common complication, mostly without a pneumothorax when positive end expiratory pressure is kept high $\left(>10 \mathrm{~cm} \mathrm{H}_{2} \mathrm{O}\right.$ ). If a pneumothorax does occur, chest tube insertion may be inevitable. ${ }^{9}$ Reported incidence of pneumothorax after Nissen fundoplication is $4 \%$, which is comparable with the findings in our study (6.25\%). Only two out of the 5 patients with a pneumothorax required chest tube drainage in our cohort. Another complication that often occurs, is delayed gastric emptying (DGE), which has both organic causes (diabetes, auto-immune disease, neuromotor dysfunction) and mechanical causes (vagal nerve injury of obstruction). The detection of DGE is difficult due to the changed anatomy in patients with a large hiatal hernia. The reported incidence is $3 \%$, however with more reoperations, higher incidence of DGE is found. This might be due to the increased risk of vagal nerve injury. ${ }^{10}$ The incidence of vagal nerve injury is supposed to be as high as $10-42 \%{ }^{11}$ This complication results in an increased recurrence of acid reflux, a significantly decreased quality of life and a lower patient satisfaction. This worse outcome leads to more re-operations, with increased risk of complications and postoperative dysphagia; the re-do fundoplication will mostly be tighter, in some cases to tight, in order to treat the persistent acid reflux. ${ }^{12}$ Symptoms of unintentional vagal nerve injury are not recognized by surgeons; one explanation might be that the tools for measuring gastric emptying and for the pancreas polypeptide test are not available in most hospitals. Furthermore, these investigations are time consuming and demanding for patients. It is therefore unlikely that these studies will become part of the standard workup for recurrent antireflux surgery. Special caution is needed when mobilizing the oesophagus to prevent vagal nerve injury and if suspicion of vagal nerve 
injury is raised, patients should be referred to an institution that performs these measurements.

\section{Mesh reinforcement in hiatal hernia surgery}

Recurrence of hiatal hernia is one of the major problems in hiatal hernia surgery. Current literature regarding this topic is reviewed extensively in chapter $\mathbf{2}$. The approximation of the crural defect starts almost always with suture repair. There is only one study that describes the difference in outcome between anterior and posterior suture repair, however no statistically significant difference was found. ${ }^{13}$ Recurrence rate after hiatal hernia repair is reduced by reinforcement of the cruroplasty with a mesh from $22.5 \%$ to $12.1 \%{ }^{14-17}$

In chapter 4 , we found a symptomatic recurrence rate of $4.9 \%(4 / 81)$, from which 3 patients experienced an early recurrence within the first 2 weeks; Most likely due to persistent nausea and extensive vomiting, which lead to an extreme intra-abdominal pressure. One late recurrence was seen after 2.4 years. We performed mesh reinforcement in 20 of the 81 patients; all recurrences were in the non-mesh group. However, due to the small sample size, proper statistical analyses are not valid. Nevertheless, it seems that mesh reinforcement reduced the risk of recurrence in our cohort. The importance of preventing postoperative nausea and vomiting is supported by lqbal et al, who described the relation between failure of Nissen fundoplication and postoperative vomiting. ${ }^{18}$ Now we have established the possible advantage of mesh reinforcement, the question is raised which type of mesh we should use. This question is addressed in chapter $\mathbf{3}$ of this thesis, where we performed a large literature review of studies from the past 11 years. There are many types of meshes available nowadays, which can be roughly be divided in synthetic and biological material. The synthetic meshes are mostly non-absorbable in contrast with the biological meshes that are often absorbable. The theoretical advantage of biological meshes is fewer mesh related complications such as erosion, migration, mesh related infection and development of fibrotic structures. However, considering the higher costs and the possible higher recurrence rate, the advantage of biological mesh should be established before standard implementation. In this study, we included 16 papers, from which 5 described repair with biological meshes. A total of 1089 patients have been described, from which 385 received a biological mesh and 704 a synthetic mesh. Due to the large heterogeneity between the studies, we were unable to perform a proper meta-analysis. Combined recurrence rate after biological mesh repair is $16.1 \%$ compared with $6.8 \%$ after synthetic mesh repair, after a median follow up of 53.4 months. $(P<0.05)$ This finding is line with the study of Watson et al, however in this study the difference was not statistically significant $(P=0.161)$, which might be the result of small sample size. ${ }^{19}$ 
In our cohort that is described in chapter 4, we used a synthetic mesh (Parietex ${ }^{\mathrm{TM}}$, Covidien, New Haven, CT, USA) and found no recurrences in the mesh group after a median follow-up of 2.7 years. In the study performed by Oelschlager et al, they described a recurrence rate after biological mesh repair of $9 \%$ after 6 months. But after 5 -years, the recurrence rate is $54 \% .^{20,21}$ It might be that the follow-up of our cohort was too short to detect recurrence. Another explanation is that most recurrences seem asymptomatic, and we did not perform routine clinical follow-up with endoscopy or barium swallow investigation. There is need for a golden standard in the definition of a recurrence in order to perform adequate comparison between studies. For now, regarding anatomical recurrence rate, the synthetic mesh seems in favour. However, there is no standard method for detecting the anatomical recurrence; some studies perform a CT-scan, where others perform a barium swallow, endoscopy or X-thorax. Therefore, this conclusion should be drawn very carefully due to the large heterogeneity in the current literature and the lack of randomized controlled trials.

\section{Complications and symptomatic outcome after mesh reinforcement}

Mesh related complications are the fear of many surgeons when using mesh, since this may lead to long lasting morbidity and even death. In chapter 3 we describe the mesh related complications that can be found in the literature up to 2015. 12 out of 1089 patients experienced a mesh related complication. Most reported mesh related complication was stenosis and 2 patients experienced an erosion of the mesh. Eleven complications occurred in the synthetic mesh group, compared with only 1 in the biological group $(P=0.065)$. Recent literature supports the rarity of mesh related complications, with no mesh related complications in a cohort of 62 mesh reinforcements. ${ }^{22}$ This is in line with our findings in chapter 4 and chapter 5 , where we used a total of 25 meshes and report no mesh related complications.

Reinforcement of the crural defect does reduce recurrence rate, but another very important aspect is the symptomatic outcome. We know that most radiological recurrences are asymptomatic. ${ }^{22}$ Interestingly, patients with an anatomical recurrence seem to be less satisfied with the overall outcome of the surgery. ${ }^{23}$ Even if surgery is performed for gastroesophageal reflux disease, objective measurements seem to have a poor correlation with the reported quality of life. ${ }^{24,25}$ Therefore, we have assessed the symptomatic outcome after mesh repair with both synthetic and biological mesh in chapter 3. Since different quality of life questionnaires have been used in the studies, we were unable to perform a meta-analysis. Instead, we use the reported successful symptomatic outcome and compared these data between both types of mesh. The successful symptomatic outcome after hiatal hernia repair with synthetic mesh is $94.6 \%$ 
compared with $85.5 \%$ for the biological mesh, overall successful symptomatic outcome is $91.6 \%$. Similar successful symptomatic outcomes have been reported in the literature. $^{22,23,26}$ This high successful symptomatic outcome is comparable with suture repair only, therefore the use of mesh in hiatal hernia repair does not improve and neither deteriorate symptomatic outcome. Of course, this conclusion must be drawn with care, since many different questionnaires are used to report on symptomatic outcome; GERD-HRQL, GIQLI and SF-36. Moreover, most studies are retrospective cohort studies and only very few randomized controlled trials with long-term follow-up have been performed.

\section{Long-term quality of life after anti-reflux surgery for GERD}

The assessment of long-term quality of life after the treatment for gastroesophageal reflux disease (GERD) was one of the aims of this thesis. In chapter $\mathbf{5}$ we studied 169 patients that underwent anti-reflux surgery for GERD in the past 10 years. All patients except one underwent Nissen fundoplication, and only 5 patients received a mesh reinforcement. We evaluated quality of life with the GERD-HRQL questionnaire, which is a validated questionnaire to assess the quality of life (QoL). Maximum score is 75, demonstrating excellent QoL. Sub-scores can be calculated to evaluate heartburn and regurgitation specific QoL. ${ }^{27,28}$ Definition on the GERD-HRQL questionnaire for resolution of symptoms regarding heartburn, is a heartburn score $>18$. This is found in $76.3 \%$ of our patients. The median overall quality of life score was 70 (range 2-75), which is comparable with a QoL score of 72.2 that is found after 5 years in the literature. $^{29}$

In chapter 5, we also compared the long-term outcome with short-term outcome, since most authors advocate for long-term follow-up. When quality of life for patients with a follow-up $<5$ years is compared with $>5$ years, we found no difference in symptomatic outcome; PPI usage was $53.0 \%$ after follow-up of less than 5 years, compared with $44.4 \%$ for patients with a follow-up of more than 5 years $(P=0.297)$. Thus, follow-up of 5 years should represent long-term follow-up, since quality of life does not further change after 5 years. This is supported by the study of Kelly et al. where they conclude that most reoperations are performed within the first 2 years of follow-up and that quality of life does not change between 5 and 10 years of follow up. ${ }^{30}$ In our cohort that is described in chapter $\mathbf{5}$, we found that $91.3 \%$ of the reoperations were performed within the first 5 years; in the ten-year follow-up of the patients in chapter $\mathbf{4}$, we also see that all re-operations were performed within 3.2 years of follow-up, supporting this theory. Therefore, follow-up of 5 years should be sufficient to evaluate the functional outcome of anti-reflux surgery and hiatal hernia repair. 


\section{The influence of re-operation on quality of life}

As demonstrated in chapter 2, re-operation after intrathoracic stomach repair comes with a reduced quality of life and should therefore be minimized. The same is valid for anti-reflux surgery in the treatment of GERD. ${ }^{27,31,32}$ We found comparable results in chapter 5, where the mean quality of life was 62.7 for patients without re-operation and 53.1 for patients that underwent re-operation. $(P=0.196)$ This difference is not statistically significant probably due to the small number of patients. We found a reoperation rate of $13.6 \%(23 / 169)$; the reasons were persistent dysphagia in $47.8 \%$ and recurrent heartburn in $52.2 \%$ of the patients. According to the literature, recurrent heartburn after Nissen fundoplication is reported in $10-20 \%$ of the patients and $3-6 \%$ require re-operation. ${ }^{33,34}$ Reported causes for this high rate of recurrence are inadequate indication for anti-reflux surgery due to incomplete pre-operative work-up, inability to execute proper technique steps due to inexperience of the surgeon or vagal nerve injury. Due to the retrospective aspect of our study, we are unable to determine what causes the high re-operation rate, most likely a combination of all causes mentioned above. However, we can conclude that re-operation is associated with a reduced quality of life which might be due to the perceived risk of vagal nerve injury.

\section{Long-term results of EsophyX device}

Due to complications that come with anti-reflux surgery, such as dysphagia, recurrence, bleeding, and vagal nerve injury, minimal invasive techniques have been developed. The EsophyX device is one of the devices to create a transoral incisionless fundoplication. The is still lack of long-term results for the EsophyX device. Chapter 6 discusses the 7-year outcome of patients who participated in a randomized controlled trial with a cross-over design between the EsophyX device and PPI treatment. After 1 year all patients crossed over and underwent TIF procedure. We found that $56.1 \%$ of the patients resumed PPI after 7 year compared with $34.1 \%$ at one year of EsophyX. ${ }^{35}$ This suggests that EsophyX does not provide a long-lasting solution for heartburn, which is supported by the study of Testoni et al.. ${ }^{36}$ They report a resumption to PPI of $74.3 \%$ after 6 years. However, only 14 out of 49 patients completed the 6 -year followup. PPI usage after anti-reflux surgery is $43 \%$ at 17 -year follow-up after laparoscopic Nissen fundoplication. ${ }^{37}$ They also performed a multi-variate analysis to predict successful outcome. Presence of a hiatal hernia $<2 \mathrm{~cm}$ or a Hill classification of 1 or 2 predicts successful outcome after 6 years. We also performed a univariate and multivariate analysis and found that a hiatal hernia or oesophagitis pre-operatively is associated with a worse quality of life after 7 years. Quality of life remained constant after 1 year and PPI resumption did not further decrease compared with 7 year results. 
In our study, $22.0 \%$ of the patients underwent re-operation for persistent or recurrent heartburn. Despite this high re-operation rate, we know from previous studies that anti-reflux after transoral incisionless fundoplication (TIF) is safe and can be performed without any further sequelae. ${ }^{38}$ However, functional results are disappointing, with minimal improvement of quality of life after Nissen fundoplication. Reflux control was excellent, but most reported cause for poor quality of life was the daily dysphagia that was experienced by most of these patients. ${ }^{38,39}$ A recent review compared the laparoscopic Nissen fundoplication with the transoral incisionless fundoplication and with the non-operative treatment with PPI. It seems that TIF is superior to PPI and/or Nissen fundoplication in improving quality of life. However, studies on PPI have an average follow-up of 6 months compared with a follow-up of 1-5 year for the Nissen groups. It is therefore difficult to draw strong conclusions. Based on current literature, TIF should not be routinely used in the treatment of gastroesophageal reflux disease. ${ }^{40}$ TIF can be considered as a first step for patients that are unwilling to take PPI for a lifelong period and/or are not suitable for laparoscopic antireflux surgery.

\section{Learning curve of Nissen fundoplication}

As described in chapter 2, hiatal hernia surgery and anti-reflux surgery requires advanced laparoscopic skills and comes with a learning curve. Initial reports describe a learning curve of 20 procedure for each surgeon before the risk of adverse event stabilizes. ${ }^{41}$ however, later studies report a reduction in operative time, complications and an improved functional outcome even up to 100 procedures. ${ }^{42,43}$

This learning curve might be due to the difficulty in creating a proper fundoplication, if this is to tight it may cause dysphagia, of it is too loose if results in persistent heartburn. Therefore, some surgeons advocate the use of a bougie, however this is associated with an increased risk of oesophageal damage and even perforation in $1.2 \%$ of the patients. $^{44,45}$ Therefore, we have developed a modified technique to create a standardized fundoplication without the use of a bougie. This technique is described in detail in chapter $\mathbf{7}$. The first 15 patients that were operated according this technique report a quality of life score of 69.0 on the GERD-HRQL questionnaire, which is comparable with the results of our retrospective cohort that is described in chapter 5 . No procedure related complications are reported and mortality rate is zero.

Theoretically this technique should provide a more symmetrical and more reproducible fundoplication. This hypothesis is studied in chapter $\mathbf{8}$, where we performed an ex-vivo experiment on porcine stomachs. Both a $5^{\text {th }}$ year resident and an experienced antireflux surgeon performed 10 fundoplications. Five according conventional technique, and five according the modified technique that is described in chapter 7. Actual distances are measured and compared between both techniques. Hypothesis is that 
this technique leads to more symmetrical fundoplication. It is indeed found that the modified technique leads to a larger degree of symmetry than the conventional technique $(P=0.047)$. Further research is needed to prove whether this technique also reduces postoperative dysphagia and results in better clinical outcome. This technique does increase the procedure time with a median of 8.9 minutes. However, this is only a small part of the entire procedure and when more experience is gained, this time will further decrease. This technique seems to help beginning surgeons to provide a reproducible, proper fundoplication.

\section{Future perspectives}

As previously stated, there are many definitions for recurrence in hiatal hernia surgery. These can be either anatomical or symptomatic, and the correlation between these is very poor. As is seen in chapter $\mathbf{3}$, there was a large heterogeneity due to different methods for determining quality of life. Since quality of life is an important outcome measurement nowadays, there is need for a golden standard in reporting quality of life after hiatal hernia repair and after anti-reflux surgery. In chapter $\mathbf{4}$ and $\mathbf{5}$ we present the results on long-term follow-up, which are good. However, high re-operation rate is reported. Also, minimal invasive techniques as described in chapter 6 result in high reoperation rate. This expresses the difficulty in anti-reflux surgery and there is still need for a long-term solution for all patients. All treatment options (endoluminal pacing, total fundoplication, partial fundoplication, transoral incisionless fundoplication) have advantages and disadvantages. Probably not one technique fits for all patients and preoperative investigations like upper-GI endoscopy, manometry, 24-hours impedance and gastric emptying measurement, must help surgeons to determine the ideal treatment for each individual patient. As mentioned in chapter $\mathbf{2}$ and also described in chapter $\mathbf{7}$ and 8, the type of surgery that is described in this thesis is difficult and requires advanced laparoscopic techniques. Since the learning curve is one predictor for successful outcome more research is needed to reduce this learning curve. Maybe with specialized training programs for beginning surgeons. Novel techniques such as 3D view or robot surgery may provide additional value to anti-reflux surgery and hiatal hernia repair. 


\section{References}

1. Hochberg LA Thoracic surgery before the 20th century. New York: Vantage Press, 1960.

2. Stylopoulos N, Rattner DW The history of hiatal hernia surgery: from Bowditch to laparoscopy. Ann Surg 2005:241:185-93.

3. Diez Tabernilla M, Ruiz-Tovar J, Grajal Marino R, Calero Garcia P, Pina Hernandez JD, et al. Paraesophageal hiatal hernia. Open vs. laparoscopic surgery. Rev Esp Enferm Dig 2009:101:706-11.

4. Klinginsmith $M$, Jolley J, Lomelin D, Krause C, Heiden J, et al. Paraesophageal hernia repair in the emergency setting: is laparoscopy with the addition of a fundoplication the new gold standard? Surg Endosc 2016:30:1790-5.

5. Baigrie RJ, Watson DI, Game PA, Jamieson GG Vascular perils during laparoscopic dissection of the oesophageal hiatus. Br J Surg 1997:84:556-7.

6. Cano-Valderrama O, Marinero A, Sanchez-Pernaute A, Dominguez-Serrano I, Perez-Aguirre E, et al. Aortic injury during laparoscopic esophageal hiatoplasty. Surg Endosc 2013:27:3000-2.

7. Leggett $\mathrm{PL}$, Bissell CD, Churchman-Winn R Aortic injury during laparoscopic fundoplication: an underreported complication. Surg Endosc 2002:16:362.

8. Yano F, Omura N, Tsuboi K, Kashiwagi H, Yanaga K Thoracic aortic injury during laparoscopic fundoplication for reflux esophagitis. Int J Surg 2008:6:490-2.

9. Yang X, Hua R, He K, Shen Q, Yao Q Laparoscopic hernioplasty of hiatal hernia. Ann Transl Med 2016:4:343.

10. Hamrick MC, Davis SS, Chiruvella A, Coefield RL, Waring JP, et al. Incidence of delayed gastric emptying associated with revisional laparoscopic paraesophageal hernia repair. J Gastrointest Surg 2013:17: 213--7.

11. van Rijn S, Roebroek YG, Conchillo JM, Bouvy ND, Masclee AA Effect of vagus nerve Injury on the outcome of antireflux surgery: an extensive literature review. Surgery 2016:33:230-9.

12. van Rijn S, Rinsma NF, van Herwaarden-Lindeboom MY, Ringers J, Gooszen HG, et al. Effect of Vagus Nerve Integrity on Short and Long-Term Efficacy of Antireflux Surgery. Am J Gastroenterol 2016:111:508-15.

13. Antiporda M, Veenstra B, Jackson C, Kandel P, Daniel Smith C, et al. Laparoscopic repair of giant paraesophageal hernia: are there factors associated with anatomic recurrence? Surg Endosc 2018:32:945-54.

14. Antoniou SA, Koch OO, Antoniou GA, Pointner R, Granderath FA Mesh-reinforced hiatal hernia repair: a review on the effect on postoperative dysphagia and recurrence. Langenbecks Arch Surg. 2012;397(1):19-27.

15. Puri V, Kakarlapudi GV, Awad ZT, Filipi CJ Hiatal hernia recurrence: 2004. Hernia 2004:8:311-7.

16. Targarona EM, Bendahan G, Balague C, Garriga J, Trias M Mesh in the hiatus: a controversial issue. Arch Surg 2004:139:1286-96.

17. Furnee $E$, Hazebroek $E$ Mesh in laparoscopic large hiatal hernia repair: a systematic review of the literature. Surg Endosc 2013:27:3998-4008.

18. Iqbal A, Kakarlapudi GV, Awad ZT, Haynatzki G, Turaga KK, et al. Assessment of diaphragmatic stressors as risk factors for symptomatic failure of laparoscopic nissen fundoplication. J Gastrointest Surg 2006:10:12-21.

19. Watson DI, Thompson SK, Devitt PG, Smith L, Woods SD, et al. Laparoscopic repair of very large hiatus hernia with sutures versus absorbable mesh versus nonabsorbable mesh: a randomized controlled trial. Ann Surg 2015:261:282-9.

20. Oelschlager BK, Pellegrini CA, Hunter J, Soper N, Brunt M, et al. Biologic prosthesis reduces recurrence after laparoscopic paraesophageal hernia repair: a multicenter, prospective, randomized trial. Ann Surg 2006:244:481-90.

21. Oelschlager BK, Pellegrini CA, Hunter JG, Brunt ML, Soper NJ, et al. Biologic prosthesis to prevent recurrence after laparoscopic paraesophageal hernia repair: long-term follow-up from a multicenter, prospective, randomized trial. J Am Coll Surg 2011:213:461-8. 
22. Koetje JH, Oor JE, Roks DJ, Van Westreenen HL, Hazebroek EJ, et al. Equal patient satisfaction, quality of life and objective recurrence rate after laparoscopic hiatal hernia repair with and without mesh. Surg Endosc 2017:31:3673-80.

23. Tam V, Luketich JD, Levy RM, Christie NA, Awais O, et al. Mesh cruroplasty in laparoscopic repair of paraesophageal hernias is not associated with better long-term outcomes compared to primary repair. Am J Surg 2017:214:651-6.

24. Mittal SK, Bikhchandani J, Gurney O, Yano F, Lee T Outcomes after repair of the intrathoracic stomach: objective follow-up of up to 5 years. Surg Endosc 2011:25:556-66.

25. Swidnicka-Siergiejko A, Dabrowski A Prolonged 2-day esophageal pH-metry with impedance monitoring improves symptom-reflux association analysis. Dig Dis Sci 2013:58:2556-63.

26. Zhang C, Liu D, Li F, Watson DI, Gao X, et al. Systematic review and meta-analysis of laparoscopic mesh versus suture repair of hiatus hernia: objective and subjective outcomes. Surg Endosc 2017:31:4913-22.

27. Gee DW, Andreoli MT, Rattner DW Measuring the effectiveness of laparoscopic antireflux surgery: long-term results. Arch Surg 2008:143:482-7.

28. Velanovich V, Vallance SR, Gusz JR, Tapia FV, Harkabus MA Quality of life scale for gastroesophageal reflux disease. J Am Coll Surg 1996:183:217-24.

29. Gunter RL, Shada AL, Funk LM, Wang X, Greenberg JA, et al. Long-Term Quality of Life Outcomes Following Nissen Versus Toupet Fundoplication in Patients with Gastroesophageal Reflux Disease. J Laparoendosc Adv Surg Tech A. 2017;27(9):931-6.

30. Kelly JJ, Watson DI, Chin KF, Devitt PG, Game PA, et al. Laparoscopic Nissen fundoplication: clinical outcomes at 10 years. J Am Coll Surg 2007:205:570-5.

31. Khaitan L, Bhatt $P$, Richards W, Houston H, Sharp K, et al. Comparison of patient satisfaction after redo and primary fundoplications. Surg Endosc 2003:17:1042-5.

32. Draaisma WA, Rijnhart-de Jong HG, Broeders IA, Smout AJ, Furnee EJ, et al. Five-year subjective and objective results of laparoscopic and conventional Nissen fundoplication: a randomized trial. Ann Surg 2006:244:34-41.

33. Carlson MA, Frantzides CT Complications and results of primary minimally invasive antireflux procedures: a review of 10,735 reported cases. J Am Coll Surg 2001:193:428-39.

34. Catarci M, Gentileschi P, Papi C, Carrara A, Marrese R, et al. Evidence-based appraisal of antireflux fundoplication. Ann Surg 2004:239:325-37.

35. Witteman BP, Conchillo JM, Rinsma NF, Betzel B, Peeters A, et al. Randomized controlled trial of transoral incisionless fundoplication vs. proton pump inhibitors for treatment of gastroesophageal reflux disease. Am J Gastroenterol 2015:110:531-42.

36. Testoni PA, Testoni S, Mazzoleni G, Vailati C, Passaretti S Long-term efficacy of transoral incisionless fundoplication with Esophyx (Tif 2.0) and factors affecting outcomes in GERD patients followed for up to 6 years: a prospective single-center study. Surg Endosc 2015:29:2770-80.

37. Oor JE, Roks DJ, Broeders JA, Hazebroek EJ, Gooszen HG Seventeen-year Outcome of a Randomized Clinical Trial Comparing Laparoscopic and Conventional Nissen Fundoplication: A Plea for Patient Counseling and Clarification. Ann Surg 2017:266:23-8.

38. Witteman BP, Kessing BF, Snijders G, Koek GH, Conchillo JM, et al. Revisional laparoscopic antireflux surgery after unsuccessful endoscopic fundoplication. Surg Endosc 2013:27:2231-6.

39. Furnee EJ, Broeders JA, Draaisma WA, Schwartz MP, Hazebroek EJ, et al. Laparoscopic Nissen fundoplication after failed EsophyX fundoplication. Br J Surg 2010:97:1051-5.

40. Richter J, Kumar A, Lipka S, Miladinovic B, Velanovich V Efficacy of laparoscopic Nissen fundoplication vs transoral incisionless fundoplication or proton pump inhibitors in patients with gastroesophageal reflux disease: a systematic review and network meta-analysis. Gastroenterology 2018.

41. Watson DI, Baigrie RJ, Jamieson GG A learning curve for laparoscopic fundoplication. Definable, avoidable, or a waste of time? Ann Surg 1996:224:198-203.

42. Soot SJ, Eshraghi N, Farahmand M, Sheppard BC, Deveney CW Transition from open to laparoscopic fundoplication: the learning curve. Arch Surg 1999:134:278-81.

43. Hwang $\mathrm{H}$, Turner $\mathrm{L}$, Blair NP Examining the learning curve of laparoscopic fundoplications at an urban community hospital. Am J Surg 2005:189:522-6. 
44. Patterson EJ, Herron DM, Hansen PD, Ramzi N, Standage BA, et al. Effect of an esophageal bougie on the incidence of dysphagia following nissen fundoplication: a prospective, blinded, randomized clinical trial. Arch Surg 2000:135:1055-61.

45. Lowham AS, Filipi CJ, Hinder RA, Swanstrom LL, Stalter K, et al. Mechanisms and avoidance of esophageal perforation by anesthesia personnel during laparoscopic foregut surgery. Surg Endosc 1996:10:979-82. 
Summary

$-$ 



\section{Summary}

This thesis addresses the long-term outcome after several treatment options for both hiatal hernia repair and gastroesophageal reflux disease. (GERD) We have developed a modified technique to create a standardized Nissen fundoplication without rotation to aid beginning surgeons to perform a proper fundoplication.

In chapter 2 we have addressed several aspects of the treatment of intrathoracic stomach. Laparoscopic approach is gold standard. The hiatal hernia should be reduced and the crural defect should be repaired with suture repair. Mesh reinforcement seems to reduce recurrence rate, however comes with a small risk of complications. Additional fundoplication is not advised, except when severe heartburn complaints are present. When intrathoracic stomach becomes incarcerated, first step should be decompression, followed by semi-elective repair.

Chapter $\mathbf{3}$ is a collective review comparing synthetic non-absorbable mesh with biological synthetic meshes. All studies between 2004 and 2015 are analysed and a total of 16 studies were included. Median follow-up was 53.4 months with a recurrence rate of $6.8 \%$ for synthetic mesh compared with $16.1 \%$ for biological mesh. Complication rate, mortality and symptomatic outcome was comparable. Due to higher costs of biological meshes, the synthetic mesh might be advocated.

In Chapter 4 we retrospectively evaluated the results of all patients that underwent laparoscopic hiatal hernia repair for intrathoracic stomach with a follow-up of up to 9.6 years. 81/85 patients completed the follow-up and reported good quality of life of 13.5. (maximum score 16 ) Re-operation rate was $9.9 \%$ with all re-operations in the nonmesh group.

Chapter 5 focusses on the long-term quality of life after Nissen fundoplication for patients with gastroesophageal reflux disease. 175 patients completed the GERD-HRQLquestionnaire with an excellent median quality of life of 70.0 (maximum score 75) Quality of life remained stable after 5 years and $91.3 \%$ of all re-operations occurred within the first 5 years. Patients that underwent re-operation experienced a reduced quality of life.

Chapter 6 describes the 7-year follow-up of a randomized controlled trial with crossover design between transoral incisionless fundoplication (TIF) versus proton pump inhibitors for GERD. Quality of life remained stable after 1 year, however resumption to PPI increased from $34.1 \%$ to $56.1 \%$. $22 \%$ of the patients underwent re-operation for persistent and/or recurrent complaints. We could not detect pre-operative or 
procedure related predictors for successful outcome at the long-term. TIF should not be used in the standard treatment of GERD.

In chapter 7 we described a modification of the conventional Nissen fundoplication. We attempt to perform a standardized fundoplication with sufficient patency and less rotation. This study describes the 1-year results of the first 15 patients. Median quality of life was 69.0 on the GERD-HRQL questionnaire, which is excellent. No complications or reoperations are reported. This technique is safe and leads to good postoperative results at the short term.

Chapter $\mathbf{8}$ is an experimental study with an ex-vivo porcine model. We evaluated the standardization and reproducibility of the modified technique described in chapter 7. The modified technique leads to a more symmetrical fundoplication ( $P=0.047)$, but increases the operative time from 5.9 to 14.8 minutes. No difference is found between the resident and the experienced surgeon regarding total diameter and degree of symmetry for this modified technique. 
Samenvatting 



\section{Samenvatting}

Dit proefschrift beschrijft de lange termijn resultaten van verschillende behandelopties voor de behandeling van zowel een middenrif breuk als van gastro-oesofageale reflux ziekte. (GORZ) We hebben een aangepaste techniek ontwikkeld om een gestandaardiseerde Nissen fundoplicatie te maken zonder rotatie. Het doel hiervan is om beginnende chirurgen te helpen bij het creëren van een correcte fundoplicatie.

In hoofdstuk 2 hebben we verschillende aspecten beschreven voor de behandeling van een intrathoracale maag. (ITM) Laparoscopie is de gouden standaard. De breuk wordt gereduceerd en hiatale defect wordt hersteld middels hechtingen. Versteviging van het herstel met een mat verlaagt het recidief risico, echter geeft een klein risico op complicaties. Het verrichten van een additionele fundoplicatie wordt niet geadviseerd, behalve wanneer iemand ernstig zuurbranden heeft. Als de intrathoracale maag beklemd raakt, is de eerste stap decompressie gevolgd door een semi-electief herstel.

Hoofdstuk 3 is een collectieve review die synthetische niet-oplosbare matten vergelijkt met biologisch oplosbare matten. Alle studies tussen 2004 en 2015 zijn bekeken en uiteindelijk zijn er 16 geïncludeerd. Mediane follow-up was 53.4 maanden met een recidief percentage van $6.8 \%$ voor synthetische matten vergeleken met $16.1 \%$ voor de biologische matten. Complicaties, mortaliteit en symptomatische uitkomst zijn vergelijkbaar. Gezien de hogere kosten van biologische matten, zou de eerste keuze een synthetische mat zijn.

In hoofdstuk 4 hebben we retrospectief de resultaten geëvalueerd van alle patiënten die een laparoscopisch herstel van een intrathoracale maag hebben ondergaan met een follow-up tot 9.6 jaar. 81/85 patiënten hebben de follow-up voltooid en rapporteren een goede kwaliteit van leven van 13.5 (maximale score 16) Re-operatie percentage was $9.9 \%$ waarbij alle re-operaties plaatsvonden in de groep waarbij geen mat is gebruikt.

Hoofdstuk 5 focust op de lange-termijn kwaliteit van leven na Nissen fundoplicatie voor patiënten met GORZ. 175 patiënten hebben de GERD-HRQL-vragenlijst ingevuld en rapporteren een zeer goede kwaliteit van leven van 70.0 (maximale score 75) Kwaliteit van leven bleef stabiel na 5 jaar en $91.3 \%$ van alle recidieven vond plaats in de eerste 5 jaar. Patiënten die een re-operatie ondergingen rapporteren en verminder kwaliteit van leven.

Hoofdstuk 6 beschrijft de 7-jaars resultaten van een gerandomiseerde trial met crossover ontwerp tussen endoscopische incisie loze fundoplicatie (TIF) versus protonpomp remmers (PPI) voor GORZ. Kwaliteit van leven blijft stabiel na 1 jaar, maar het aantal 
mensen dat PPI's gebruikt is toegenomen van $34.1 \%$ tot $56.1 \%$. $22 \%$ van de patiënten hebben een re-operatie ondergaan vanwege blijvende of recidiverende klachten. We hebben geen variabelen kunnen detecteren om succesvolle resultaten na 7 jaar te kunnen voorspellen. TIF moet nog niet standaard toegepast worden in de behandeling van GORZ.

In hoofdstuk 7 beschrijven we een aangepast techniek voor de Nissen fundoplicatie we hebben geprobeerd om een gestandaardiseerde fundoplicatie te creëren met voldoende doorgang en minder rotatie. Deze studie rapporteert de 1-jaars resultaten van de eerste 15 patiënten. Mediane kwaliteit van leven is 69.0 op de GERD-HRQLvragenlijst, wat zeer goed is. Geen complicaties of re-operaties zijn gerapporteerd. Deze techniek is veilig en leidt tot goede postoperatieve resultaten op de korte termijn.

Hoofdstuk 8 is een experimentele studie met een ex-vivo model met varkensmagen. We hebben de standaardisatie en reproduceerbaarheid van de techniek uit hoofdstuk 7 bestudeerd. De aangepaste techniek resulteert in een meer symmetrische fundoplicatie $(P=0.047)$, maar geeft een toename van operatieduur van 5.9 tot 14.8 minuten. Er is geen verschil gevonden tussen de assistent en de ervaren chirurg met betrekking tot de diameter en de mate van symmetrie in de aangepast techniek. 
Valorisation addenduim 



\section{Valorisation addendum}

\section{Introduction}

Gastroesophageal reflux disease (GERD)has an estimated prevalence of $18.1-27.8 \%$ in North America. GERD is currently the most common reason for outpatient gastrointestinal visits in the United States (US), with an estimated 8.9 million outpatient visits. With increasing number of patients, GERD has become a serious burden for the general population. GERD reduces quality of life in patients and comes with high costs for healthcare. Initial treatment is with life-style interventions, but next step is medical therapy. Medical therapy for GERD costs approximately 7.7 billion dollars annually in the US.

\section{Relevance of this thesis}

If left untreated GERD may lead to severe complications including erosive oesophagitis, pulmonary complaints and even Barret's dysplasia. First step in the treatment of GERD is medical treatment with PPI's, however long-term PPI usage can lead to an increased risk of pneumonia, dementia, Vit B12 deficiency and osteoporosis. Surgery is found to be more cost-effective at the long-term for the treatment of GERD, however comes with the risk of complications. Dysphagia, recurrence and vagal nerve injury are some of the most feared complications. To reduce complications and recurrence rates, several modifications have been developed. Total fundoplication, partial fundoplication, transoral incisionless fundoplication(TIF), lower oesophageal stimulation and even oesophageal lengthening procedures are available. Chapter $\mathbf{2}$ and 3 provide an overview of current techniques of hiatal hernia repair and the treatment of hiatal hernia with special emphasis on the use of mesh. We have shown that synthetic mesh might be superior to biological mesh in hiatal hernia repair.

All techniques have advantages and disadvantages and for many techniques the longterm effects are still lacking. This thesis therefore addresses long-term outcome of several techniques to provide more inside in the effects of these techniques.

Since quality of life has become a more important outcome measurement over time, we have tried to establish the quality of life after hiatal hernia repair and after Nissen fundoplication for GERD. Chapter $\mathbf{4}$ demonstrates that quality of life is good after a follow-up of up to 9.6 years and re-operation rate is $9.9 \%$. Most re-operations occur within the first year after surgery and quality of life does not further change after 5 years of follow-up, as is seen in chapter $\mathbf{5}$. Therefore, a follow-up period of 5 years should be sufficient to evaluate quality of life after antireflux surgery. Chapter $\mathbf{5}$ also addresses quality of life after antireflux surgery for GERD and shows an excellent quality of life at long-term follow-up. Patient who underwent re-operation reported worse quality of life, therefore the re-operation rate should be as low as possible. 
We have found that $48 \%$ of the re-operations is due to persistent dysphagia after Nissen fundoplication. We believe that this might be due to failure of creating a proper fundoplication. It is difficult to create a symmetrical wrap that is neither too tight, nor too loose. In an attempt to help, especially beginning surgeons, we have developed a modified technique to create a more symmetrical and more reproducible fundoplication. This technique is described in chapter 7 and further evaluated in chapter 8. Results are promising, but further research is needed to evaluate the possible clinical benefit.

\section{Target population}

The results of this thesis are relevant for patients with a hiatal hernia or with gastroesophageal reflux disease who are not satisfied with their medical therapy. Further, it offers a modified technique for beginning surgeons to create a proper Nissen fundoplication.

\section{Innovation and future}

This thesis evaluated existing treatment options for hiatal hernia repair and anti-reflux surgery. However, we also studied a more experimental and less invasive technique. The EsophyX device creates a transoral incisionless fundoplication. The results after 1 year were rather disappointing with a high recurrence rate. (22.7\%-50.0\%) However, we have studied the long-term results in chapter 6, in attempt to detect a subgroup that benefits from TIF procedure. We found that patients with a hiatal hernia or oesophagitis reported a worse quality of life after 7 years. We found a failure rate of $22 \%$. Since additional surgery after previous TIF does not come with increase morbidity and mortality TIF can be a first step in the treatment of GERD. With this thesis, we hope to provide a tailor-made approach to all future GERD patients. 
Dankwoord 



\section{Dankwoord}

Na 5 jaar hard werken aan mijn promotietraject naast mijn klinische werkzaamheden, is het uiteindelijk toch gelukt. Het proefschrift is af, maar niet zonder de hulp van een heel team. Graag wil ik iedereen bedanken die me geholpen en gesteund heeft de afgelopen jaren, maar een aantal mensen in het bijzonder. Uiteraard is dit in de eerste plaats mijn promotor, maar ik wil graag voor een persoon een uitzondering maken, die voor mij een essentiële rol heeft gespeeld in mijn ontwikkeling als arts en mijn enthousiasme voor de chirurgie heeft weten te vergroten.

Beste drs. Smulders, Frans, het zal je misschien verbazen, maar jij bent toch echt de eerste die ik wil bedanken! Dankzij jou ben ik tijdens mijn coschappen al in aanraking gekomen met het wetenschappelijk onderzoek naar de anti-reflux chirurgie en je hebt me vanaf toen gesteund en sturing gegeven. Niet alleen tijdens mijn promotie, maar ook in de kliniek ben je een mentor voor me geweest. Je hebt me geïnspireerd en enthousiast gemaakt voor het vak en alles daaromheen. We zijn beiden geen onderzoeker pur sang, maar we hebben het toch mooi voor elkaar gekregen, 'de $\mathrm{S}$ is weggepoetst'. Ik heb veel van je geleerd en je zal altijd een voorbeeld voor me blijven. Dankjewel voor alles!

Prof. dr. Bouvy, beste Nicole, op de (bijna) eerste plaats wil ik uiteraard jou bedanken! Pas later tijdens mijn promotietraject ben je als promotor onderdeel geworden van het team, maar wat was je belangrijk. Je weet het misschien niet meer, maar in het $3^{\mathrm{e}}$ jaar van geneeskunde heb ik mijn mondelinge examen bij jou gedaan en al vrij snel was je tevreden en was je reactie: 'volgens mij heb jij het wel begrepen'. Dit vertrouwen in mij heb je niet verloren in de daaropvolgende jaren en je hebt me gestimuleerd om in rap tempo door te werken aan mijn promotie. Mede dankzij jouw innovatieve blik hebben we mijn proefschrift nog kunnen uitbreiden met een mooie vervolgstudie naar de EsophyX. Heel erg bedankt voor je hulp en begeleiding, zowel bij mijn proefschrift als bij het bemachtigen van een opleidingsplek. Zonder jouw was dit beiden niet gelukt!

Dr. v.d. Poll, beste Marcel, mijn co-promotor. Bedankt voor je kritische blik op mijn artikelen en je bijdrage aan dit prachtige boekwerk. Bedankt voor de avonden die we bij je thuis hebben gewerkt, gediscussieerd en gelachen. Je hebt mijn proefschrift naar een wetenschappelijk hoger niveau weten te tillen en je bent onmisbaar geweest in de totstandkoming van dit werk.

Beste Jeroen, $\mathrm{dr}(\mathrm{s})$. Ponten, vriend en paranimf. Waar moet ik beginnen met mijn dankwoord voor jou. Mede dankzij jou ben ik enthousiast geworden voor de chirurgie en tja, daar hoort de wetenschap nou eenmaal bij..... Maar we hebben er samen het beste van gemaakt, ik heb een tijdje je RCT mogen waarnemen in de periode dat jij in 
het MUMC+ zat. Daarnaast hebben we onze kennis mogen uitbreiden op de diverse congressen, waar we ook de nodige ontspanning wisten te vinden, in het bijzonder in Milaan. Heel erg bedankt voor je hulp bij de totstandkoming van dit proefschrift, je begeleiding in de kliniek en mede het vele plezier dat we samen hebben gehad en hopelijk nog gaan beleven.

Graag zou ik de leden van de beoordelingscommissie, voorzitter prof. dr. L.P.S. Stassen, dr. E.J. Hazebroek, prof. dr. A.A.M. Masclee, prof. dr. H.J.T. Rutten, dr. J.H.M.B. Stoot willen bedanken voor de tijd en moeite die jullie hebben genomen voor de beoordeling van mijn proefschrift. Ik kijk uit naar de verdediging van dit proefschrift om met jullie te discussiëren over dit onderwerp.

Dr. Nienhuijs, Simon, onder jouw supervisie ben ik gestart met mijn wetenschappelijke en klinische carrière. Je hebt me als jonge student begeleid en gesteund. Dankjewel hiervoor en mede dankzij jou is het gelukt om aangenomen te worden voor de opleiding tot chirurg.

Onderzoekers uit de 'kelder', Yannick, Pieter, Thijs, Geert, Lindy, David, Martin, Marijn en Dennis, dank jullie wel voor de gezelligheid en de gastvrijheid in jullie hok. Ook al was ik geen fulltime onderzoeker, ik kon altijd bij jullie terecht voor een werkplek, een koffietje, wat gezelligheid en ook als ik hulp nodig had bij mijn onderzoek kon ik jullie om advies vragen! Jullie zijn een inspiratie en voorbeeld voor me geweest tijdens mijn promotietraject.

Arts-assistenten van de chirurgie en intensive care in het Catharina ziekenhuis Eindhoven, met heel veel plezier heb ik gewerkt bij jullie in de kliniek en mede dankzij jullie heb ik de energie gehad om kliniek en wetenschap te combineren. De borrels en feestjes na het werk hebben gezorgd voor de nodige ontspanning en zorgde ervoor dat we een hechte groep werden die voor elkaar klaar stond. Dank jullie wel en hopelijk tot snel weer in de kliniek!

Arts-assistenten van de chirurgie in het MUMC+, huidige collega's, dank jullie wel voor de gezelligheid op het werk. Ik kwam als vreemde eend in de bijt, na 5 jaar in het Catharina, als 'Eindhoven boy' bij jullie binnen. Desondanks werd ik met open armen ontvangen en heb ik het erg naar mijn zin en is het gelukt om mijn proefschrift bij jullie af te ronden.

Niet te vergeten, mijn andere paranimf. Skip, goeie vriend, boef. Ik leerde je inmiddels alweer 11 jaar geleden kennen als collega in de horeca. Samen met Noudje zijn we als de Freak'a Dellen al vele borrels, avonden in 'de minibar' en later in 'the little one', etentjes, 2 verhuizingen en een toppersconcert verder. De laatste tijd zijn we allemaal 
erg druk met ons werk waardoor we elkaar wat minder zien, maar als we elkaar zien blijft het gezellig als vanouds! Een hele eer dat je mijn paranimf wilt zijn, al heb ik je eerste even uit moeten leggen wat dit dan ook wel precies betekend. En nee, het is geen prada-milf. Bedankt voor alles van de afgelopen jaren en dat we samen nog maar veel plezier mogen maken in het leven!

Mijn grote passie is skydiven en hier haal ik dan ook de nodige ontspanning uit. ledereen die met mij gesprongen heeft afgelopen jaren wil ik bedanken voor de gezelligheid, ontspanning en gave sprongen die we samen gemaakt hebben! In het bijzonder Floortje, Tom en Jan. Met jullie heb ik toch echt wel de meeste tijd in de lucht en daarna 'op de grond' doorgebracht. Ik kijk er enorm naar uit om met jullie komend jaar weer op skydive reis te gaan, laten we er weer een mooi avontuur van maken! En ik zou zeggen, laten we er snel nog maar 'eentje' op drinken $(;$

Lieve Nick, broertje. Wat ben ik trots op je, met succes een eigen hoveniersbedrijf gestart, wat kan jij werken, ongekend. Je gedrevenheid is een voorbeeld en een bron van inspiratie voor me. Je bent altijd geïnteresseerd in mijn werk en staat altijd voor me klaar. Ik kan altijd op je rekenen! Dankjewel voor alles en ik wens jou alle succes en geluk.

Lieve papa en mama, bedankt dat jullie altijd voor me klaar hebben gestaan. Jullie hebben me altijd onvoorwaardelijk gesteund en zonder jullie hulp was ik nooit gekomen waar ik nu ben. Jullie zijn altijd betrokken en geïnteresseerd geweest in mijn promotietraject en hebben mij altijd gestimuleerd om door te zetten en te blijven werken voor een opleidingsplek binnen de chirurgie. Jullie zijn de beste ouders die iemand zich kan wensen en hopelijk mag ik nog lang van jullie liefde genieten! Dank jullie wel.

Tot slot wil ik graag nog mijn meisje bedanken, de liefde van mijn leven. Lieve Carmen, je hebt me enorm gesteund en dankjewel dat je mij al die avonden hebt laten werken. Het is nu eindelijk klaar, zodat we meer tijd met elkaar kunnen doorbrengen. Ik hoop dat we samen oud worden en nog heel veel mooie dingen gaan meemaken in ons leven! Dikke kus, ik hou van je. 





\section{List of publications}

1. Castelijns PSS, Woensdregt K, Hoevenaars B, Nieuwenhuijzen GAP. Intraabdominal esophageal duplication cyst: A case report and review of the literature. World J Gastrointest Surg. 2014;6(6):112-6.

2. Castelijns PSS, Boesten RHM, van der Veen AH. Case report, Het PellegriniStiedafenomeen: casus en overzicht van de literatuur. Ned. Tijdschrift voor traumachirurgie. 2015; (4):75-7.

3. Castelijns PSS, Ponten JEH, Van de Poll MCG, Nienhuijs SW, Smulders JF. Subjective outcome after laparoscopic hiatal hernia repair for intrathoracic stomach. Langenbecks Arch Surg. 2017 May;402(3):521-30.

4. Castelijns PSS, Ponten JEH, Bouvy ND, Smulders JF, van de Poll MCG. Intrathoracic stomach in hiatal hernia: th.e role of laparoscopic repair. Minerva Chir. 2018;73(1):64-76.

5. Castelijns PSS, Ponten JEH, van de Poll MCG, Nienhuijs SW, Smulders JF. A collective review of biological versus synthetic mesh-reinforced cruroplasty during laparoscopic Nissen fundoplication. J Minim Access Surg. 2018;14(2):87-94.

6. Ponten JEH, Leenders BJM, Leclercq WKG, Lettinga T, Heemskerk J, Konsten JLM, Castelijns PSS, Nienhuijs SW. Mesh Versus Patch Repair for Epigastric and Umbilical Hernia (MORPHEUS Trial); One-Year Results of a Randomized Controlled Trial. World J Surg. 2018;42(5):1312-20.

7. Castelijns PSS, Ponten JEH, Vd Poll MCG, Bouvy ND, Smulders JF. Quality of life after Nissen fundoplication in patients with gastroesophageal reflux disease: Comparison between long- and short-term follow-up. J Minim Access Surg. 2018; 14(3):213-20.

8. Castelijns PSS, van de Poll MCG, Smulders JF. A Modified Technique to Create a Standardized Floppy Nissen Fundoplication Without a Bougie. J Laparoendosc Adv Surg Tech A. 2018;28(7):853-8.

9. Castelijns PSS, Ponten JEH, Van de Poll MCG, de Greef BTA, Bouvy ND, Smulders JF, Standardized method for Nissen fundoplication: reproducibility and effect on learning curve. Submitted. 
10. Castelijns PSS, de Greef BTA, Peeters A, vd Poll MCG, MD, Witteman BPL, Koek GH, Conchillo JM, Bouvy ND, 7-year follow up after transoral incisionless fundoplication for treatment of gastroesophageal reflux disease; results of patients who participated in a randomized controlled trial. Submitted 
Curriculum vitae 



\section{Curriculum vitae}

Petrus Sebastianus Simon Castelijns was born on June 4th, 1991, in Geldrop, the Netherlands. In 2009, he graduated from the Strabrecht College in Geldrop. Immediately thereafter he started medical school at the Faculty of Medicine at the Maastricht University. During the 6th year of this study he started with research under the supervision of J.F. Smulders. After his medical training was completed, he started as a resident (ANIOS) at the surgery department of the Catharina Hospital in Eindhoven. (2015-2016) He combined clinical activities with research and started an official PhD project under supervision of Prof. dr. N.D. Bouvy. The main goal of this PhD project was to evaluate quality of life after anti-reflux surgery and hiatal hernia repair. Thereafter he worked as a resident (ANIOS) at the intensive care of the same hospital. (2016-2017) From 2017 he started working at the surgery department of the Maastricht University Medical Centre and started his surgical training program in June 2018 under the supervision of L.P.S. Stassen and R.M.H. Roumen. 
